SAND88-25.11.

Unlimited Release

Printed July 1990

\title{
COVE 2A Benchmarking Calculations Using LLUVIA
}

\author{
Polly L. Hopkins \\ Fluid Mechanics and Heat Transfer Division I \\ Sandia National Laboratories \\ Albuquerque, NM 87185
}

\begin{abstract}
Benchmarking calculations using the code LLUVIA have been performed in support of the corth verification activity (COVE2A.) for the Yucca Mombain Project (YMP). LlolVIA is a program designed for the efficient solution of one-dimensional, steady flow through mulliple layers nf sall. urated or partially saturated, fractured, porous media. The benchmarking calculations incolu. six steady-state and six time-dependeit infiltration problems. For the time-fependent andit. ses, LLUVIA reported only the final steady-state results. This report durmments prolinimaln: calculations, resulting code modifications and final calculations for the (covel as sturts.
\end{abstract}

\section{MASTER}


The analyses described in this document and the preparation of this document were performed under Quality Assurance Level Ill procedures of the Nuclear Waste Repository Technology Department's quality assurance program.

WBS $1.2 \cdot 1 \cdot 4.9$ 


\section{Contents}

1 Introduction $\quad 1$

2 COVE 2A Problem Definitinns $\quad 1$

2.1 Mathematical Description .................. 1

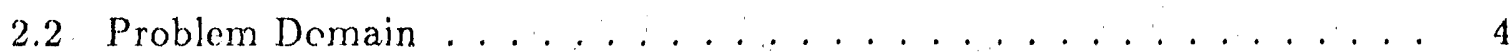

2.3 Boundary Conditions ................... 6

2.4 Requested Output ...................... 7

3. LLUVIA - y

3.1 Solution Approach . . . . . . . . . . . . . . . 7

3.2 Original Post-Processing Procedure ............... 8

3.3 Modi.ied Post-Processing Procedure . . . . . . . . . . . . 11

4 Results $\quad 13$

5 References $\quad 55$

6 Appendix A $\quad 56$ 


\section{List of Tables}

1. Material Properties . . . . . . . . . . . . . . . . 4

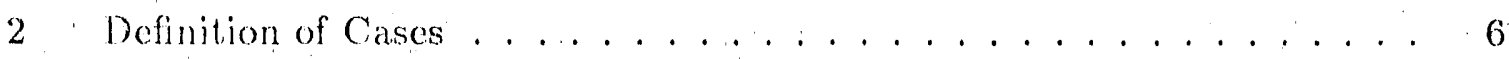

3 Performance Mcasures ...................... 13 


\section{List of Figures}

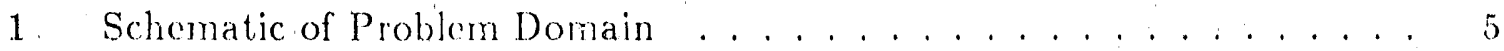

2 Comparison of Normalized Average Flux, Case 4 . . . . . . . . 10

3 Comparison of Pressure Head, Case $4 \ldots \ldots . \ldots 14$

4 Comparison of Matrix Saturation, Case $4 \ldots \ldots \ldots \ldots$

5 Comparison of Hydraulic Conductivity, Case $4 \ldots \ldots \ldots$

6 Comparison of Water Velocity in the Matrix, Case 4 . . . . . . 17

7 Comparison of Water Velocity in the Fractures, Case $4 \ldots \ldots \ldots$

8 Normalized Flux Profile with $q_{0} 0.1 \mathrm{~mm} / \mathrm{y} \cdot \mathrm{r}, \mathrm{CHnz}$ (Case 1) $\ldots \ldots 19$

9 Pressure Head Profile with $q_{0}-0.1 \mathrm{~mm} / \mathrm{yr}$, CHnz (Case 1) . . . . . 19

10 Matrix Saturation Profile with $q_{0}=0.1 \mathrm{~mm} / \mathrm{yr}, \mathrm{CHnz}$ (Case 1) . . . 20

11 Hydraulic Conductivity Profile with $q_{0}=0.1 \mathrm{~mm} / \mathrm{yr}$, CHnz (Case 1) . 20

12 Matrix Water Velocity Profile with $q_{0}-0.1 \mathrm{~mm} / \mathrm{yr}$, CHnz (Case 1) . . 21

13 Fracture Water Velocity Profile with $q_{0} \cdots 0.1 \mathrm{~mm} / \mathrm{yr}$, CHnz (Case 1) . . 21

14 Normalized Flux Profile with $q_{0}=0.1 \mathrm{~mm} / \mathrm{yr}$, Clinv (Case 2) . . . 22

15 Pressure Head Profile with $q_{0}=0.1 \mathrm{~mm} / \mathrm{yr}$, CHnv (Case 2) . . . . 22

16 Matrix Saturation Profile with $q_{0}=0.1 \mathrm{~mm} / \mathrm{yr}$, Chnv (Case 2) . . . 23

17 Hydraulic Conductivity Profile with $q_{0}=0.1 \mathrm{~mm} / \mathrm{yr}, \mathrm{CHnv}$ (Case 2) . . 23

18 Matrix Water Velocity Profile with $q_{0}=0.1 \mathrm{~mm} / \mathrm{yr}, \mathrm{CHnv}$ (Case 2) . . 24

19 Fracture Water Velocity Profile with $q_{0}=0.1 \mathrm{~mm} / \mathrm{yr}$, CHnv (Case 2) . . 24

20 Normalized Flux Profile with $q_{0}=0.5 \mathrm{~mm} / \mathrm{yr}$, CHnz (Case 3) $\ldots \ldots 25$

21 Pressure Head Profile with $q_{0}=0.5 \mathrm{~mm} / \mathrm{yr}, \mathrm{CHnz}$ (Case 3) . . . . 25

22 Matrix Saturation Profile with $q_{0}=0.5 \mathrm{~mm} / \mathrm{yr}$, CHnz (Case 3) . . . 26

23 Hydraulic Conductivity Profile with $q_{0}=0.5 \mathrm{~mm} / \mathrm{yr}$, CHnz (Case 3) . . 26 
24 Matrix Water Velocity Profile with $q_{0} \ldots 0.5 \mathrm{~mm} / \mathrm{yr}$, CHnz (Case 3) . . . 27

25. Fracture Water Velocity Profile with $q_{0} 0.5$ mm/yr, CHnz (Case 3) . . 27

26 Normalized Flux Profile with $q_{0} 0.5 \mathrm{~mm} / \mathrm{yr}$, Cllnv (Case 4) . . . . 28

27 Pressure Head Profile with $q_{0} 0.5 \mathrm{~mm} / \mathrm{yr}$, CHnv (Case 4) . . . . . 28

28 Matrix Saturation Profile with $q_{0}: 0.5 \mathrm{~mm} / \mathrm{yr}$, Cllnv (Case 4) . . . . 29

29 Mydraulic Conductivity Profile with $q_{0}=0.5 \mathrm{~mm} / \mathrm{yr}$, CHnv (Casc 4) . . 29

30 Matrix Water Velocity Profile with $q_{0} 0.5 \mathrm{~mm} / \mathrm{yr}$, Cllnv (Case 4) . . 30

31 Fracture Water Velocity Profile with $q_{0}-0.5 \mathrm{~mm} / \mathrm{yr}$, CHnv (Case 4) . . 30

32 Normalized Flux Profile with $q_{0} \div 4.0 \mathrm{~mm} / \mathrm{yr}$, Cllnz (Case 5) . . . . . 31

33 Pressure llead Profile with $q_{0}=4.0 \mathrm{~mm} / \mathrm{yr}$, CHnz (Case 5) . . . . . 31

34 Matrix Saturation Profile with $q_{0}=4.0 \mathrm{~mm} / \mathrm{yr}$, CHnz (Case 5) . . . . 32

35 Hydraulic Conductivity Profile with $q_{0}=4.0 \mathrm{~mm} / \mathrm{yr}$, CHnz (Case 5) . . 32

36 Matrix Water Velocity Profile with $q_{0} 4.0 \mathrm{~mm} / \mathrm{yr}$, CHnz (Case 5) . . . 33

37 Fracture Water Velocity Profile with $q_{0} \cdots 4.0 \mathrm{~mm} / \mathrm{yr}, \mathrm{CHnz}$ (Case 5) . . 33

38 Normalized Flux Profile with $q_{0}=4.0 \mathrm{~mm} / \mathrm{yr}$, CHnv (Case 6) . . . . 34

30 Pressure Head Profile with $q_{0} \cdot 4.0 \mathrm{~mm} / \mathrm{yr}$, CHnv (Case 6) . . . . . . 34

40 Matrix Saturation Profile with $q_{0}=4.0 \mathrm{~mm} / \mathrm{yr}$, CHnv (Case 6) . . . 35

41 Hydraulic Conductivity Profile with $q_{0}=4.0 \mathrm{~mm} / \mathrm{yr}$, CHnv (Case 6) . . 35

12 Matrix Water Velocity Profile with $q_{0}=4.0 \mathrm{~mm} / \mathrm{yr}$, CHnv (Case 6) . . . 36

43 Fraciure Water Velocity Profile with $q_{0}=4.0 \mathrm{~mm} / \mathrm{yr}$, CHnv (Case 6) . 36

44 Normalized Flux Profile with $q_{0}=0.2 \mathrm{~mm} / \mathrm{yr}, \mathrm{CHn}$ (Case 7 ) . . . . . 37

45 Pressure Head Profile with $q_{0}=0.2 \mathrm{~mm} / \mathrm{yr}$, CHnz (Case 7) . . . . . . 37

46 Matrix Saturation Profile with $q_{0}=0.2 \mathrm{~mm} / \mathrm{yr}, \mathrm{CHnz}$ (Case 7) . . . . 38

47 Hydraulic Conductivity Profile with $q_{0}=0.2 \mathrm{~mm} / \mathrm{yr}$ : CHnz (Case 7 ) . . 38 


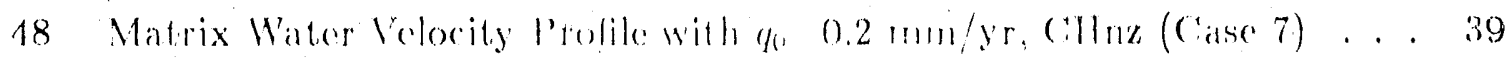

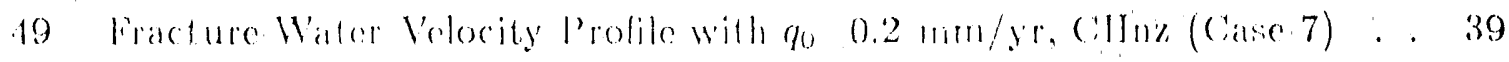

50 Normalizud Flux Profile with $g_{0} 0.2 \mathrm{~mm} / \mathrm{yr}$, Clluv (Case 8) . . . . . 40

5.1 Pressure Hoad Prolile with go 0.2 mm/yr, C:llon (Case 8) . . . . . 40

52 Matrix Saturation Profile with go $0.2 \mathrm{~mm} / \mathrm{yr}$, (CHnv (Case 8) . . . 41

53 Hydranlic Conductivity Profile with go 0.2 mm/yr, C:llny (Cake 8) . . 41

54 Matrix Wator Voincity Profile with $q_{0} 0.2 \mathrm{~mm} / \mathrm{yr}, \mathrm{CHnv}$ (Casn 8) . . 42

55 Fracture Water Volocity Profilc with $q_{0} 0.2 \mathrm{~mm} / \mathrm{yr}$, CHnv (Case 8) . 42

56 Normalized Flux Profile with $q_{0}-1.0 \mathrm{~mm} / \mathrm{yr}$, Chnz (Case 9) . . . . 43

57 Pressure Head Profile with $q_{0} \ldots \uparrow \mathrm{mm} / \mathrm{yr}$, CHnz (Case 9) . . . . . 43

58 Matrix Saturation Profile with $q_{0}=1.0 \mathrm{~mm} / \mathrm{yr}$, CHnz (Case 9 ) . . . 44

59 Mydraulic Conductivity Profile with $q_{0}=1.0 \mathrm{~mm} / \mathrm{yr}$, CHnz (Case 9) . 4 44

(i) Matrix Water Velocity Profile with $q_{0}: 1.0 \mathrm{~mm} / \mathrm{yr}$, CHnz (Case 9) . . 45

61 Fracture Water Velocity Profile with $q_{0} 1.0 \mathrm{~mm} / \mathrm{y}$, CHnz (Case 9) . . 45

62 Normalized Flux Profile with $q_{0}-1.0 \mathrm{~mm} / \mathrm{yr}$, CHnv (Case 10) . . . . 46

63 Prosisure Head Profile with qu $1.0 \mathrm{~mm} / \mathrm{yr}$, Chnv (Case 10) . . . . . 46

64 Matrix Saturation Profile with qu $1.0 \mathrm{~mm} / \mathrm{yr}$, CHnv (Case 10) . . . 47

65 Hydraulic Conductivity Profile with go $1.0 \mathrm{~mm} / \mathrm{yr}$, CHnv (Case 10) . 47

66 Matrix Water Velocity Profile with $q_{0} 1.0 \mathrm{~mm} / \mathrm{yr}$, CHnv (Case 10) . . 48

of Fracture Water Velocity Profile with $q_{0}=1.0 \mathrm{~mm} / \mathrm{yr}$, CHnv (Case 10) . 48

68 . Normalized Flux Profile with $q_{0}, 8.0 \mathrm{~mm} / \mathrm{y}$, CHnz (Case 11) . . . . 49

69 Pressure Head Profile with $q_{0}=8.0 \mathrm{~mm} / \mathrm{yr}$, CHnz (Case 11) . . . . . 49

70 Matrix Satuation Profile with $q_{0} 8.0 \mathrm{~mm} / \mathrm{yr}$, CHnz (Case 11 ) . . . 50

71 Hydraulic Conductivity Profile with $q 0 \ldots 8.0 \mathrm{~mm} / \mathrm{yr}$, CHnz (Case 11) . . 50 


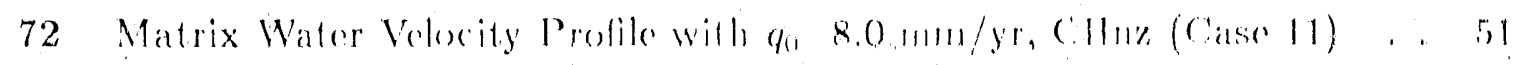

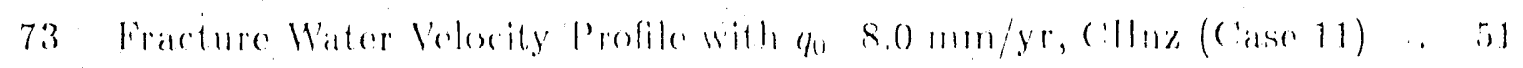

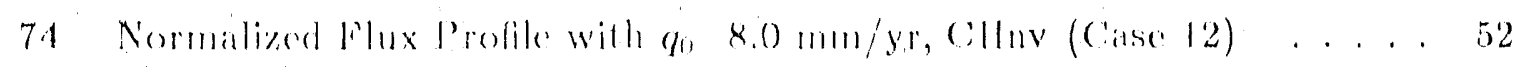

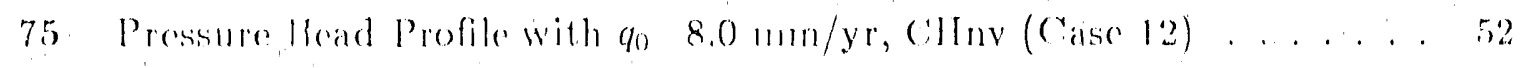

76 Matrix Saturation Profile with qo $8.0 \mathrm{~mm} / \mathrm{yr}$, Cllnv (Case 12) . . . 58

77 Ilydraulic Conductivily Profile with $0_{0} 8.0 \mathrm{~mm} / \mathrm{yr}$, Clluv (Case 12) . . 53)

78 Matrix Water Volocity Profile with qo 8.0 mm/yr, (:lluv (Case 12) . . 54

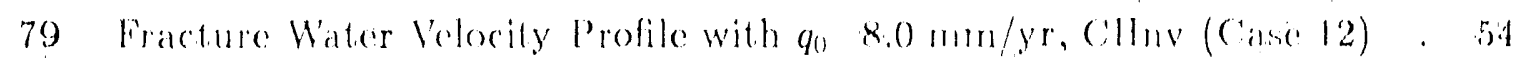




\title{
Nomenclature
}

\author{
$g$ gravitatimal arceleration \\ $K$ hydraulic conductivity \\ $K$ hydraulic conductivity tensor \\ $n$ porosity \\ $q$ specific discharge \\ $S$ saturation \\ $t$ time \\ $v$ velocity of water \\ $z$ elevation
}

Greek Symbols

$\alpha$ curve fitting parameter

$\beta$ curvelitting paramoter

$\lambda$ curve fiting parameter $=(1-1 / \beta)$

$\rho$ density of water

$\psi$ pressure head

Subscripts

ave average

$f$ fracture

$m$ matrix

$f, b$ bulk fracture value for a unit volume of fractured, porous inedia $m, b$ bulk inatrix value for a unit volume of fractured, porous modia

$r$ residual

$s$ saturated 


\section{Introduction}

Computer models are essential in evaluating a geologic site as the potential location for a proposed nuclcar waste repository. Computer simulations are useful in exploring scenarios for changes in conditions at the site, gaining insight into small- and largescale hydrologic behavior and providing input to field experiments or facility design. To have some degree of confidence in the results of these calculations, the computer codes must be verified. Verification of a computer code demonstrates that the code solves the given mathematical models to a degree of accuracy sufficient for the application. The COVE $2 \mathrm{~A}$ benchmarking activity is intended to verify several computer codes for use in simulations involving the unsaturated, fractured tuffs found at Yucca Mountain.

The COVE $2 \mathrm{~A}$ andyses (six steady-state and six transient flow cases) are defined in Problem Definition Memo (PDM) 72-01 issued by the Nuclear Waste Repository Technology (NWRT) Department at Sandia National Laboratories. All cases involve onc-dimensional flow through strata representing five primary units at Yucca Mountain. The applied infiltration rate is varied to result in flow regimes dominated by matrix flow, a transition from matrix to fracture flow, and finally, by fracture flow. LLUVIA [1] was used to solve the steady-state cases and the final state for the transient cases. This report documents the results of the analyses performed using LLUVIA. The LLUVIA results will be compared in another report with the results from other codes used to perform these same analyses.

\section{COVE 2A Problem Definitions}

\subsection{Mathematical Description}

For purposes of this benchmarking exercise, the mathematical/physical model for hydrologic flow in fractured porous media was defined in the PDM. The features incorporated into the COVE $2 \mathrm{~A}$ benchmarks are intended to simulate the variably saturated layers under study at the Yucca Mountain site. These layers include Tiva Canyon (TCw), Paintbrush (PTn), Topopah Spring I (TSw1) and 11-111 (TSw2-3), vitric Calico Hills (CHnv) and zeolitic Calico Hills (CHnz). This geologic regime is currently the focus of investigations to determine its suitability for a high-level radioactive waste repository. The relevant equations used in the simulations were given in the PDM and are repeated below. 
Saluration

Saturation, $S$, as defined by van Cenuchten $[2]$, is given by a nonlinear function of pressure hoad, $\psi$.

$$
S(\psi)=\left(S_{s}-S_{r^{\prime}}\right)\left[\begin{array}{c}
1 \\
\hdashline-|\alpha \psi|^{\beta}
\end{array}\right]^{\lambda}+S_{r}
$$

where

$S_{s}$ is the maximum saturation $(\simeq 1.0)$

$S_{r}$ is the residual saturation

$\alpha$ is a curve fitting parameter

$\beta$ is a curve fitting parameter

$\lambda$ is $1 \cdots 1 / \beta$.

The saturation function given in Equation 1 is used for both matrix and fractures.

Iydraulic Conductivity

Hydraulic conductivity, $K(\psi)$, is obtained from the method of Mualem [3] using the saturation model given above.

$$
K(\psi)=K_{s}\left[1+|\alpha \psi|^{\beta}\right]^{-\lambda / 2}\left\{1 \cdots\left[\frac{|\alpha \psi|^{\beta}}{1+|\alpha \psi|^{\beta}}\right]^{\lambda}\right\}^{2}
$$

where $K_{s}$ is the saturated hydraulic conductivity. The conductivity function given in Equation (2) is used for both matrix and fractures.

Flow Fquation

The steady equation for flow through an unsaturated, fractured material is given by Peters and Klavetter's adaptation of the Darcy equation [4]. This formulation assumes that under steady-flow conditions the pressure in the matrix and fractures is equal. Note that $\bar{K}_{m, b}$ and $\bar{K}_{f, b}$ represent volume-weighted conductivity tensors:

$$
\bar{q}_{\text {total }}=\bar{q}_{m}+\bar{q}_{f}=-\left(\bar{K}_{m, b}+\bar{K}_{f, b}\right) \cdot \nabla(\psi+z)=-\bar{K} \cdot \nabla(\psi+z)
$$


where

$\ddot{q}$ is Darcy flux

$z$ is elevation

$m, f$ are subscripts reforing to matrix and fracture respectively.

The time-dependent transport equation is also defined by Peters and Klavetter but is not given here because LLUVIA does not solve transient problems.

\section{Velocity of Water}

Water is assumed to flow through both fractures and matrix. The water velocity, $\bar{v}$, is the Darcy flux divided by the fraction of the area across which the water flows. Water that is associated with the residual level of saturation in the layers does not contribute to the flow. The following formulations for fracture and matrix velocities are obtained from the work of Pcters, Gauthier and Dudley [5]:

$$
\begin{aligned}
\bar{v}_{m}= & \bar{q}_{m} \\
= & \bar{K}_{m, b}\left(S_{m}-\nabla(\psi+z)\left[\begin{array}{c}
1 \\
\left.S_{m, r}\right) \\
n_{m}\left(S_{m}^{\prime} \cdots S_{m, r}\right)
\end{array}\right]\right. \\
\bar{v}_{f}= & n_{f}\left(S_{f}-S_{f, r}\right) \\
= & \bar{K}_{f, b} \cdot \nabla(\psi+z)\left[\begin{array}{c}
1 \\
n_{f}\left(S_{f}-S_{f, r}\right)
\end{array}\right]
\end{aligned}
$$

where $n$ is porosity. 


\subsection{Problem Domain}

Figure 1 is a schematic illustrating the one-dimensional stratigraphy assumed for all COVE $2 \mathrm{~A}$ problems. The numbers on the right side indicate elevation in meters above the water table. The Calico Hills layer $(\mathrm{CHn})$ has both vitric (CHnv) and zeolitic ( $\mathrm{CHnz}$ ) forms. Each specified infiltration rate is applied to a column model with the zeolitic form and is repeated with the vitric form of the Calico Hills layer.

Table 1 gives properties for all six materials involved in the calculations. These properties were defined in the PDM. The density of water, $\rho$, was taken to be $1.0 \times 10^{\text {* }}$ $\left(\mathrm{kg} / \mathrm{m}^{3}\right)$ and gravitational acceleration, $g$, as $9.8\left(\mathrm{~m} / \mathrm{s}^{2}\right)$.

Table 1: Material Properties

\begin{tabular}{|c|c|c|c|c|c|c|}
\hline & TC.w & PTn & TSw 1 & TSw2-3 & CHnv & CHnz \\
\hline$n_{m}$ & 0.08 & 0.40 & 0.11 & 0.11 & 0.46 & 0.28 \\
\hline $\begin{array}{l}K_{m, b} \\
(\mathrm{~m} / \mathrm{s})\end{array}$ & $9.7 \times 10^{-12}$ & $3: 9 \times 10^{-07}$ & $1.9 \times 10^{-11}$ & $1.9 \times 10^{-11}$ & $2.7 \times 10^{-07}$ & $2.0 \times 1011$ \\
\hline$S_{r, m}$ & 0.002 & 0.100 & 0.080 & 0.080 & 0.041 & 0.110 \\
\hline $\begin{array}{c}a_{m} \\
(1 / m)\end{array}$ & $8.21 \times 10^{-3}$ & $1.50 \times 10^{-2}$ & $5.67 \times 10^{-3}$ & $5.67 \times 10^{-3}$ & $1.60 \times 10^{-2}$ & $3.08 \times 10^{-3}$ \\
\hline$\beta_{m}$ & 1.558 & 6.872 & 1.798 & 1.798 & 3.872 & 1.602 \\
\hline$n_{f}$ & $1.4 \times 10^{-4}$ & $2.7 \times 10^{-5}$ & $4.1 \times 10^{-5}$ & $1.8 \times 10^{-4}$ & $4.6 \times 10^{-5}$ & $4.6 \times 10^{-5}$ \\
\hline $\begin{array}{l}K_{f, b} \\
(\mathrm{~m} / \mathrm{s})\end{array}$ & $5.3 \times 10^{-9}$ & $1.6 \times 10^{-8}$ & $0.9 \times 10^{-9}$ & $3.1 \times 10^{-5}$ & $9.2 \times 10^{-9}$ & $9.2 \times 10^{-9}$ \\
\hline$S_{r, f}$ & 0.0395 & 0.0395 & 0.0395 & 0.0395 & 0.0395 & 0.0395 \\
\hline $\begin{array}{c}a_{f} \\
(1 / \mathrm{m})\end{array}$ & 1.285 & 1.285 & 1.285 & 1.285 & 1.285 & 1.285 \\
\hline$\beta_{f}$ & 4.23 & 4.23 & 4.23 & 4.23 & 4.23 & 4.23 \\
\hline
\end{tabular}




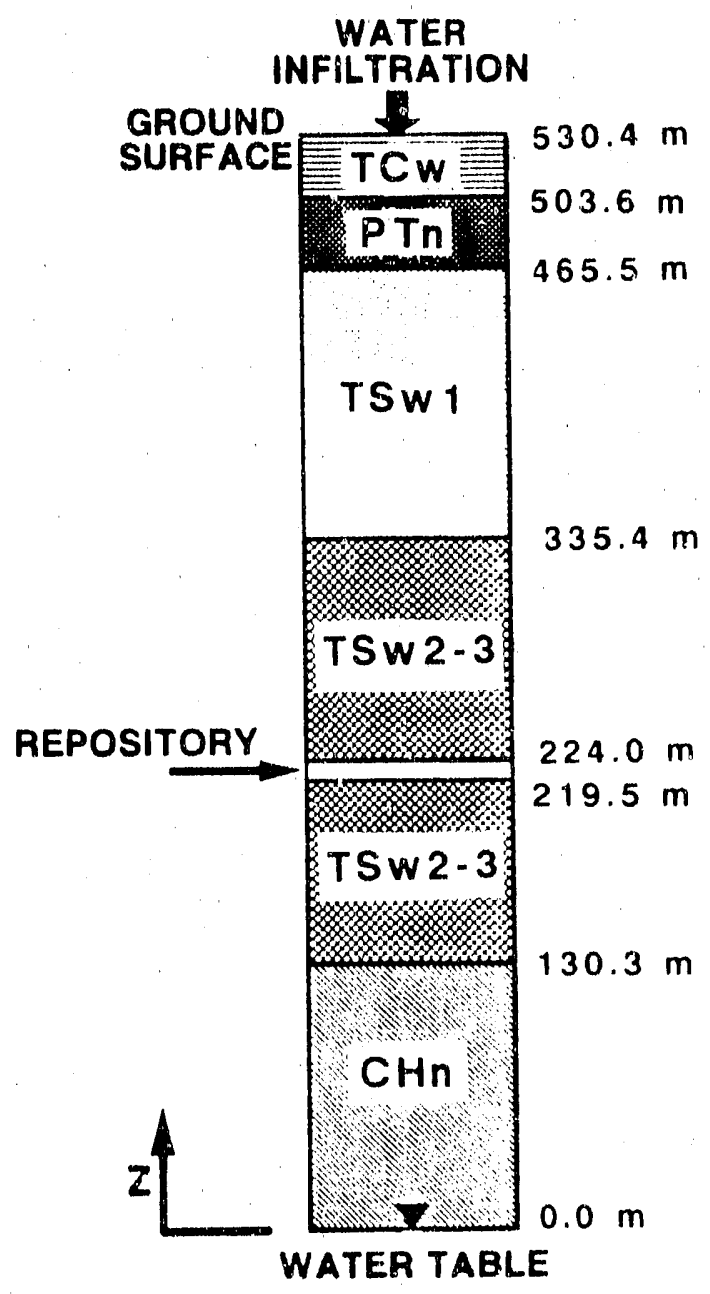

Figure 1: Schematic of Problem Domain 


\subsection{Boundary Conditions}

Table 2 lists the boundary conditions at the top of the permeable column for all cases. In the PDM. Cases 16 are defined as steady-flow analyses and Cases 7-12 are defined as transient analyses. In Cases 1-6, the boundary condition at the top of the column is constant flux; in Cases $7-12$, the top boundary condition involves a factor-of-two step change in flux from the corresponding steady-flow condition in Cases 1-6. Because LLUVIA is a steady-state solver. only the final steady-flow conditions at the increased flux rates (Table 2) have been calculated. A zero pressure head condition representing the water table was applied at the bottom of the donain.

Table 2: Definition of Cases

\begin{tabular}{|c|c|c|c|}
\hline Case & $\begin{array}{l}\text { Flux at Ground } \\
\text { Surface }(\mathrm{mm} / \mathrm{yr})\end{array}$ & $\begin{array}{c}\text { Calico Hills } \\
(\mathrm{CHn}) \text { Properties }\end{array}$ & $\begin{array}{c}\text { Time } \\
\text { Domain }\end{array}$ \\
\hline 1 & 0.1 & zeolitic & steady \\
\hline 2 & 0.1 & vitric & steady \\
\hline 3 & 0.5 & zeolitic & steady \\
\hline 4 & $0 . j$ & vitric & steady \\
\hline 5 & 4.0 & zeolitic & steady \\
\hline 6 & 4.0 & vitric & steady \\
\hline 7 & 0.2 & zeolitic & steady for LLUVIA only \\
\hline 8 & 0.2 & vitric & steady for Ll, VIA only \\
\hline 9 & 1.0 & zeolitic & steady for LLUVIA only \\
\hline 10 & 1.0 & vitric & steady for LLUVIA only \\
\hline 11 & 8.0 & zeolitic & steady for LluVlA only \\
\hline 12 & 8.0 & vitric & steady for LLL'VIA mly \\
\hline
\end{tabular}




\section{$2.4 \quad$ Requested Output}

The quantities of interest are the calculated total flux normalized by the input boundary flux $\left(\bar{q}_{\text {total }} / q_{0}\right)$, pressure head $(\psi)$, matrix saturation $\left(S_{m}\right)$, hydraulic conductivity $\left(k^{\prime}\right)$, and water velocity in the matrix $\left(v_{m}\right)$ and fractures $\left(v_{f}\right)$. For stearly-state results, the ahuve quantities are to be plotted as a function of depth and also tabulated according to problem definition specifications. These specifications include 75 values of elevation at which output is recauested

\section{LLUVIA}

LLUVIA was developed to efficiently solve a particular class of flow problens. The isothermal problem involves the steady flux of an incompressible, Newtonian fluid through a oncdimensional domain of saturated or partially saturated layers of rigid, porous media. The media may contain fractures whose properties vary from those of the matrix. The composite matrix/fracture model representation treats the material as a single continum in solving for the pressure field. The first-order differential equation describing such a flow is Darcy's equation. Conservation of mass is ensured by the imposed steady-state cordition, and Darcy's equation is a strtement of momentum balance (Equation 3).

\subsection{Solution Approach}

Darcy's equation is the ordinary differential equation to be solved for pressure. For partially saturated conditions, the hydraulic conductivity, $K$, is a strong function of pressure head, $\psi$, and Equation 3 can become extremely nonlinear. The solver in LLUVIA, DEBDIS [6], is based on A. Hindmarsh's code, LSODE |7|. The implicit solution procedure uses a hackward differentiation formula of orders one through five and is interval-oriented. It is particularly woll suited to the solution of stiff problems. The specified flux or infittration rate, $q_{0}$, is an imposed condition and is constant throughout the domain.

The user defines specific initial nodal point locations. During the solution procedure, nodes may be added by the code. A tolerance on the allowable percentage change in conductivity between neighboring nodes controls the addition of nodal points. This provides solution refinement, without the need to know a priori where significant nonlinearities may occur. The user also defines material interface elevations. These elevations are used in determining which material properties are assigned to a node. If $z(i)$ is the ele ation of the $i^{\text {th }}$ node and $z$ int $(j)$ represents the $j^{\text {th }}$ input interface elevation, then if $z i n t(j-1)<z(i) \leq z i n t .(j)$, the $j^{\text {th }}$ set of material properties are assigned to node $i$. The node at the interface is considered to be the topmost node of a layer, i.e., a part of the material below it rather than part of the material above it.

The elevation at which a pressure is to be computed, i.e., a nodal location, is defined and

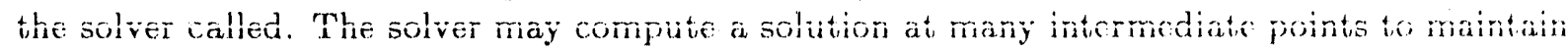


the requested accuracy but will return the solution only at the requested output location. The solver requires is subroutine to evaluate the derivative defined by

$$
\frac{d(\psi+z)}{d z}=\frac{q_{0}}{K(\psi)}
$$

Given a location and pressure, the subroutine evaluates this derivative at many points during the solution algorithm.

The percentage change in conductivity between the current and the previous node is computed and compared against the user input tolerance. If the tolerance is exceded, a new node is added at the midpoint of these nodes, and the solver is called to compute a pressure solution at this point. This procedure is repeated until the tolerance is met. The limiting case would be when the node and midpoint node locations are indistinguishable in terms of machine accuracy. At this point, the solver would stop the simulation. At a material interface, the conductivity between the interface node and the first node into the next material layer is likely to exceed the specified tolerance. Therefore, the conductivity at the interface node is computed again, for comparison purposes only, as though it were part of the next material. The solution procedure is repeated to compute a pressure at each node.

The pressure field produced by the solution of Equation 3 is subsequently used to compute the hydraulic conductivity, matrix saturation, and water velocities in both the matrix and fractures (if present). In these calculations, the matrix and fractures are treated as separate continua.

\subsection{Original Post-Processing Procedure}

The LLUVIA output originally focused on groundwater travel times because of its intended application to performance-assessment iseues. Groundwater travel times can be computed from average water velocities in a number of different ways. A common approach within a finitedifference formulation is to define an average hydraulic conductivity over a cell. Because of the possibility of numerous material layers, a cell was defined to be the area between two nodes. Ideally, the functional representation for the conductivity would allow analytical integration over the cell. However, the complexity of some conductivity models (Eq. 2) precludes this. Several methods of computing an average conductivity were tested including

- evaluating the conductivity at the average pressure head of neighboring nodes;

- dividing the cell into increments and, assuming a linear pressure head profile across the cell, evaluating the conductivity at each increment and averaging arithmetically; and

- geometric averaging.

Testing indicated that an average computed at ten increments across a cell showed insignificant difference in groundwater travel time from that conpiated with throe values of pressure 
head, the end nodes and midpoint. 'The choice of arithmetic or geometric averaging also showed little influence. The average conductivity was computed as

$$
\begin{aligned}
& \bar{K}_{m, a v e}=\frac{\bar{K}_{m}\left(\psi_{i}\right)+\bar{K}_{m}\left(\psi_{m i d}\right)+\bar{K}_{m}\left(\psi_{i+1}\right)}{3}, \\
& \bar{K}_{\text {f,ave }}=\frac{\bar{K}_{f}\left(\psi_{i}\right)+\bar{K}_{f}\left(\psi_{m i d}\right)+\bar{K}_{f}\left(\psi_{i+1}\right)}{3},
\end{aligned}
$$

where $\psi_{\text {mid }}=\left(\psi_{i}+\psi_{i+1}\right) / 2$.

For the sake of consistency, an average saturation was computed in the same manner. The average water velocity in the matrix and in the fractures was calculated using average properties and a pressure gradient approximated by differencing across neighboring nodes. The equal pressure assumption implicit in Equation 3 allow's the computed pressure gradient to be applied separately to the matrix and fractures.

$$
\begin{gathered}
\bar{v}_{m}=-\frac{\bar{K}_{m, a v e} \Delta(\psi+z)}{n_{m}\left(S_{m, a v e}-S_{m, r}\right)} \Delta z \\
\bar{v}_{f}=-\frac{\bar{K}_{f, a v e}}{n_{f}\left(S_{f, a v e}-S_{f, r}\right)} \frac{\Delta(\psi+z)}{\Delta z}
\end{gathered}
$$

A minimum groundwater travel time was determined by selecting the faster of the two velocities $\left(\bar{v}_{m}\right.$ or $\left.\bar{v}_{f}\right)$ across each cell to compute the minimum groundwater travel time through each cell and then summing these travel times over the domain. The average total flux was defined by

$$
\bar{q}_{t o t a l, a v e}=-\left(\bar{K}_{m, a v e}+\bar{K}_{f, a v e}\right) \frac{\Delta(\psi+z)}{\Delta z}
$$

Output values of average conductivity, average matrix saturation, average matrix and fract,ure velocities and average flux were reported at cell midpoints along with the midpoint pressure head $\left(\psi_{\text {mid }}\right)$. The average values were certain to contain some error. Because the correct flux is known, the average flux would provide the user with a feel for the accuracy of the resulting groundwater travel time. The dotted line in Figure 2 shows the normalized average flux profile for Case $4,0.5 \mathrm{~mm} / \mathrm{yr}$, vitric Calico Hills. The jagged nature is a result of applying the averaged hydraulic conductivity across a finite cell. 


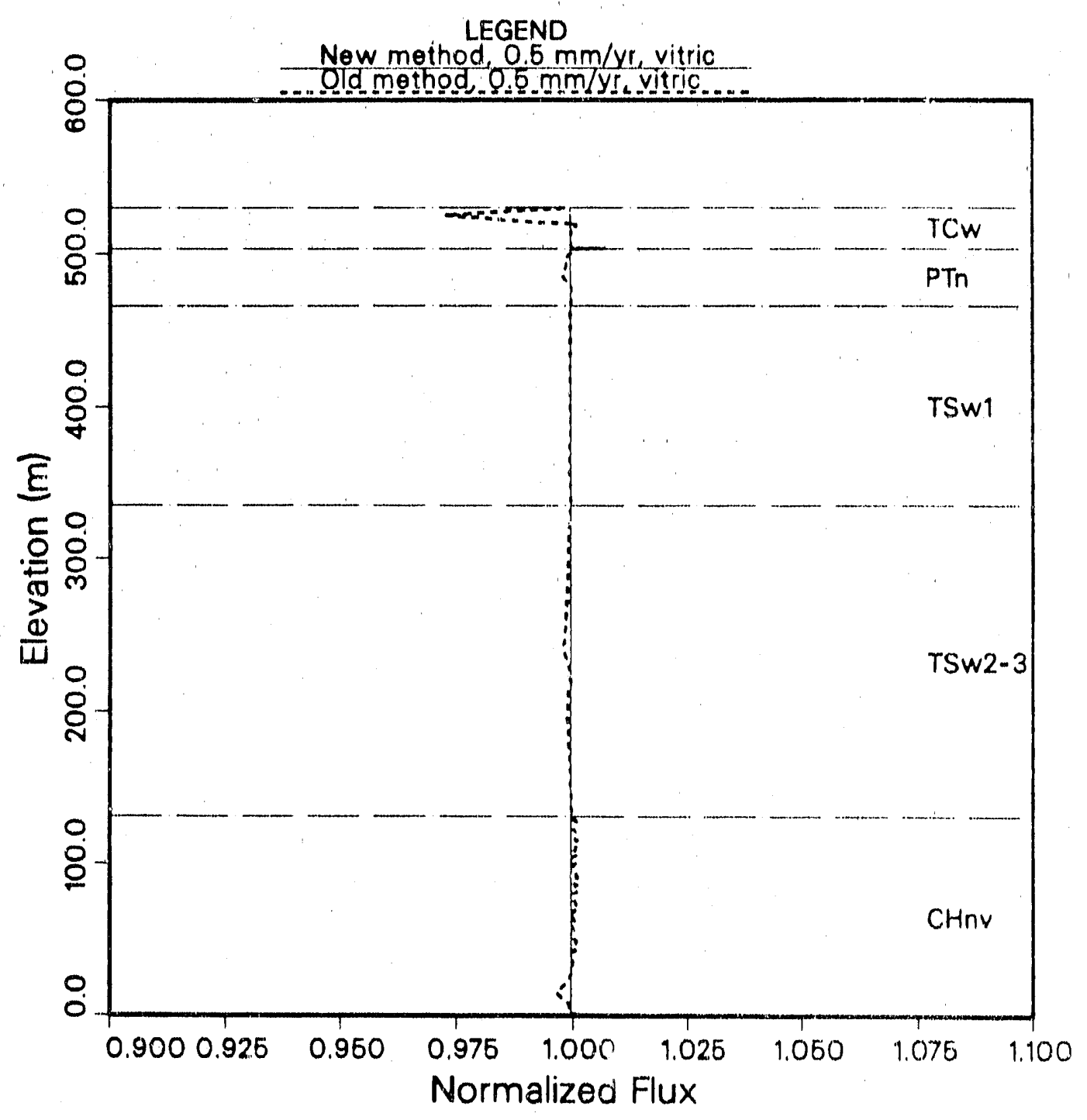

Figure 2: Comparison of Normalized Average Flux, Case 4 


\subsection{Modified Post-Processing Procedure}

During the COVE $2 A$ axercise, it heathe apparent that LLUVIA would be used in analyses whore groundwater travel times were not of primary interest. The accuracy of intermoliate: output values, i.e., saturation, conductivity, and water velocitices were degraded in reporting them as averages over a finite coll. Also, a user may reguire the output values at a specific clevation which is difficult to predict when nodes are added and results reported at midpoints. Therefore, luUUVIA's post-processing procedure was changed to covaluato intcrmediate output values at each node whose pressure head is computed by the solver. With the use of the calculated hydraulic conductivity, the specified total flux, and Darcy's cquation, the presisure gradient is compuled at each node from Fquation 6.

Tise of Baluation 3 allows the pressure gradient, compuled at cach node by beflation 6 , to be applied separately to the matrix and fractures. The flux in the matrix and in the fractures are determined at each node by

$$
\begin{aligned}
& \dot{q}_{m} \cdots K_{m}(\psi)^{d(\psi+z)} \\
& \bar{q}_{f}=\cdots K_{f}(\psi) \frac{d(\psi+z)}{d z}
\end{aligned}
$$

The velocity of the water in the matrix and in the fractures at a nodal point are computed by

$$
\begin{aligned}
& v_{m}=\frac{\bar{q}_{m}}{n_{m}\left(S_{m}-S_{m, r}^{\prime}\right)}, \\
& \bar{v}_{f} \cdots n_{f}\left(s_{f}{ }^{\ddot{q}} S_{f, r}\right)
\end{aligned}
$$

These values are output, by LluUVIA at each node.

An average matrix flux and an average fracture flux through a coll (i.e, betwen nodal points) are computed as simple arithmetic averages of adjoining, nodal-point flux values. The average total flux through a cell is the sum of the average matrix and average fracture fluxes. The average total flux is the output flux value, which is equal to $q_{(1}$.

$$
\begin{aligned}
& \bar{q}_{m, a v e}(i)=\frac{\bar{q}_{m}(i+1)+\bar{q}_{m}(i)}{2} . \\
& \ddot{q}_{f, a v e}(i)=\frac{\bar{q}_{f}(i+1)+\bar{q}_{f}(i)}{2} . \\
& \ddot{q}_{\text {total,ave }}(i)=\ddot{q}_{m, a v e}(i)+\bar{q}_{f, a v e}(i) \cdots q_{(1)} .
\end{aligned}
$$


To crmpute groundwater travel times, these average matrix and fracture fluxes are used to comput average velocities through a coll as deacribed below.

$$
\begin{aligned}
& S_{m, a v e}(i)=\frac{S_{m}(i+1)+S_{m}(i)}{2} \\
& S_{f, a v e}(i)=\frac{S_{f}(i+1)+S_{f}(i)}{2} . \\
& \bar{v}_{m, a v e}(i)=\frac{\bar{q}_{m, a v e}(i)}{n_{m}\left[S_{m, a v e}(i)-S_{m, r}(i)\right]} . \\
& \bar{v}_{f, a v e}(i)=\frac{\bar{q}_{f, a v e}(i)}{n_{f}\left[S_{f, a v e}(i)-S_{f, r}(i)\right]}
\end{aligned}
$$

The more nonlinear the solution through the cell, the greater the error in the resulting average velocities. This error can be controlled by restricting the allowable percentage change in conductivity across a cell, which controls cell size, or by providing nodal locations at sufficiently small increments.

With the water velocities in the matrix and fractures at each node and the average water velocilies in the matrix and fractures across a cell, the minimum groundwater travel time is computed three ways. One method uses the faster of the average matrix water velocity and the average fracture water velocity. Another selects the faster matrix water velocity of the coll's adjoining nodes and the faster fracture water velocity. 'These matrix and fracture velocities are compared and the faster is used to compute a lower bound on minimum travel time. Finally, the slower matrix water velocity of the cell's adjoining nodes and the slower fracture water velocity are compared and the faster is used to compute an upper bound on minimum travel time.

$$
\begin{aligned}
& \operatorname{tmin}_{\min , i}=\frac{z_{i+1}-z_{i}}{\max \left(\left|\bar{v}_{m}\right|_{\max },\left|\bar{v}_{f}\right|_{m a x}\right)}, \\
& \operatorname{tmin}_{a v e, i}=\frac{z_{i+1}-z_{i}}{\max \left(\left|\bar{v}_{m}\right|_{a v e},\left|\bar{v}_{f}\right|_{\text {ave }}\right)}, \\
& \operatorname{tmin}_{\max , i}=\frac{z_{i+1}-z_{i}}{\max \left(\left|\bar{v}_{m}\right|_{\min },\left|\bar{v}_{f}\right|_{\min }\right)}
\end{aligned}
$$

The three estimates of minimum travel time give the user bounds on the travel time and a basis for judging the sufficiency of the nodal point locations because, in the limit, all three values are equal. 
Figures 2-7 compare results obtained using the modified procedure with those obtained using the previous method. The results are again for Case 4 . Note that there is excellont agrement in all but the flux and velocity profiles. This suggests that the greatest source of error in the original method was not in the average hydraulic conductivity or average saturation, but in the approximation to the pressure gradient.

\section{Results}

LLUVIA was able to solve the nonlinear flow equation for all specified flux rates with no difficulty. The code, using the modified post-processing procedure, was executed on a VAX 8650 . A listing of the source code resides in the NWRT Department's Software Quality Assurance System as LLuVIA V'ersion 0.0. All cases were run with 75 initial nodes at the requested outpul elevations and a conductivity change tolerance of 0.10 . The central-processing unit (cpu) times and final numbers of nodes are shown in Table 3 for Cases 1-6. Performance measures for Cases 7-12 are not reported because those were defined as transicnt problems. Execution times for this set of problems could have been reduced by relaxing the tolerance on conductivity change because acrurate travel times were not of interest herc.

The output quantities of interest for steady-state cases are plotted in Figures 8-79 for all 12 cases. Output quantities were calculated using the modified post-processing procedure and are plotted only at the 75 elevations defined in the PDM. Trends and abrupt changes in the output profiles are as expected. For example, at low saturations (Cases 1, 2, 3, 4, 7, and 8) the TSw' and TSw'2-3 units are in predominantly matrix flow and because their matrix material properties are the same, the profiles across their interface are smooth. However, at higher saturations (Cases 5, 6, 9, 10,11, and 12) the fractures play a role. Differences in fracture properties for TSw 1 and TSw2-3 cause a relatively small change in some output quantities at the interface (Figure 67).

Table 3: Performance Measures

\begin{tabular}{|c|c|c|c|}
\hline $\begin{array}{c}\text { Case } \\
\text { number }\end{array}$ & $\begin{array}{c}\text { Number } \\
\text { of nodes }\end{array}$ & $\begin{array}{c}\text { VAX cpu } \\
\text { time (s) }\end{array}$ & $\begin{array}{c}\text { cpu time } \\
\text { per node (s) }\end{array}$ \\
\hline 1 & 214 & 30.6 & 0.143 \\
2 & 211 & 20.4 & 0.097 \\
3 & 187 & 28.8 & 0.154 \\
4 & 207 & 21.8 & 0.105 \\
5 & 215 & 38.0 & 0.153 \\
6 & 281 & 46.9 & 0.167 \\
\hline
\end{tabular}




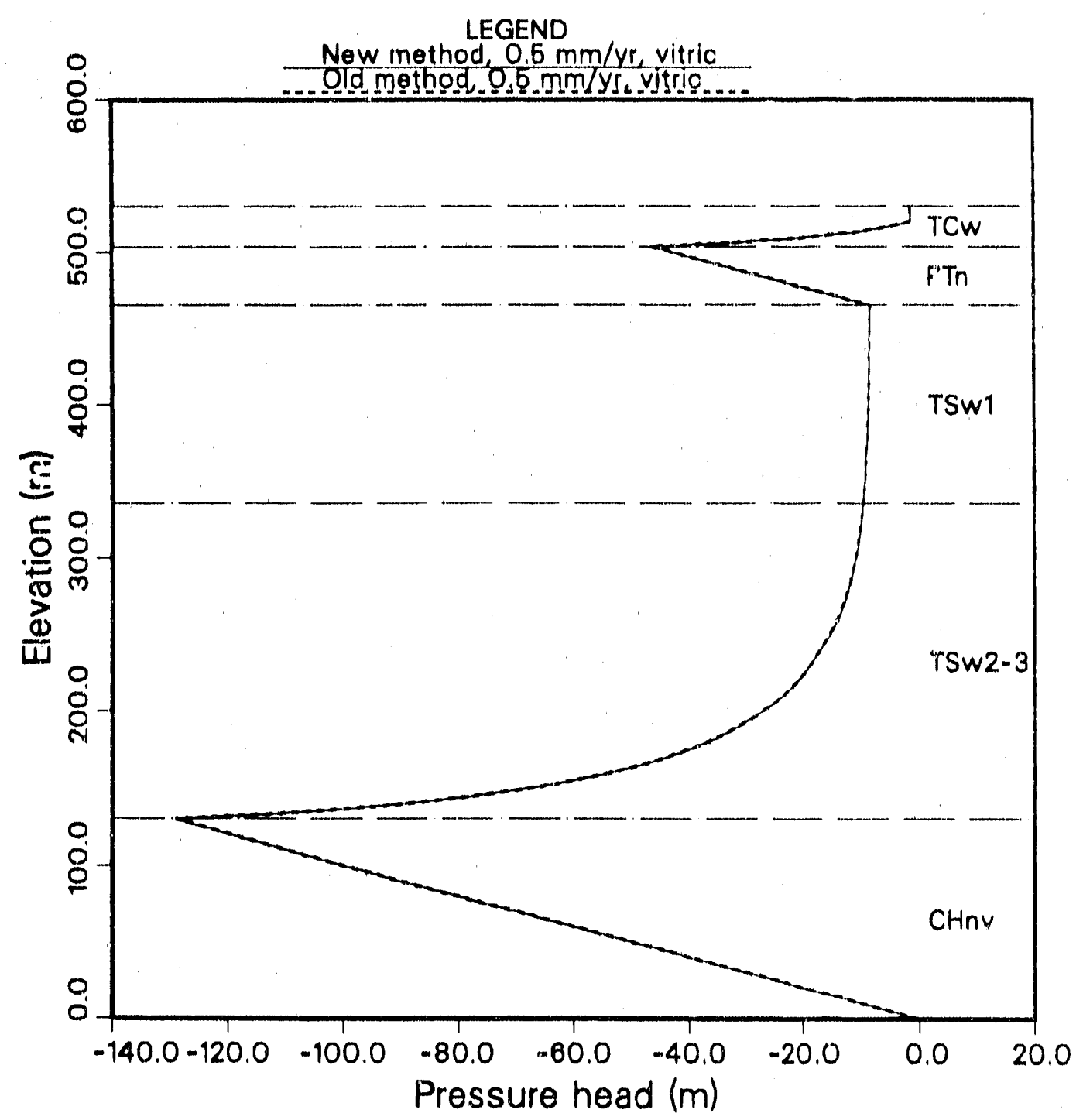

Figure 3: Comparison of Pressure Head, Case 4 


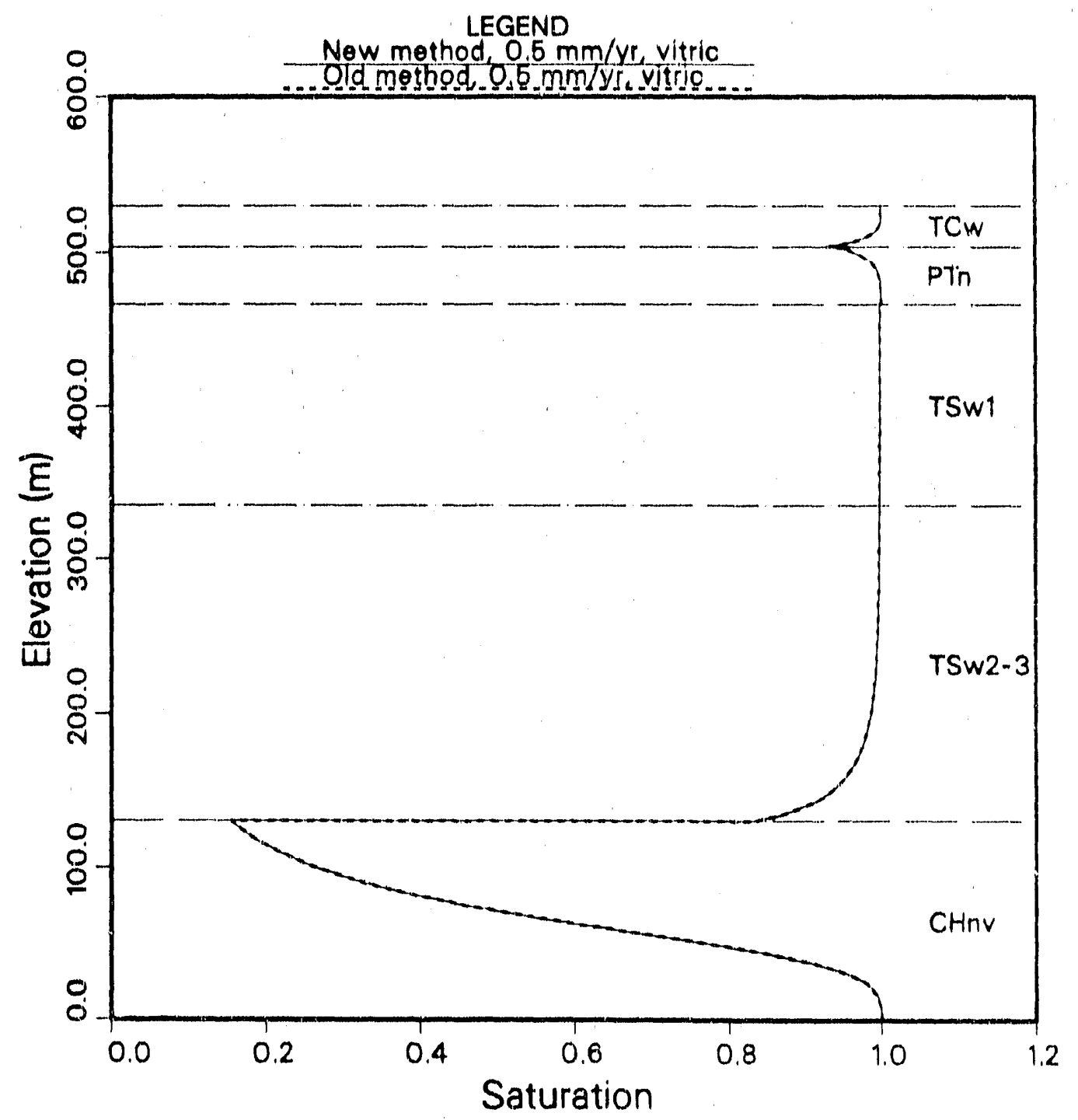

Figure 4: Comparison of Matrix Saturation, Case 4 


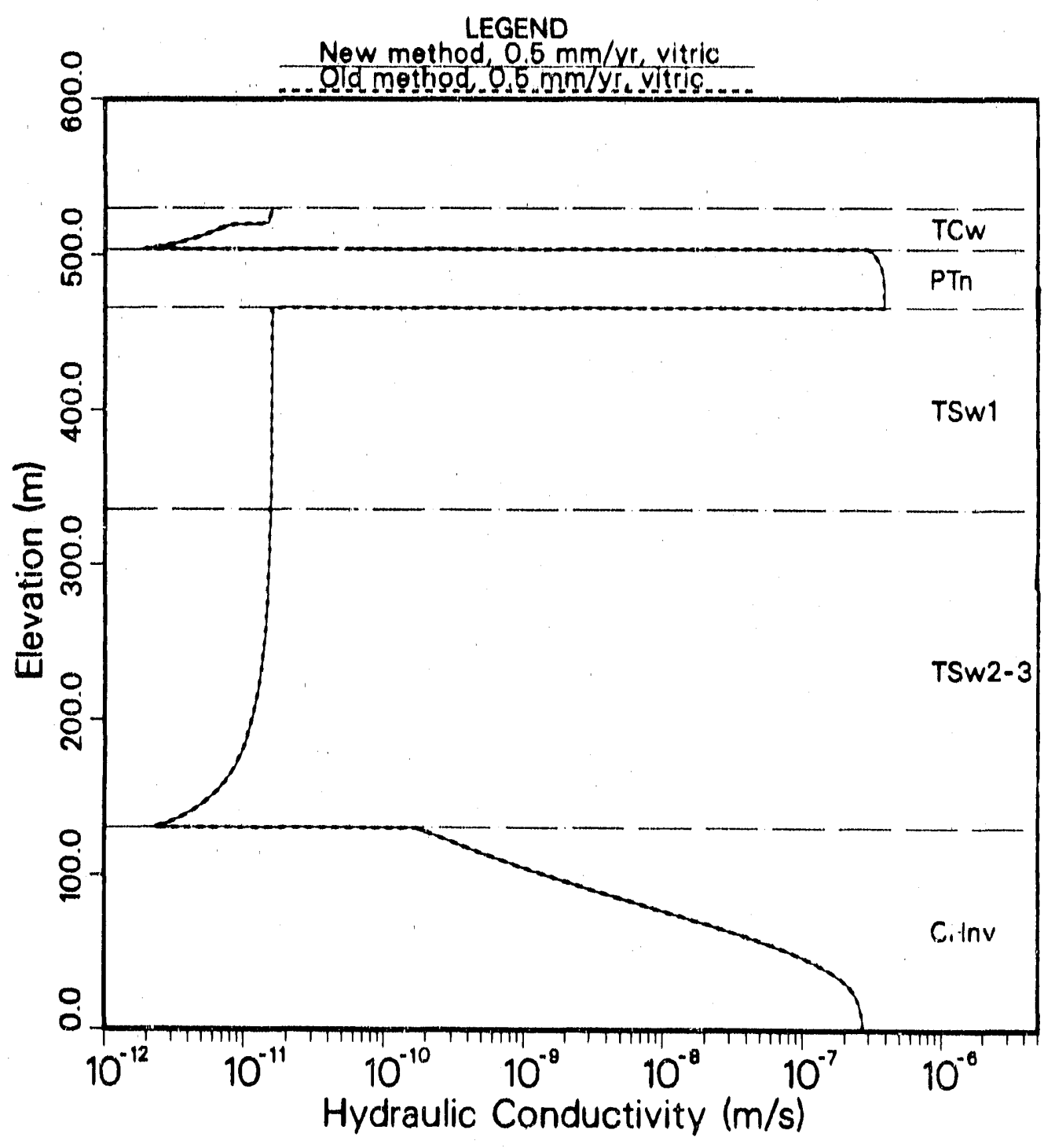

Figure 5: Comparison of Hydraulic Conductivity, Case 4 


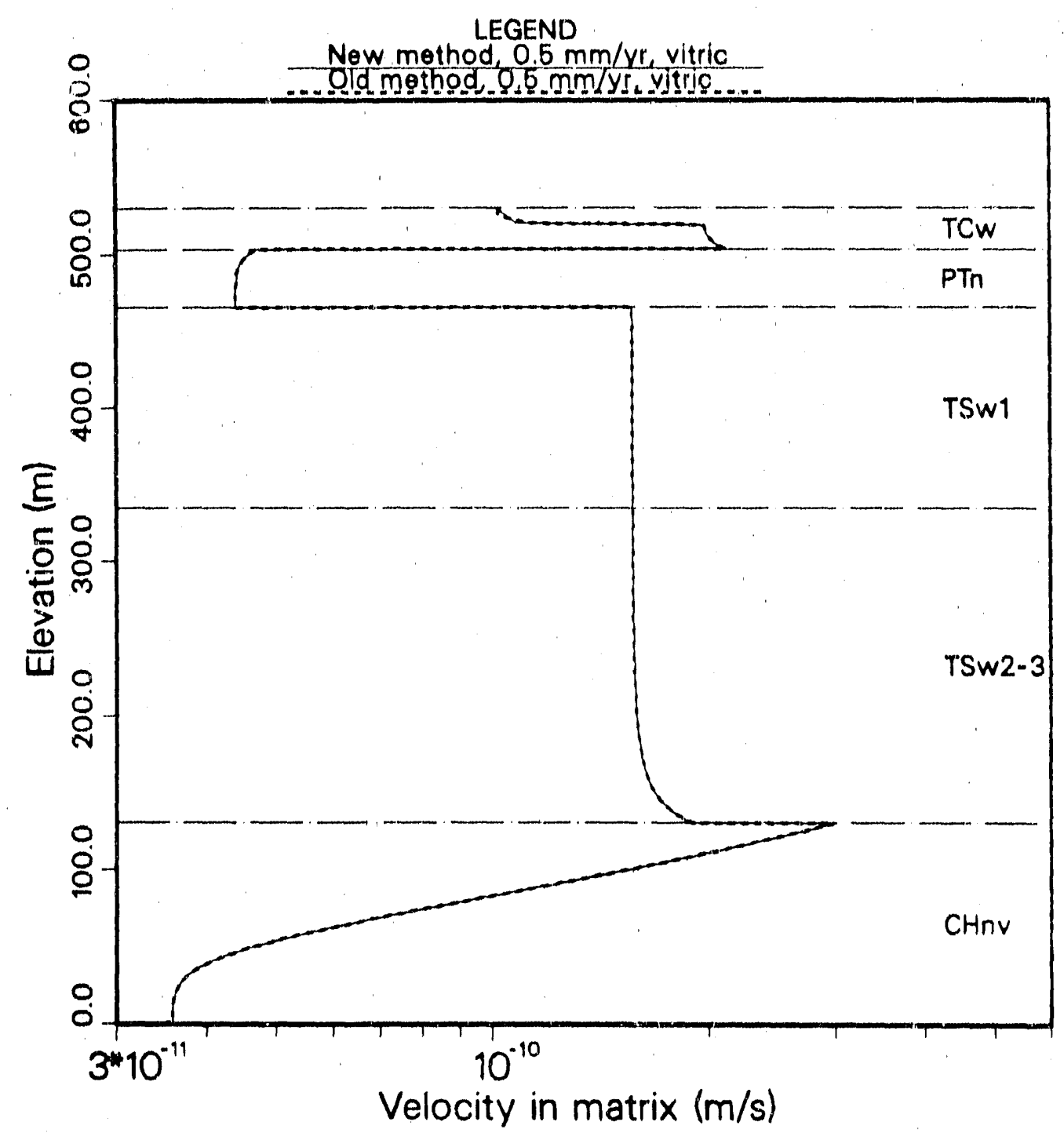

Figure 6: Comparison of Water Velocity in the Matrix, Case 4 


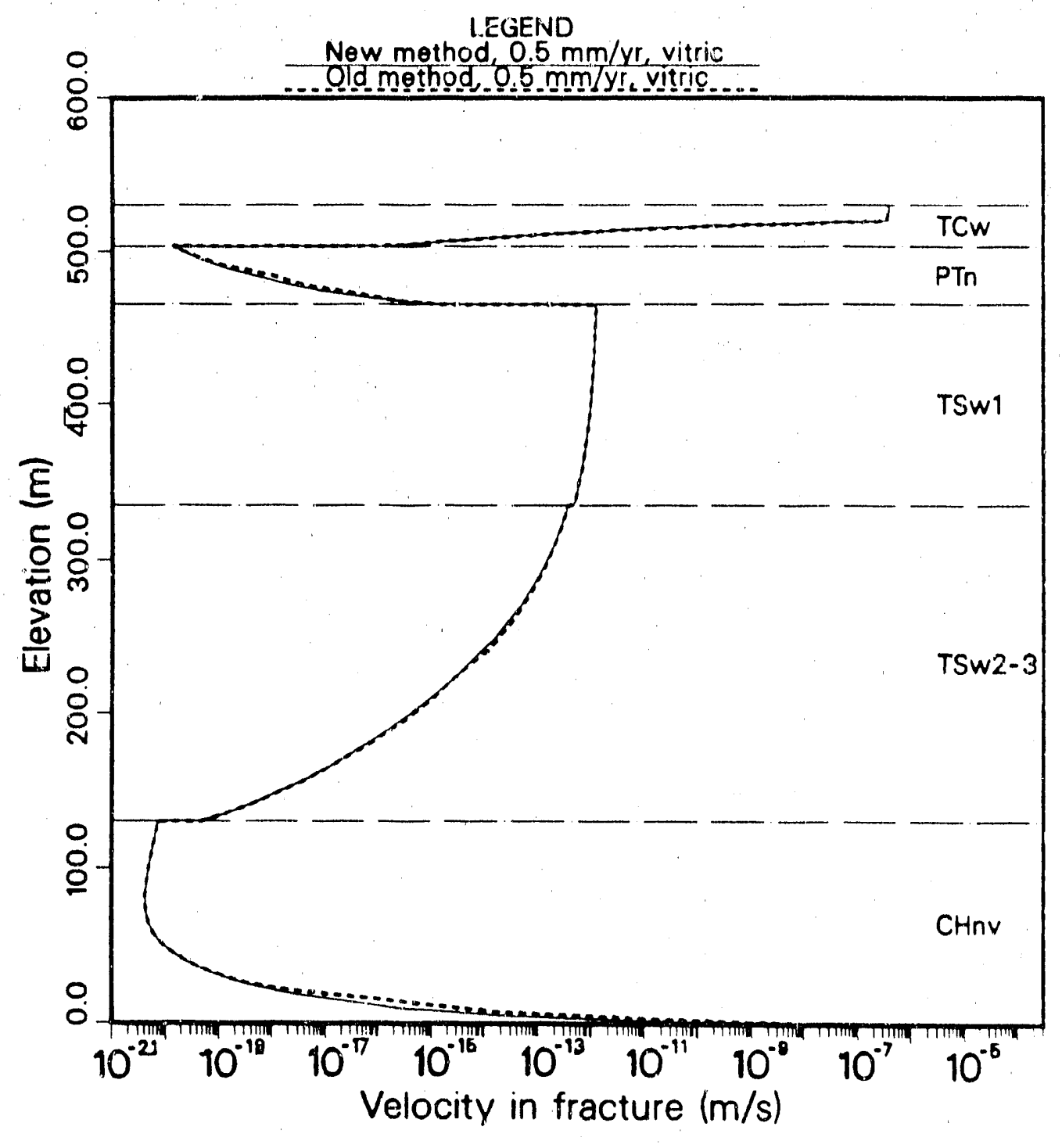

Figure 7: Comparison of Water Velocity in the Fractures, Case 4 


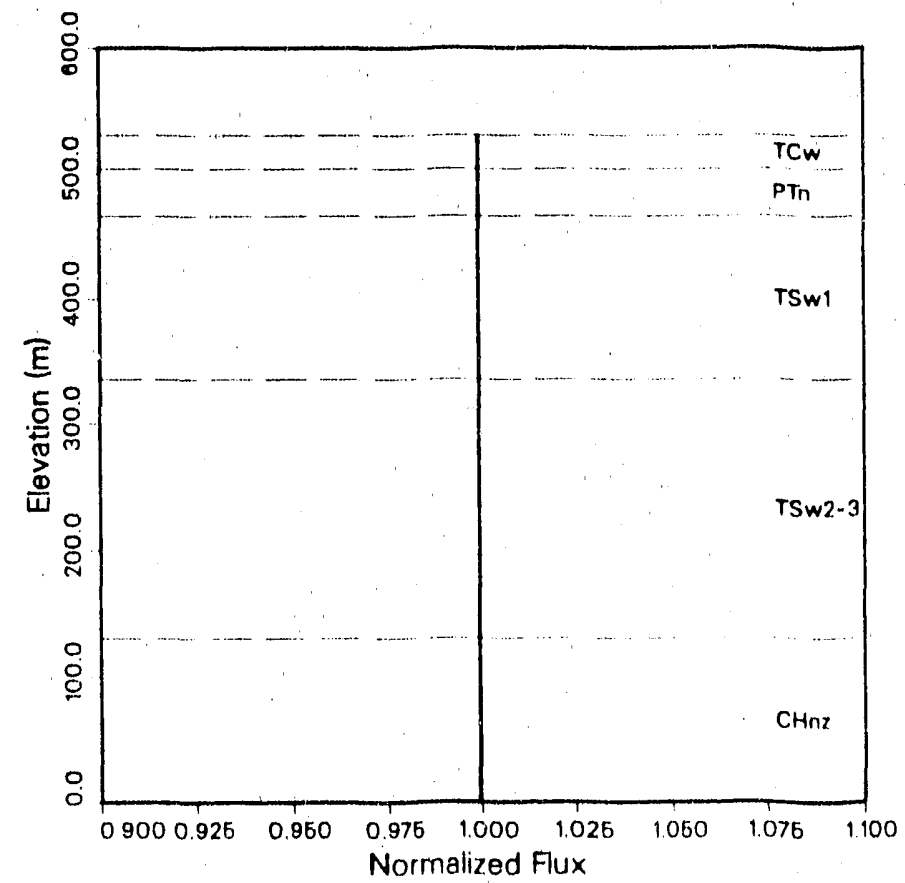

Figure 8: Normalized Flux Profile with $q_{0}=0.1 \mathrm{~mm} / \mathrm{yr}, \mathrm{CHnz}$ (Case 1)

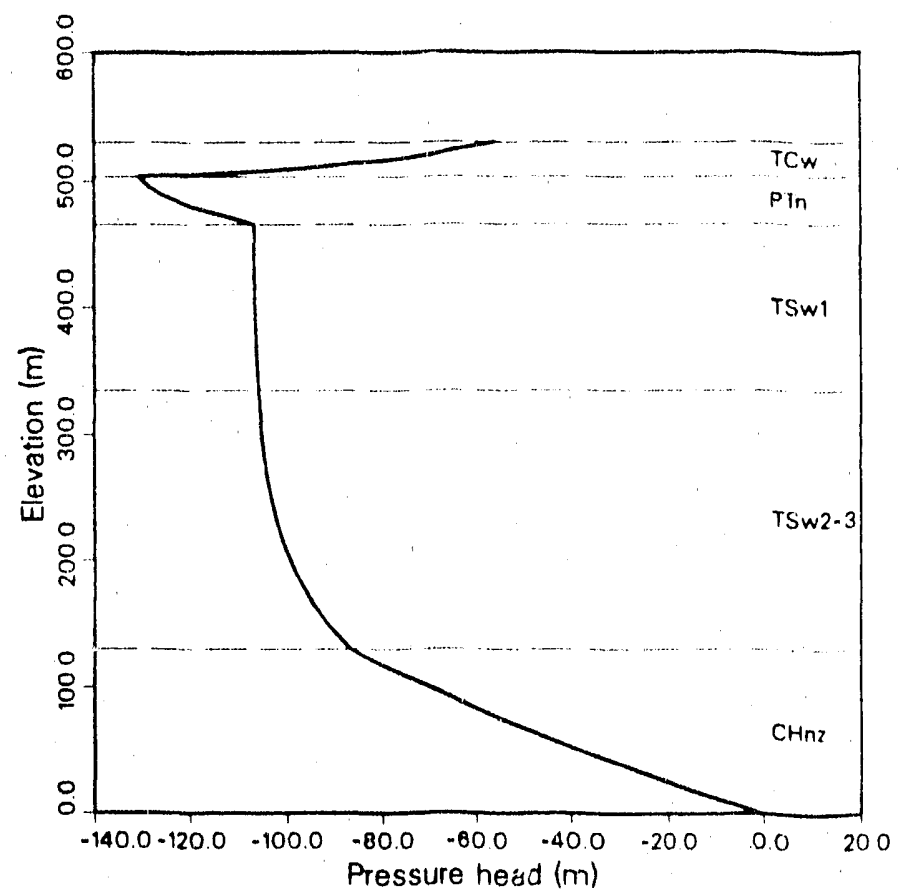

Figure 9: Pressure Head Profile with $q_{0}=0.1 \mathrm{~mm} / \mathrm{yr}, \mathrm{CHnz}$ (Case 1) 


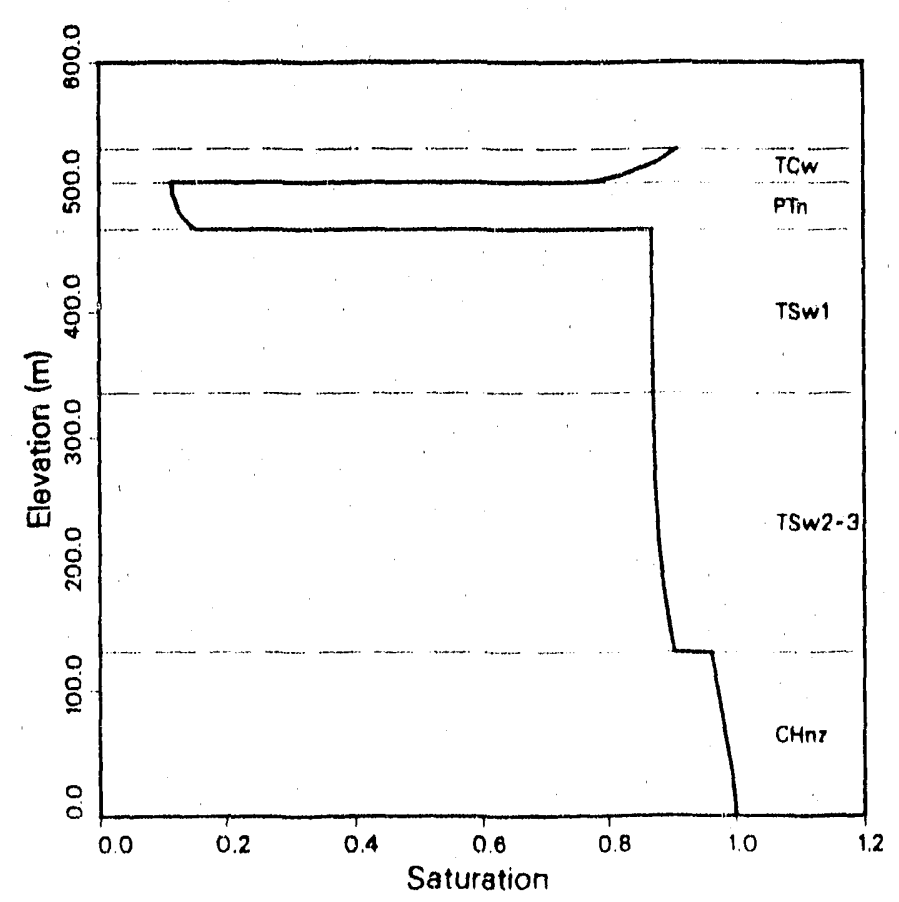

Figure 10: Matrix Saturation Profile with $q_{0}=0.1 \mathrm{~mm} / \mathrm{yr}, \mathrm{CHnz}$ (Case 1)

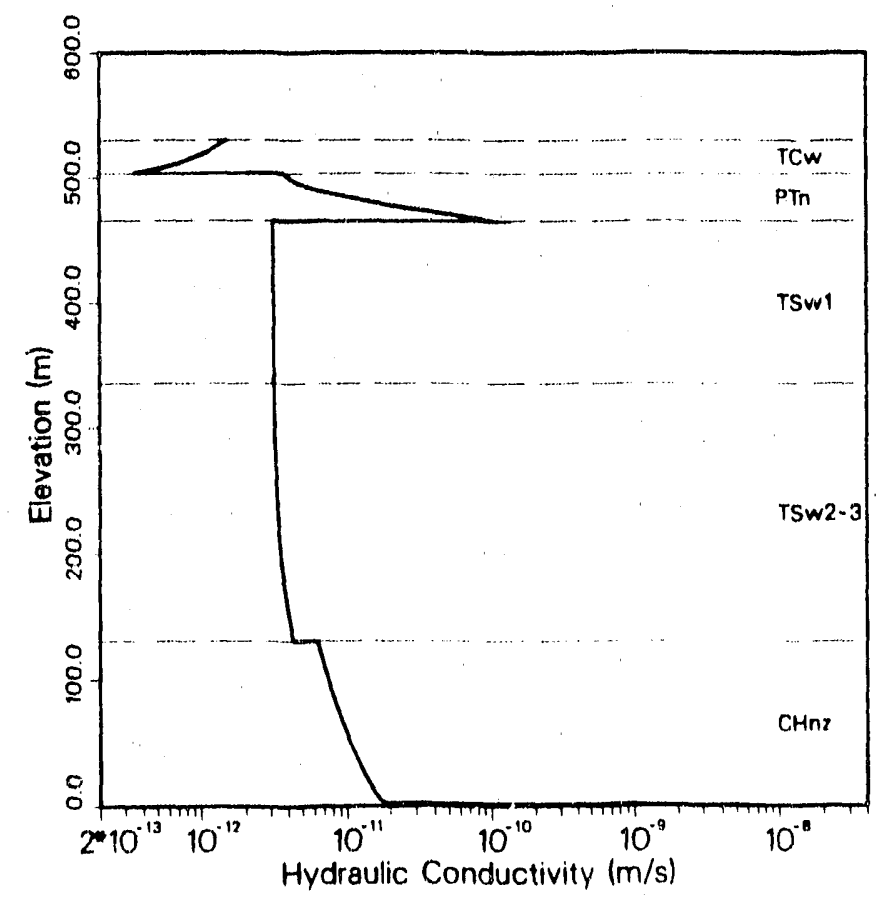

Figure 11: Hydraulic Conductivity Profile with $q_{0}=0.1 \mathrm{~mm} / \mathrm{yr}, \mathrm{CHnz}$ (Case 1) 


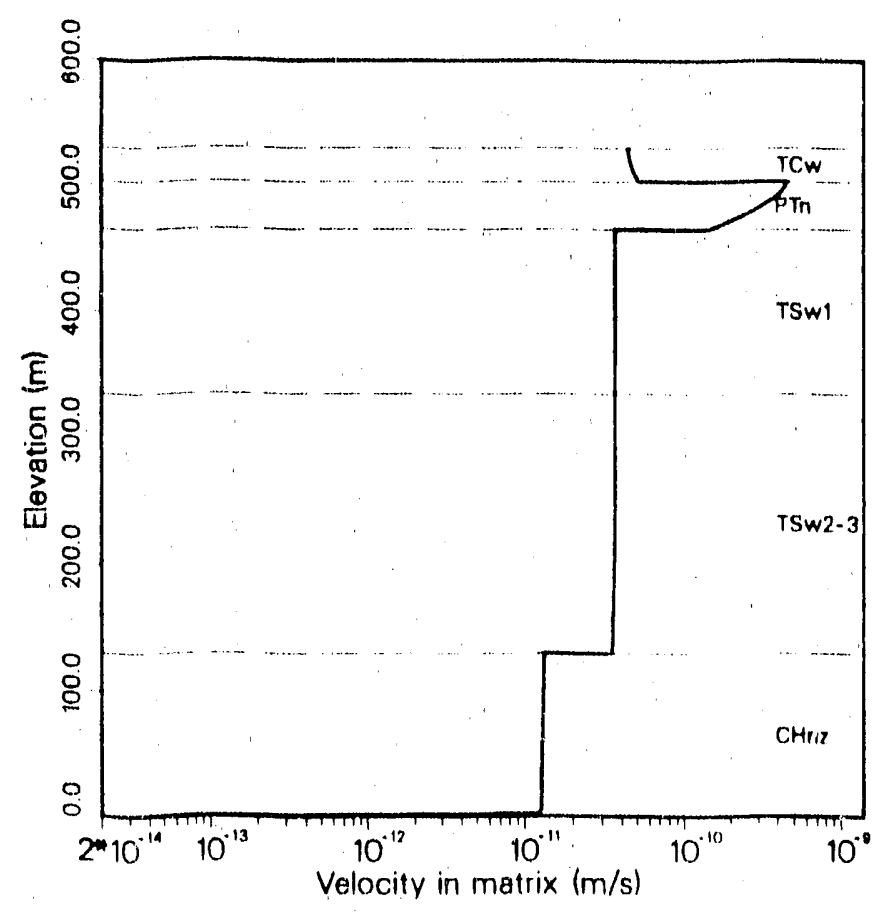

Figure 12: Matrix Water Velocity Profile with $q_{0}=0.1 \mathrm{~mm} / \mathrm{yr}, \mathrm{CHnz}$ (Case 1)

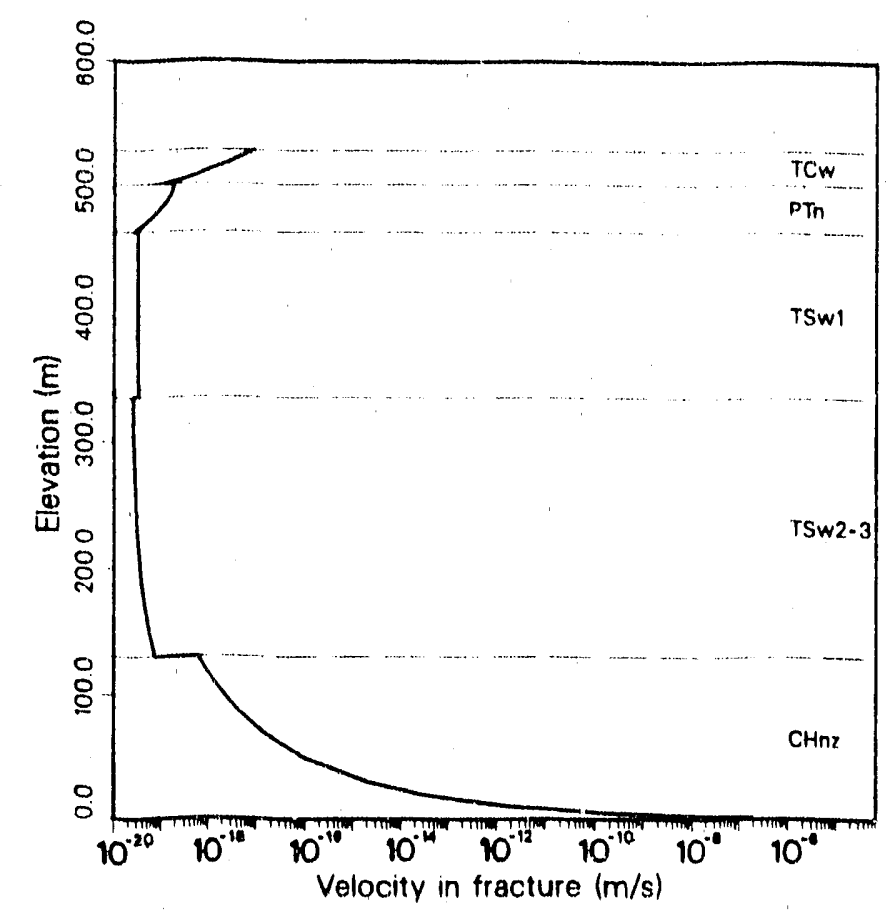

Figure 13: Fracture Water Velocity Profile with $g_{0}=0.1 \mathrm{~mm} / \mathrm{yr}, \mathrm{CHnz}$ (Case 1) 


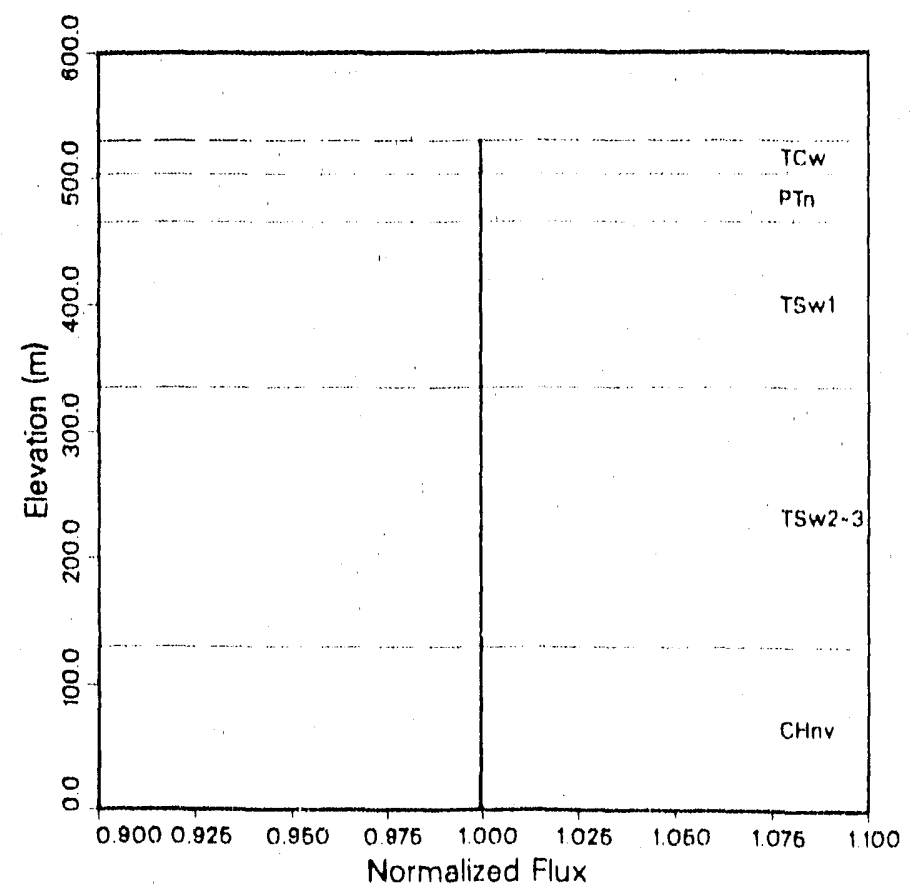

Figure 14: Normalized Flux Profile with $q_{0}=0.1 \mathrm{~mm} / \mathrm{yr}, \mathrm{CHnv}$ (Case 2)

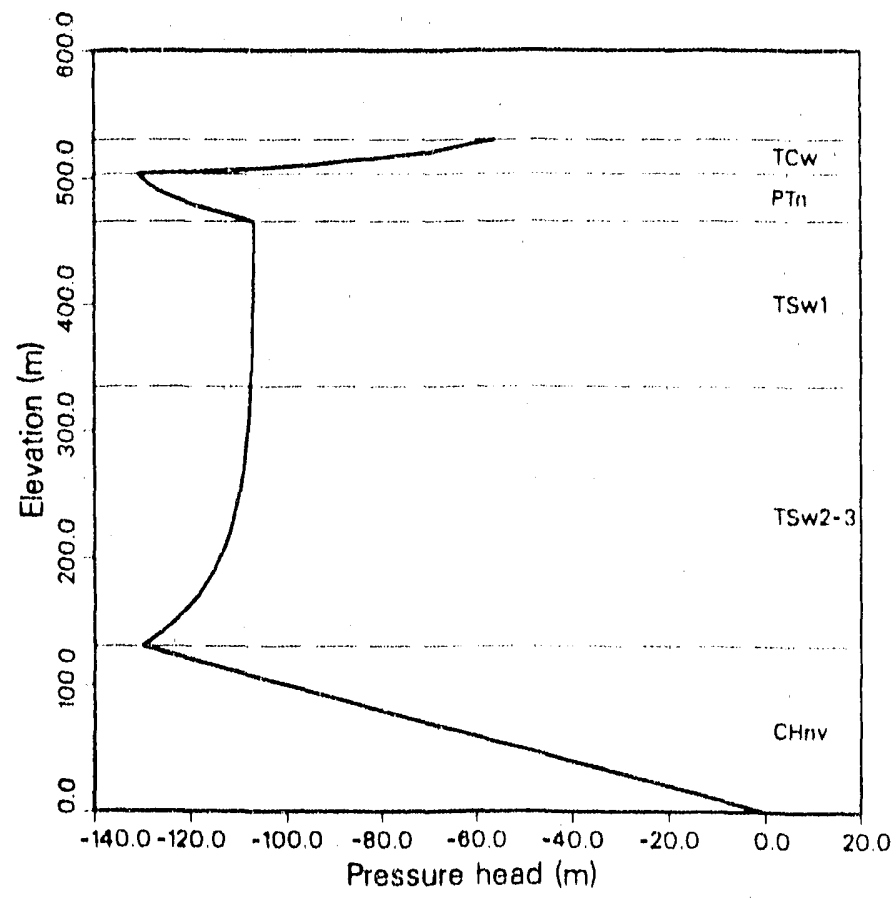

Figure 15: Pressure Head Profile with $q_{0}=0.1 \mathrm{~mm} / \mathrm{yr}$, CHnv (Case 2) 


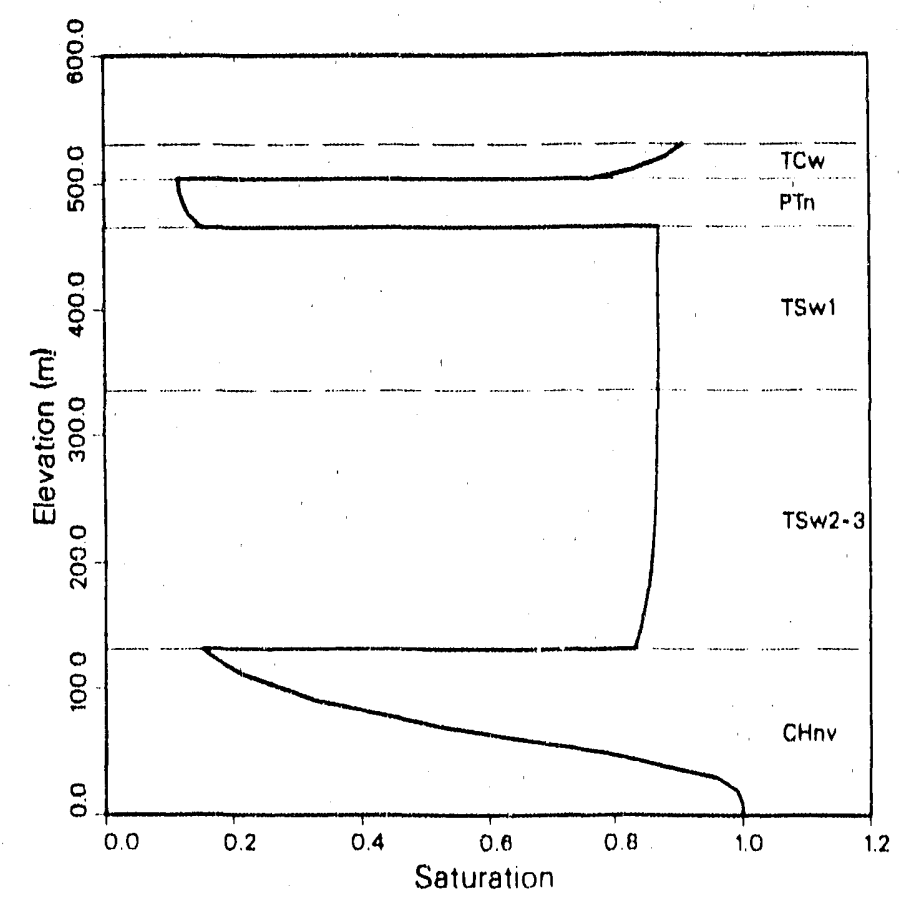

Figure 16: Matrix Saturation Profile with $q_{0}=0.1 \mathrm{~mm} / \mathrm{yr}, \mathrm{CHnv}$ (Case 2)

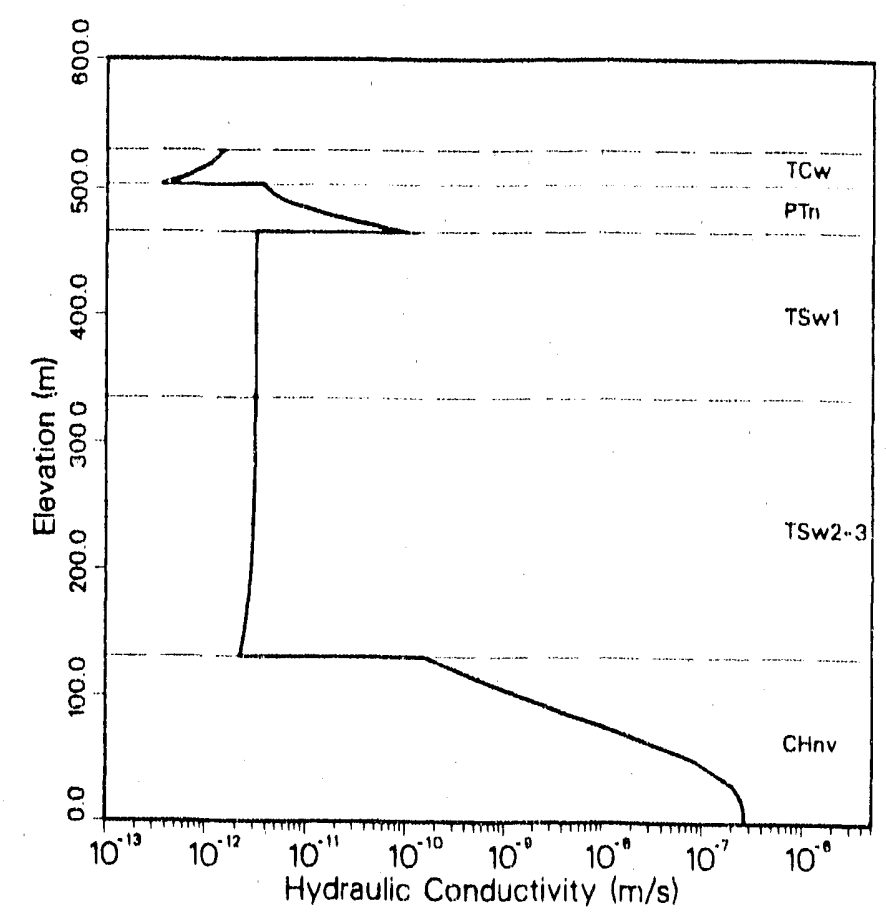

Figure 17: Hydraulic Conductivity Profile with $q_{0}=0.1 \mathrm{~mm} / \mathrm{yr}, \mathrm{CHnv}$ (Case 2) 


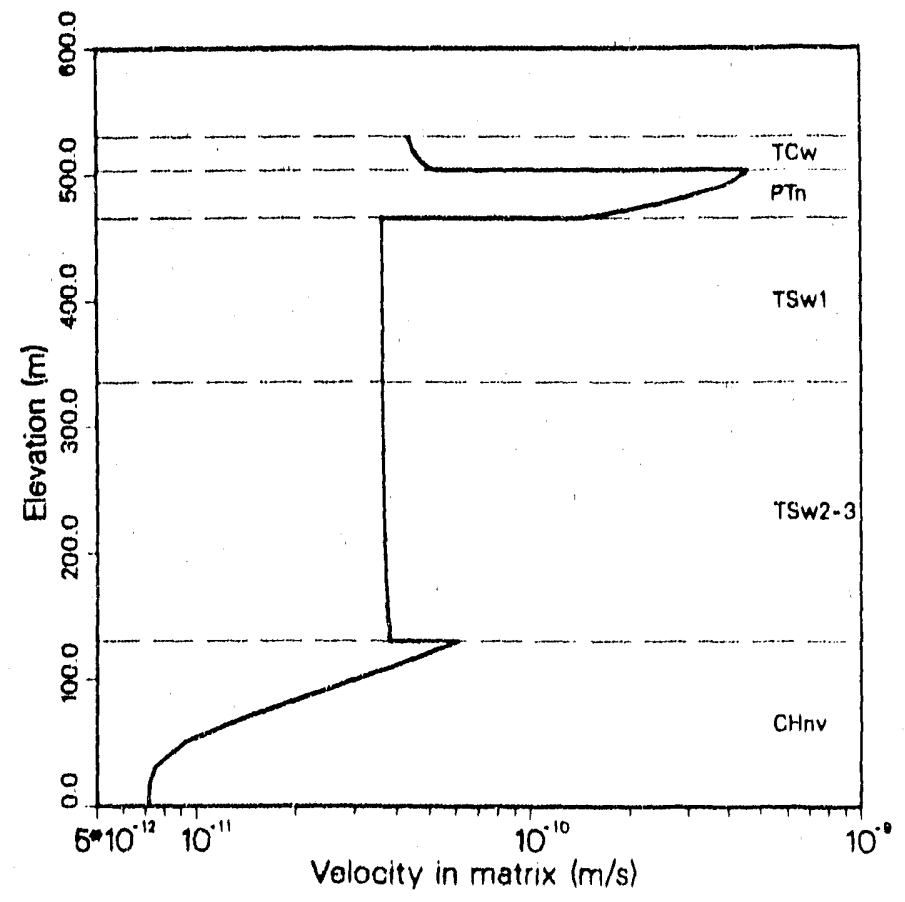

Figure 18: Matrix Water Velocity Profile with $q_{0}=0.1 \mathrm{~mm} / \mathrm{yr}, \mathrm{CHnv}$ (Case 2)

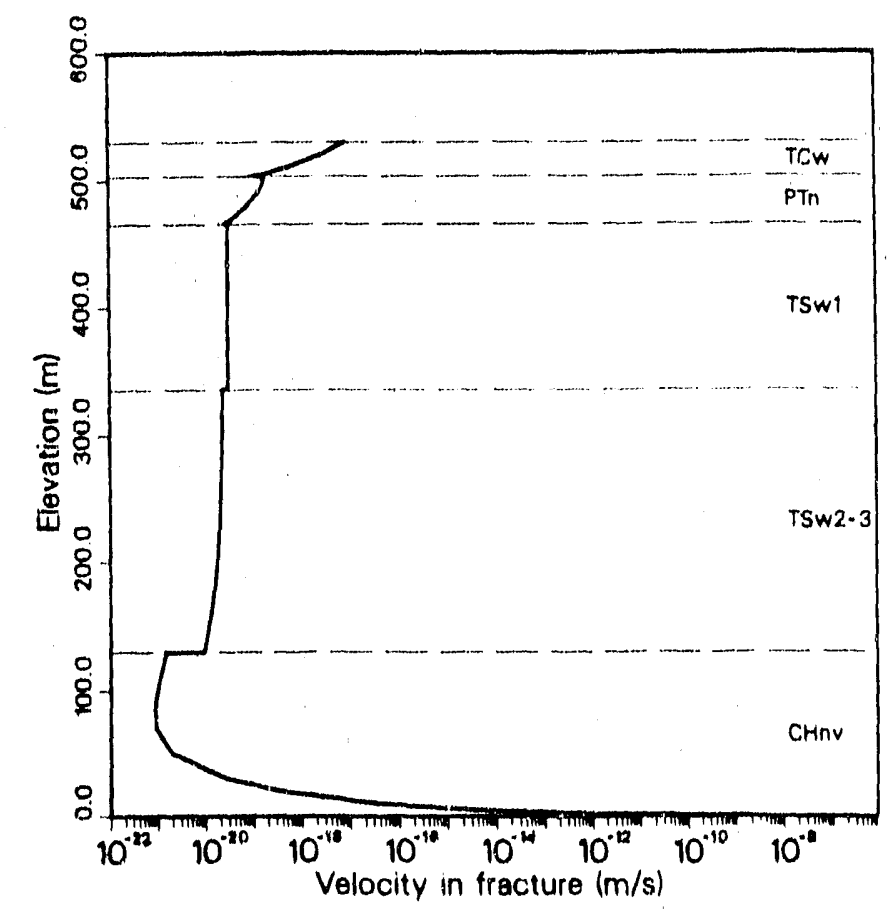

Figure 19: Fracture Water Velocity Profile with $q_{0}=0.1 \mathrm{~mm} / \mathrm{yr}, \mathrm{CHnv}$ (Case 2) 


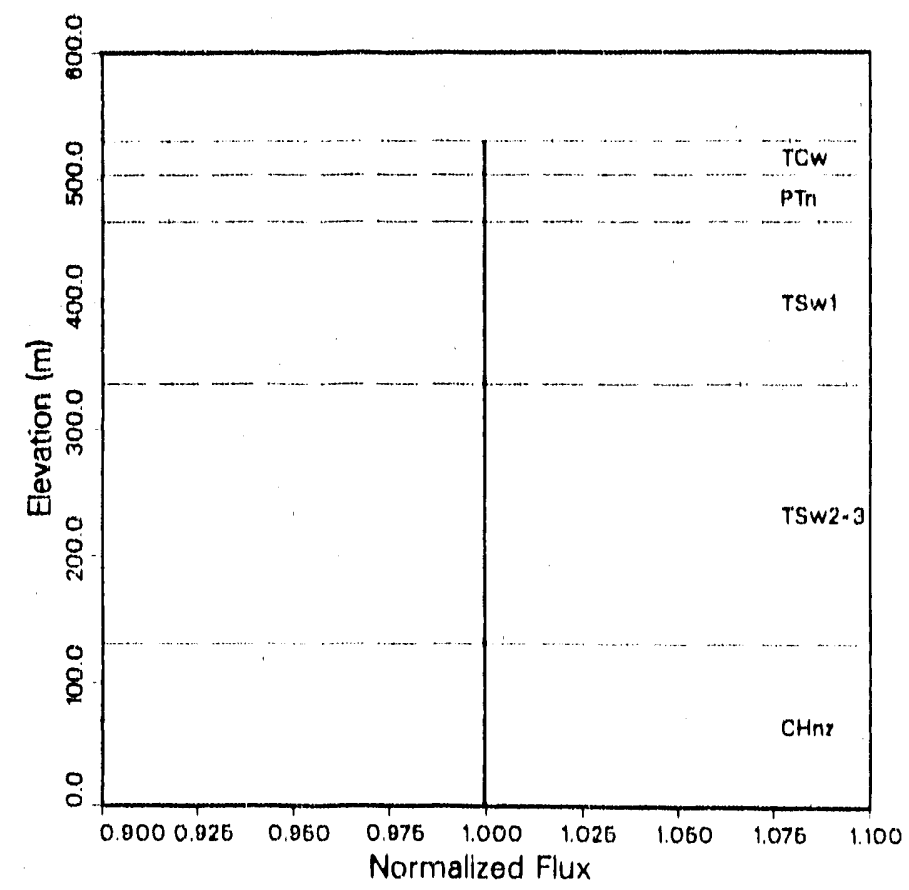

Figure 20: Normalized Flux Profile with $q_{0}=0.5 \mathrm{~mm} / \mathrm{yr}, \mathrm{CHnz}$ (Case 3)

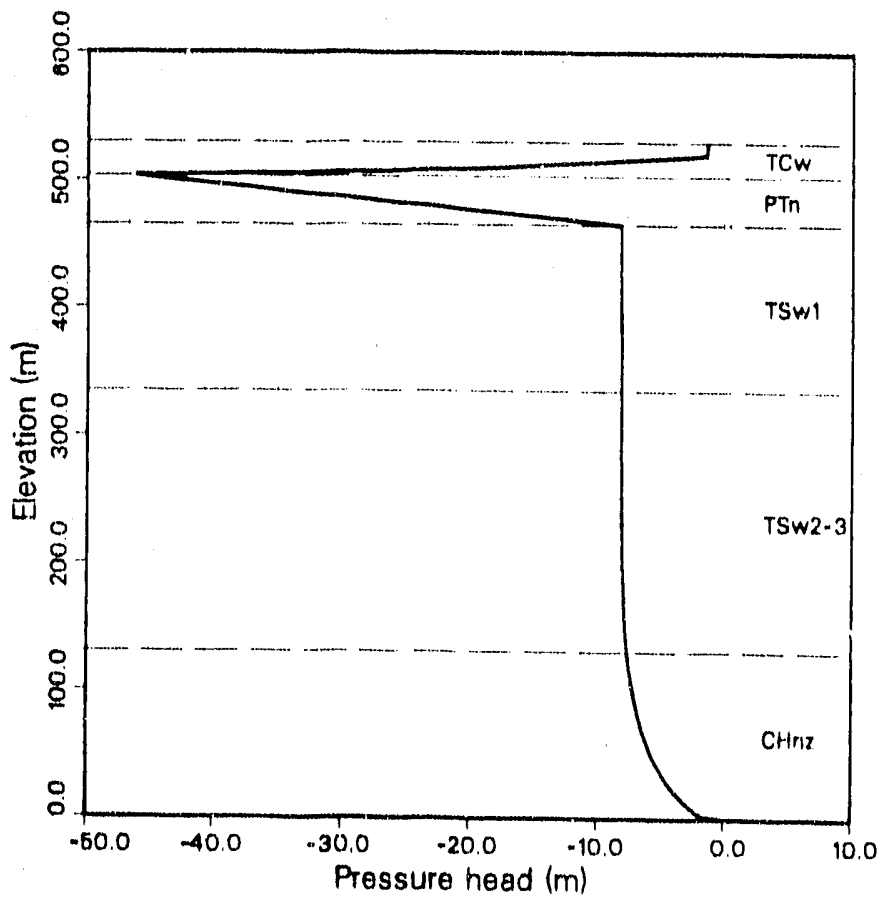

Figure 21: Pressure Head Profile with $q_{0}=0.5 \mathrm{~mm} / \mathrm{yr}, \mathrm{CHnz}$ (Case 3) 


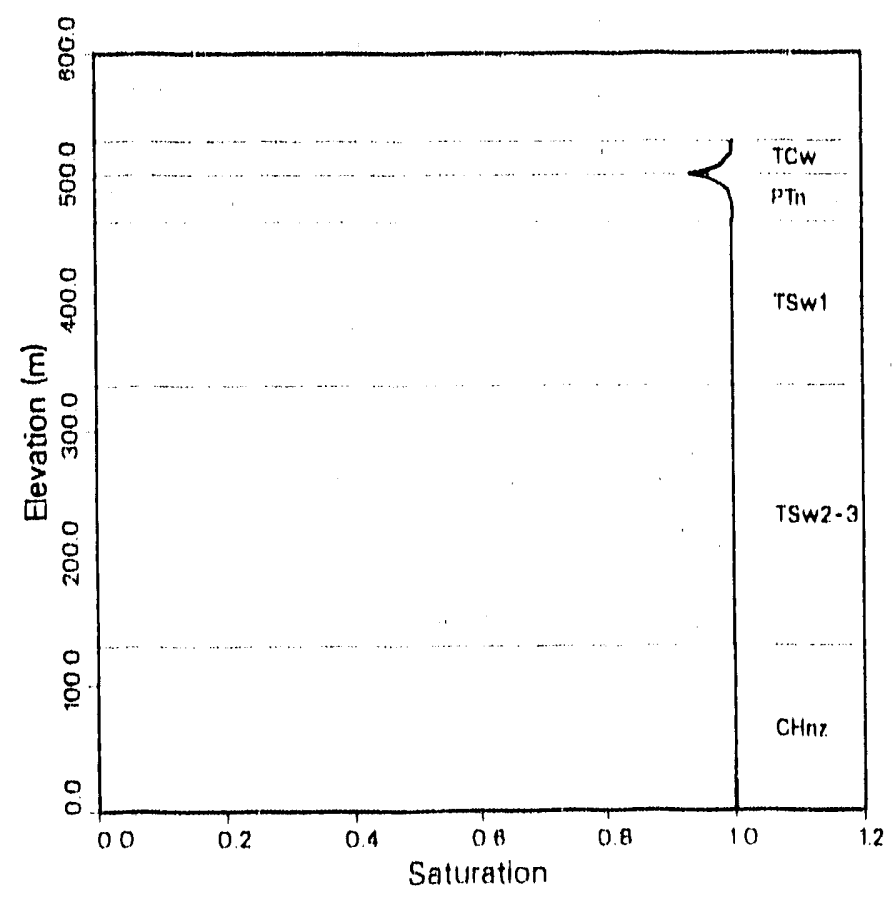

Figure 22: Matrix Saturation Profile with $q_{0}=0.5 \mathrm{~mm} / \mathrm{yr}, \mathrm{CHnz}$ (Case 3)

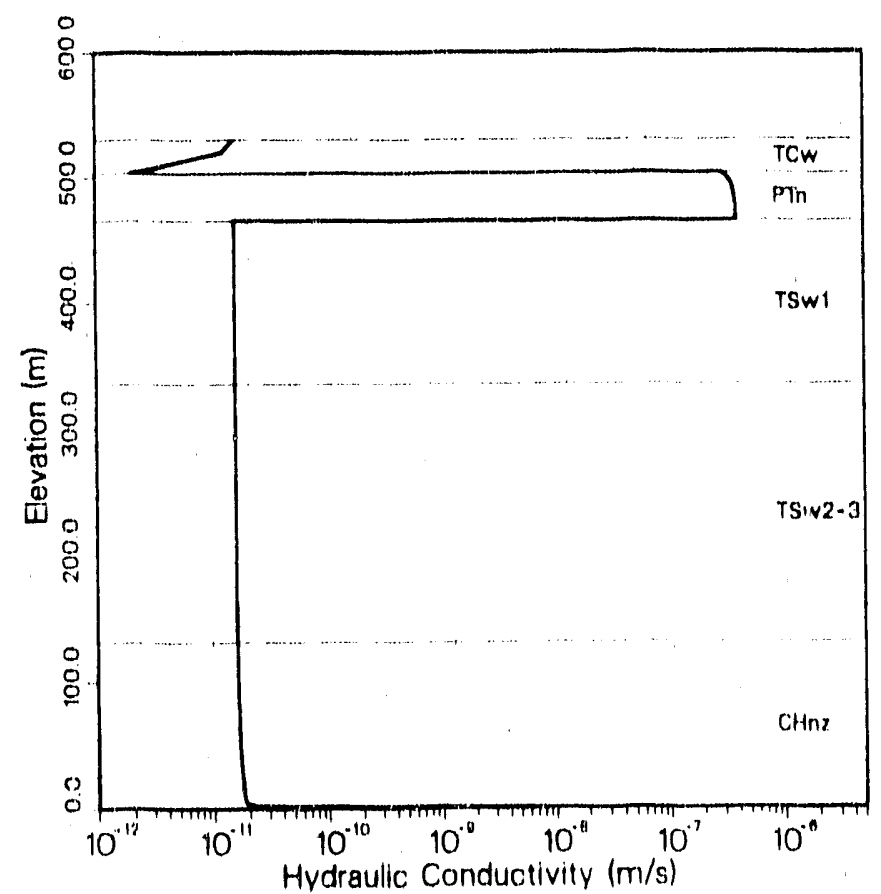

Figure 23: Hydraulic Conductivity Profile with $q_{0}=0.5 \mathrm{~mm} / \mathrm{yr}, \mathrm{CHnz}$ (Case 3) 


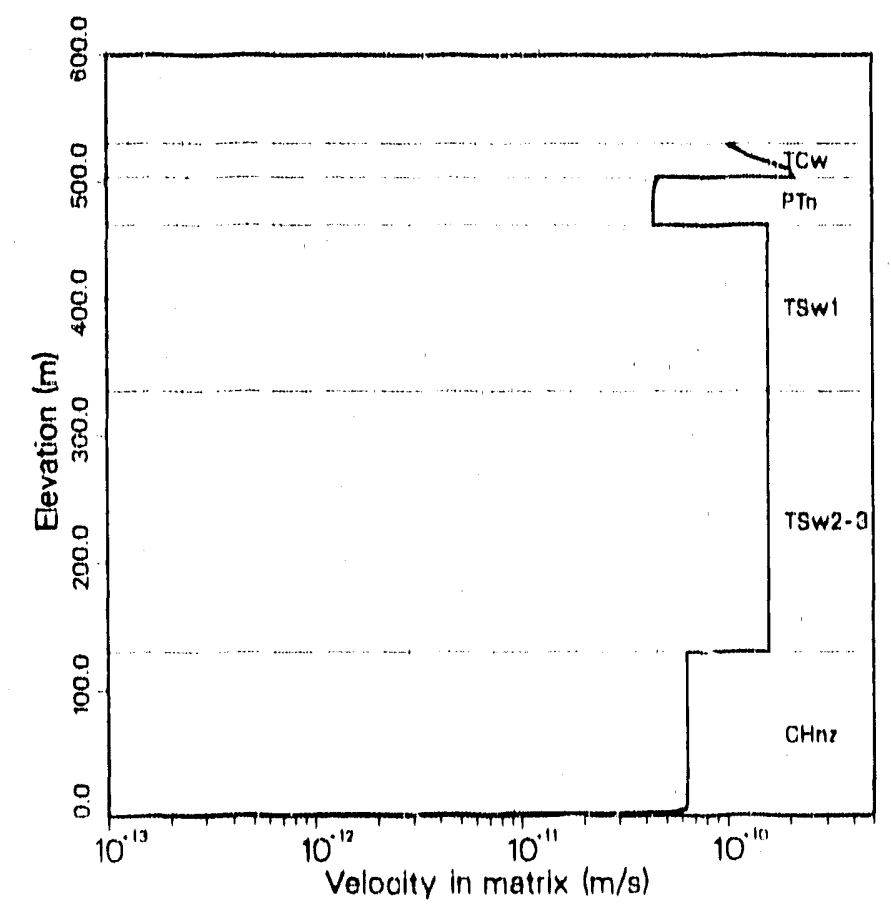

Figure 24: Matrix Water velocity Profile with $q_{0}=0.5 \mathrm{~mm} / \mathrm{yr}, \mathrm{CHnz}$ (Case 3)

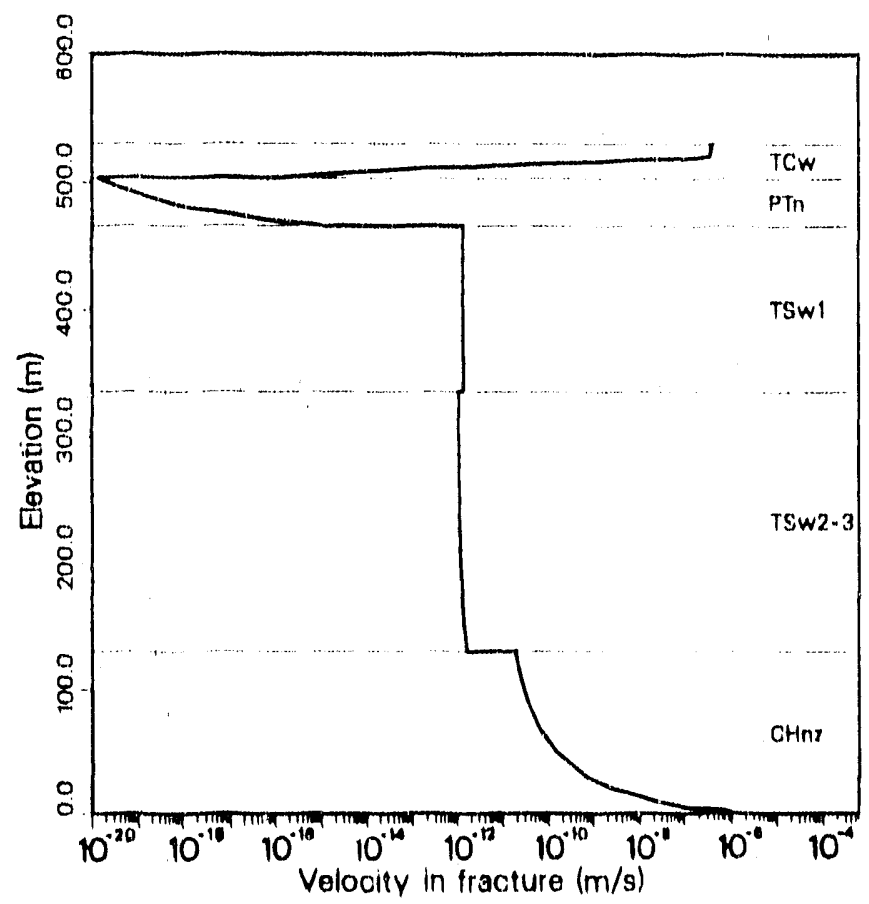

Figure 25: Fracture Water Velocity Profile with $q_{0}=0.5 \mathrm{~mm} / \mathrm{yr}$, CHnz (Case 3) 


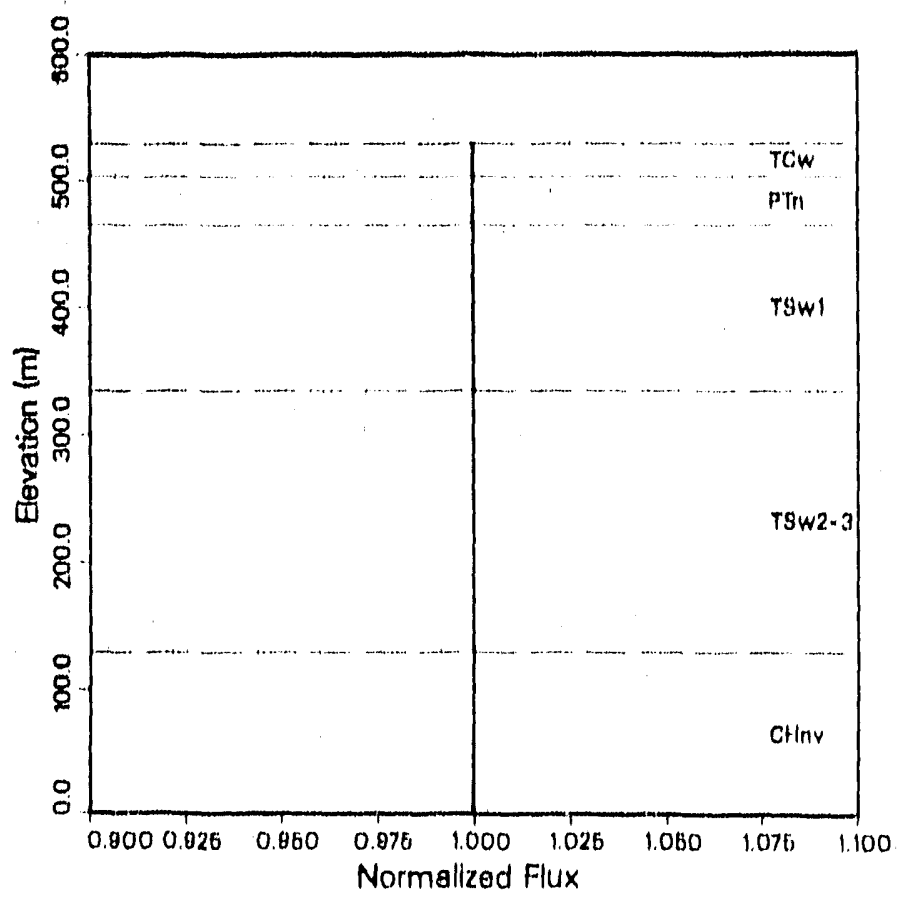

Figure 26: Normalized Flux Profile with $q_{0}=0.5 \mathrm{~mm} / \mathrm{yr}$, CHnv (Case 4)

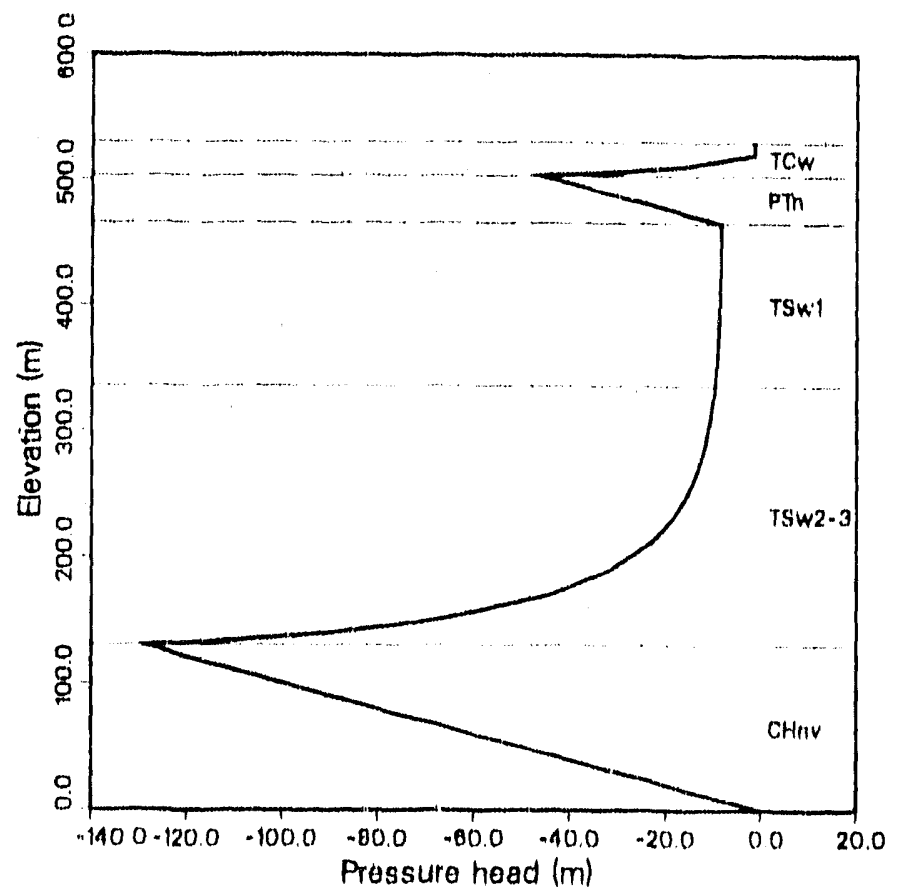

Figure 27: Pressure Head Proflle with $q_{0}=0.5 \mathrm{~mm} / \mathrm{yr}, \mathrm{CHnv}$ (Case 4) 


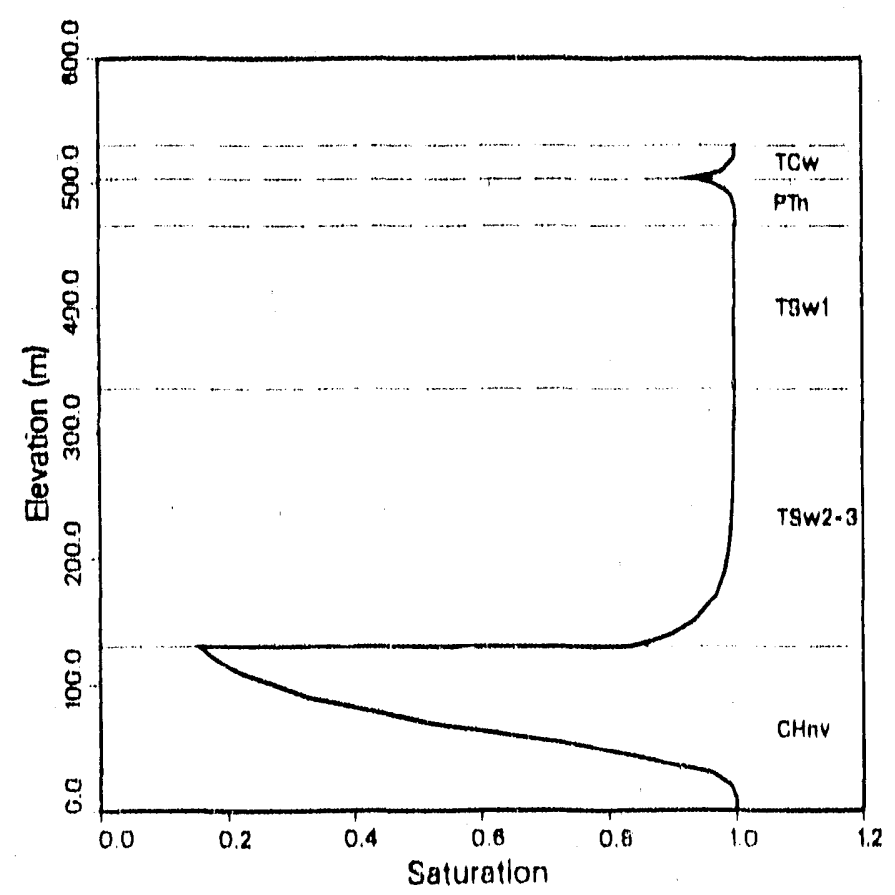

Figure 28: Matrix Saturation Profile with $q_{0}=0.5 \mathrm{~mm} / \mathrm{yr}, \mathrm{CHnv}$ (Case 4)

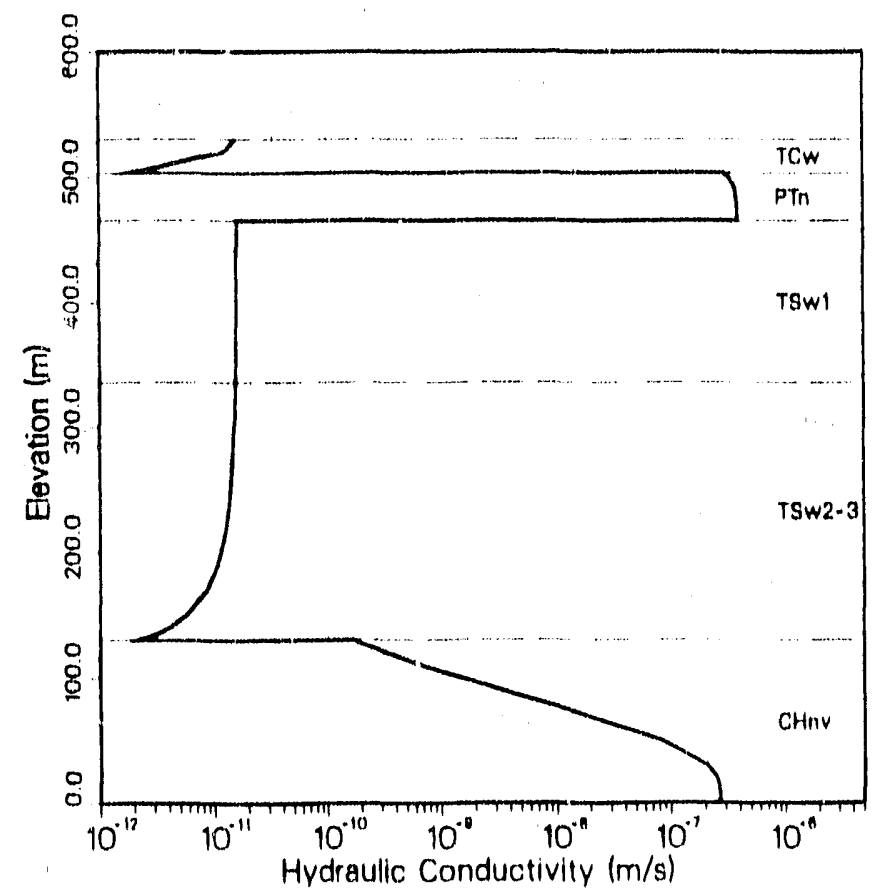

Figure 29: Hydraulic Conductivity Profile with $q_{0}=0.5 \mathrm{~mm} / \mathrm{yr}$, CHnv (Case 4) 


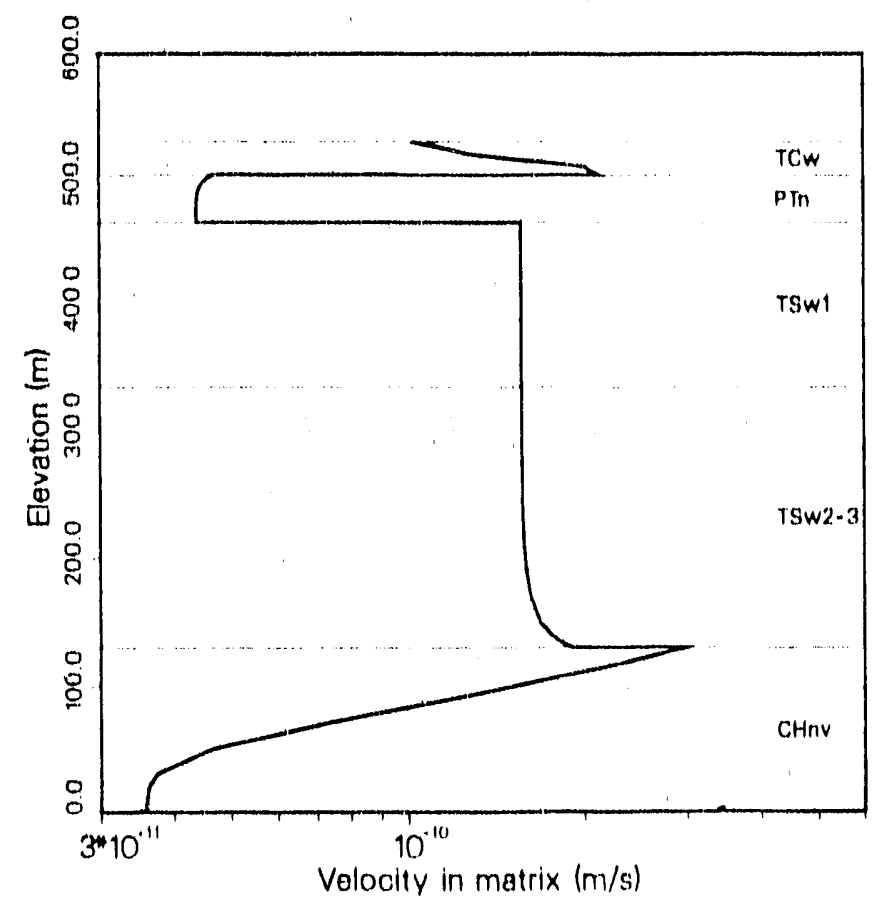

Figure 30: Matrix Water Velocity Profile with $q_{0}=0.5 \mathrm{~mm} / \mathrm{yr}$, CHnv (Case 4)

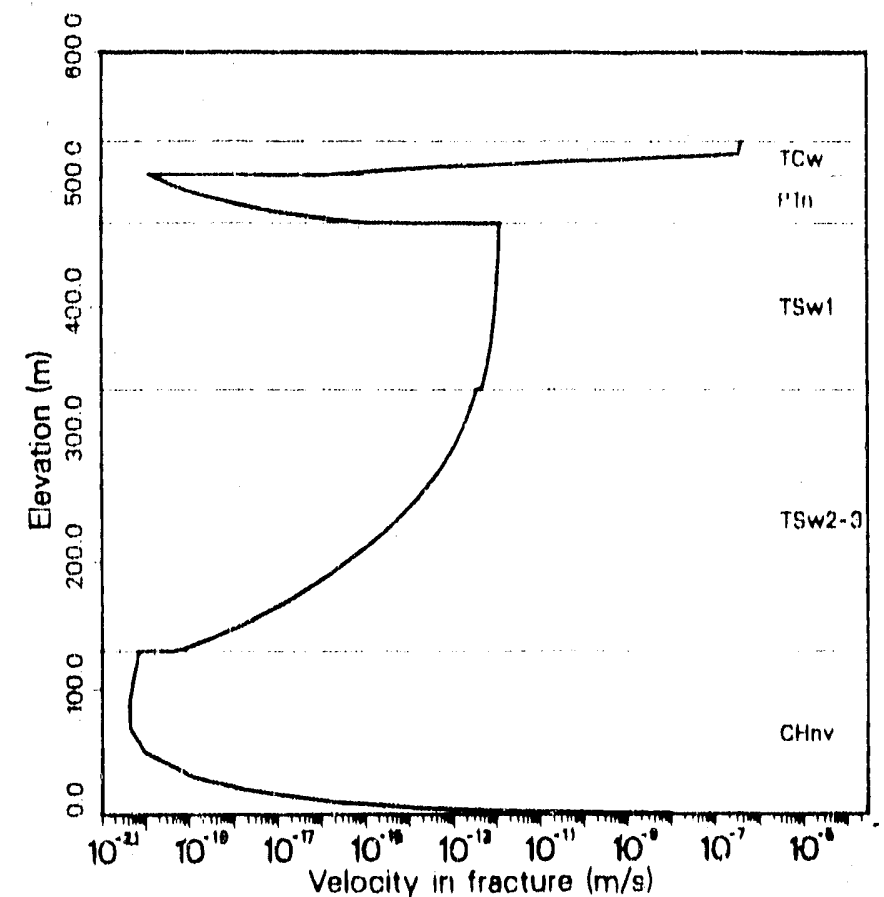

Figure 31: Fracture Water Velocity Profile with $q_{0}=0.5 \mathrm{~mm} / \mathrm{yr}$, CHnv (Case 4) 


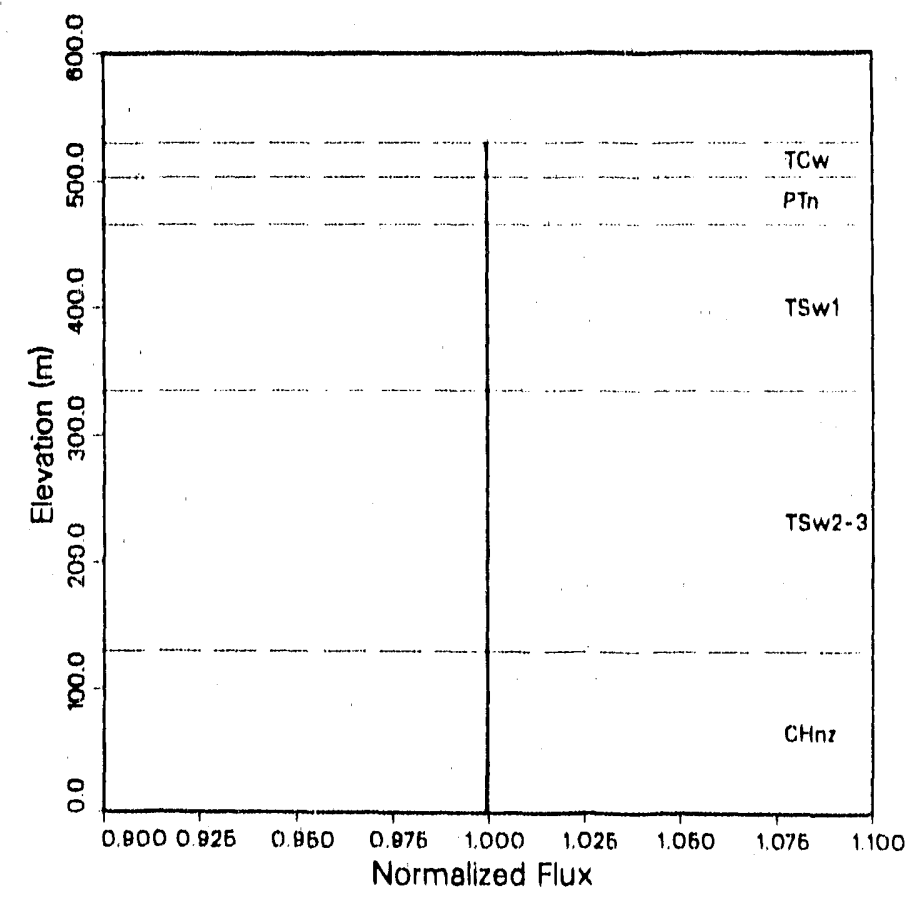

Figure 32: Normalized Flux Profile with $q_{0}=4.0 \mathrm{~mm} / \mathrm{yr}, \mathrm{CHnz}$ (Ciase 5)

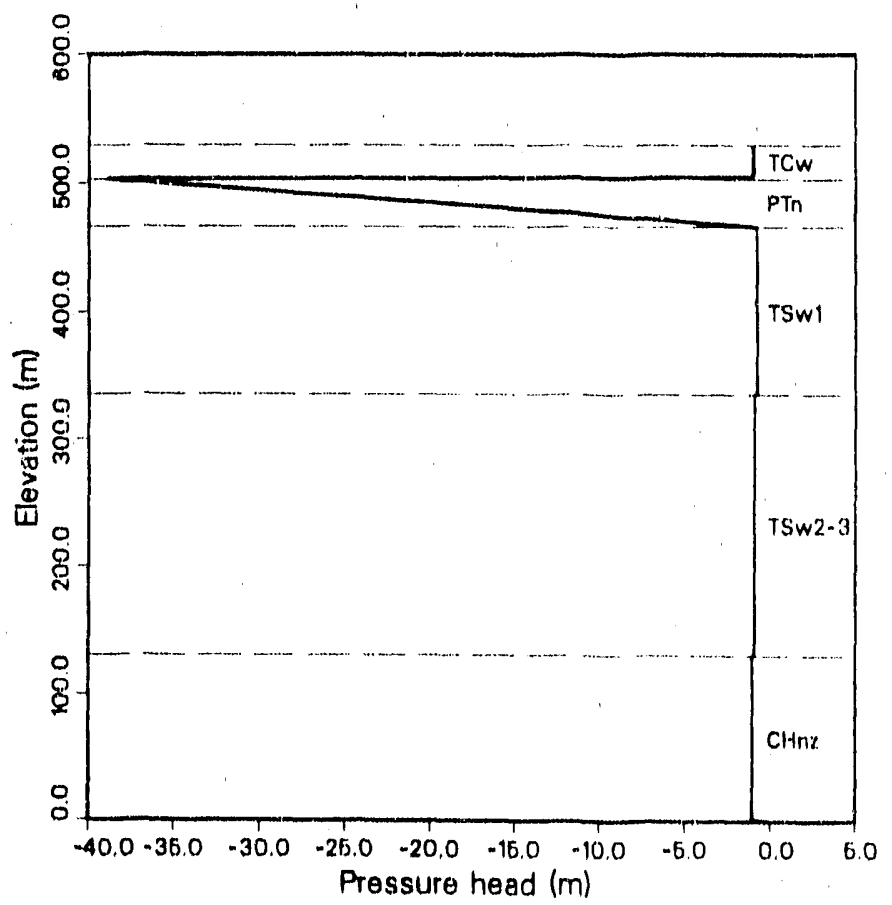

Figure 33: Pressure Head Profile with $q_{0}=4.0 \mathrm{~mm} / \mathrm{yr}$, CHnz (Case 5) 


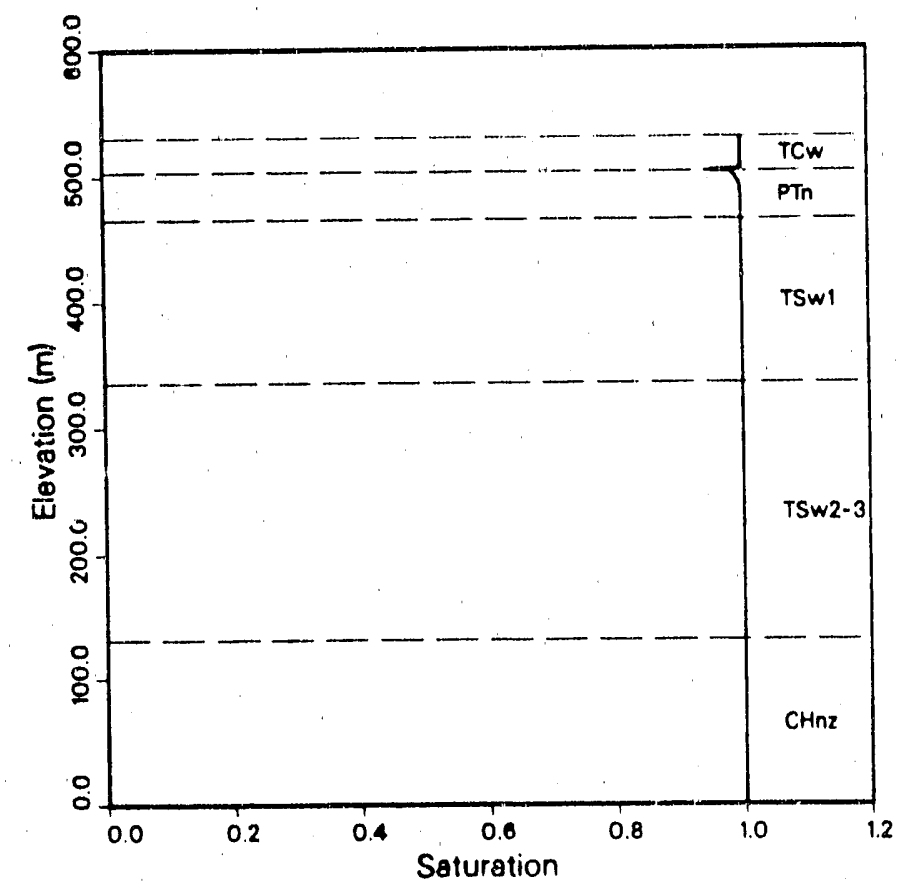

Figure 34: Matrix Saturation Profile with $q_{0}=4.0 \mathrm{~mm} / \mathrm{yr}, \mathrm{CHnz}$ (Case 5)

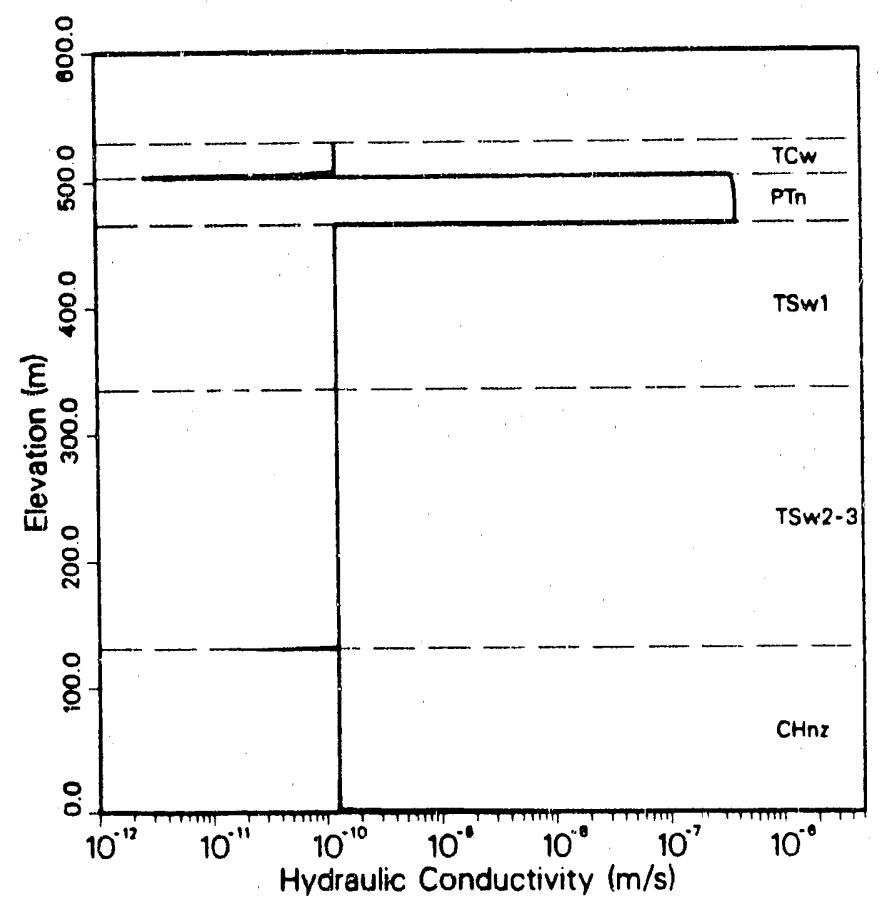

Figure 35: Hydraulic Conductivity Profile with $q_{0}=4.0 \mathrm{~mm} / \mathrm{yr}, \mathrm{CHnz}$ (Case 5) 


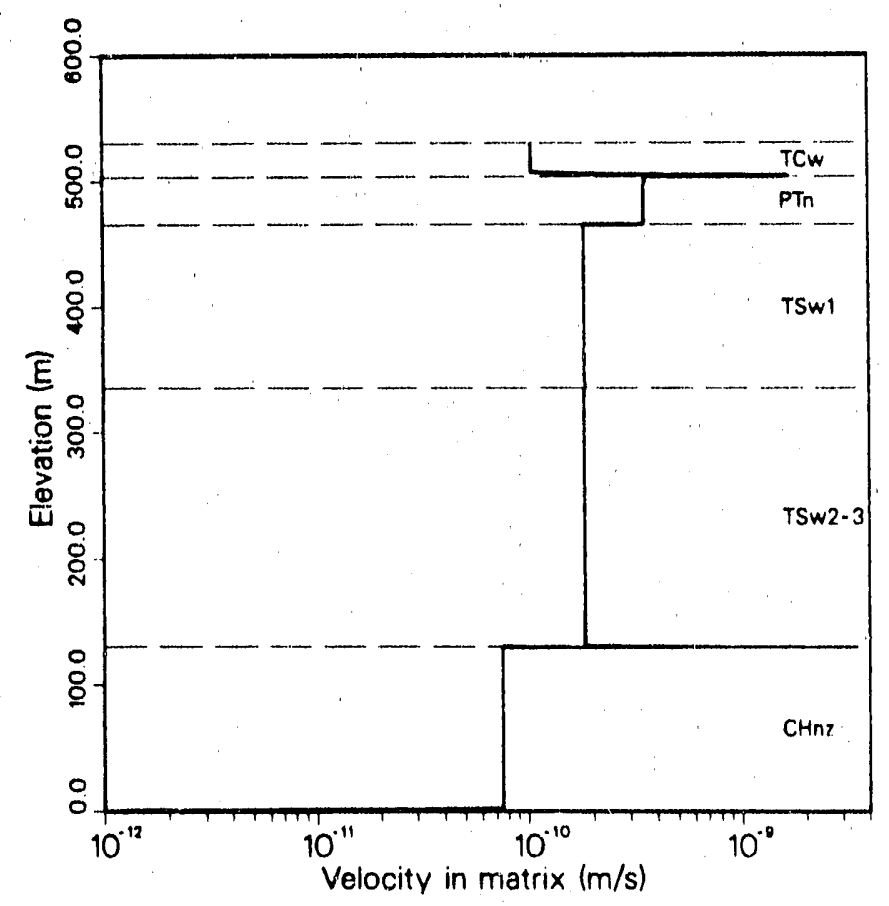

Figure 36: Matrix Water Velocity Profile with $q_{0}=4.0 \mathrm{~mm} / \mathrm{yr}, \mathrm{CHnz}$ (Case 5)

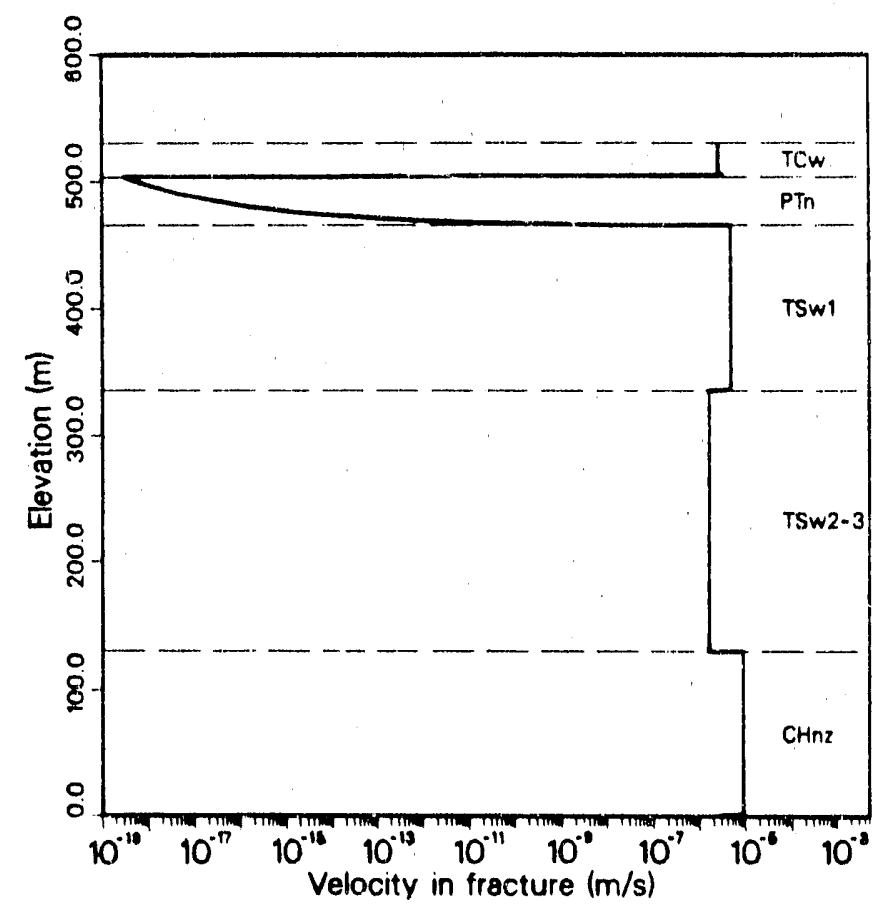

Figure 37: Fracture Water Velocity Profile with $g_{0}=40 \mathrm{~mm} / \mathrm{yr}$, CHnz (Case 5) 


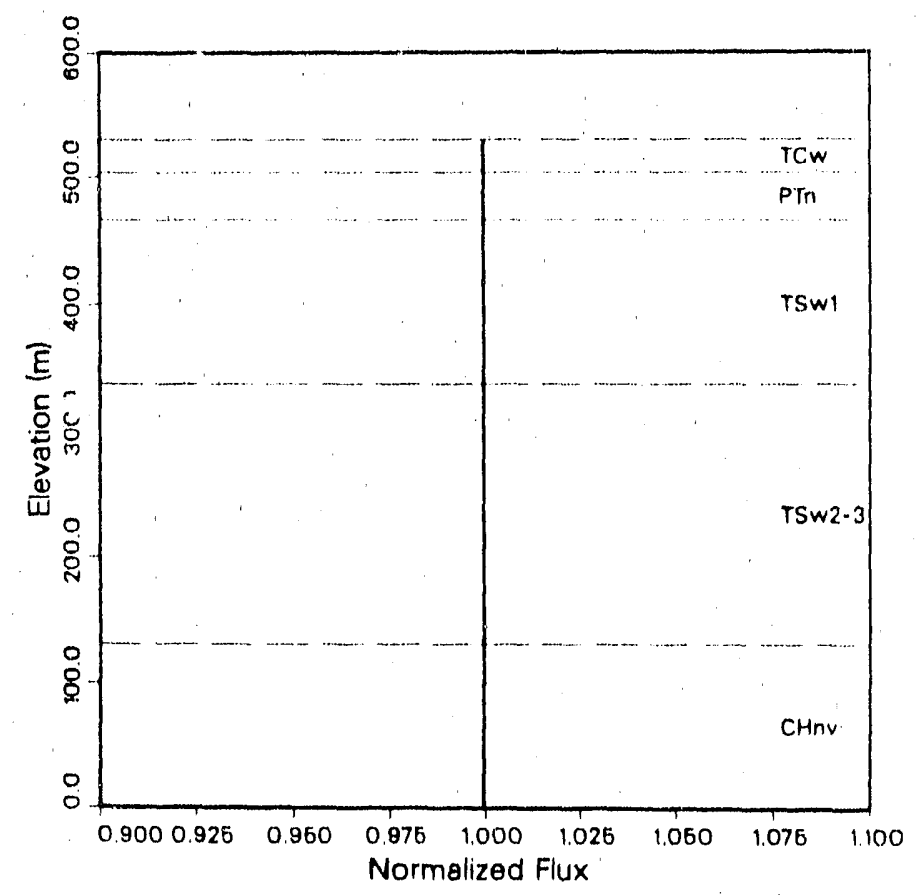

Figure 38: Normalized Flux Profile with $q_{0}=4.0 \mathrm{~mm} / \mathrm{yr}, \mathrm{CHnv}$ (Case 6)

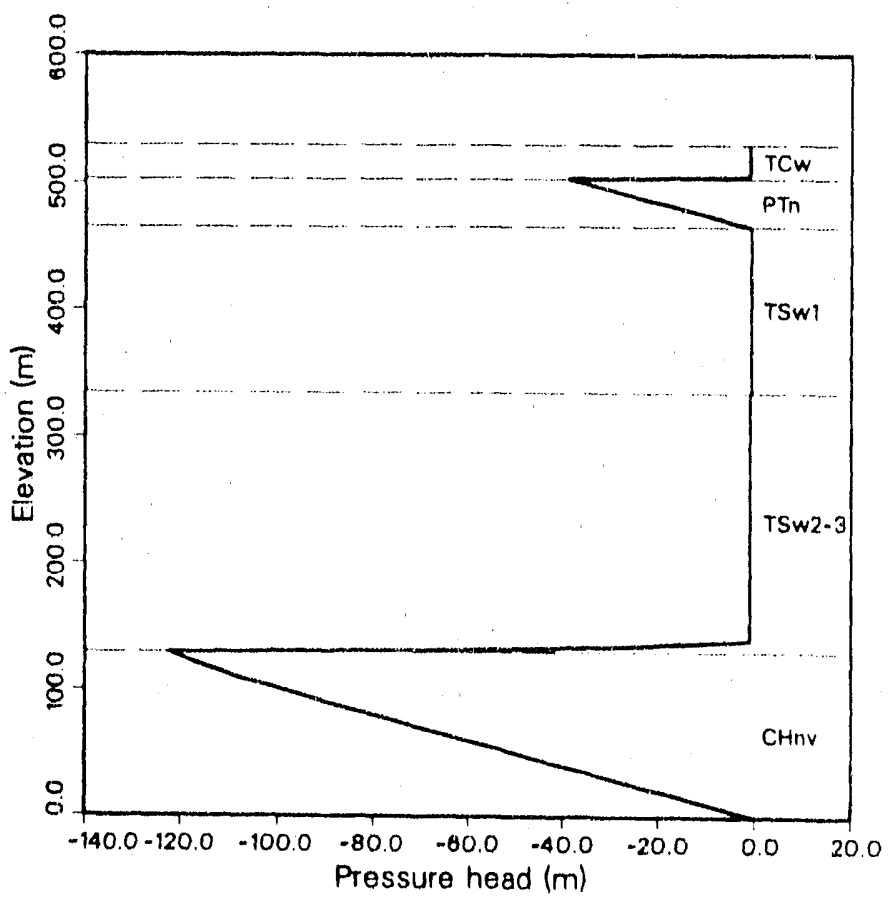

Figure 39: Pressure Head Profile with $q_{0}=4.0 \mathrm{~mm} / \mathrm{yr}, \mathrm{CHnv}$ (Case 6) 


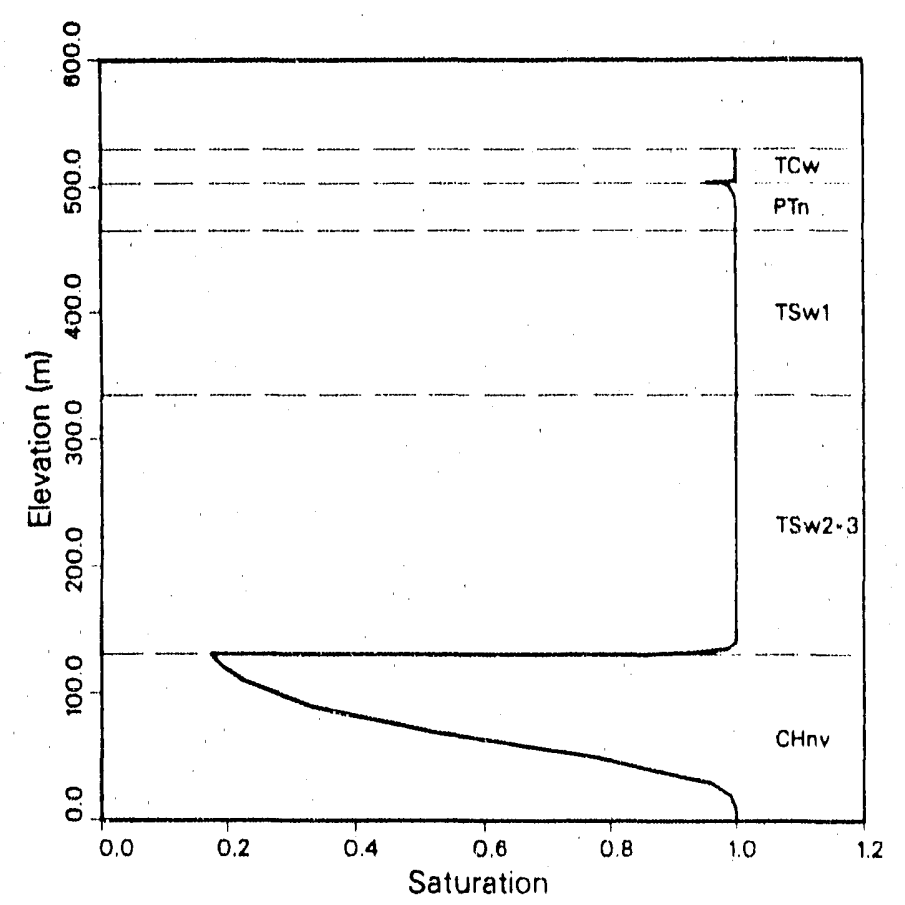

Figure 40: Matrix Saturation Profile with $q_{0}=4.0 \mathrm{~mm} / \mathrm{yr}$, CHnv (Case 6)

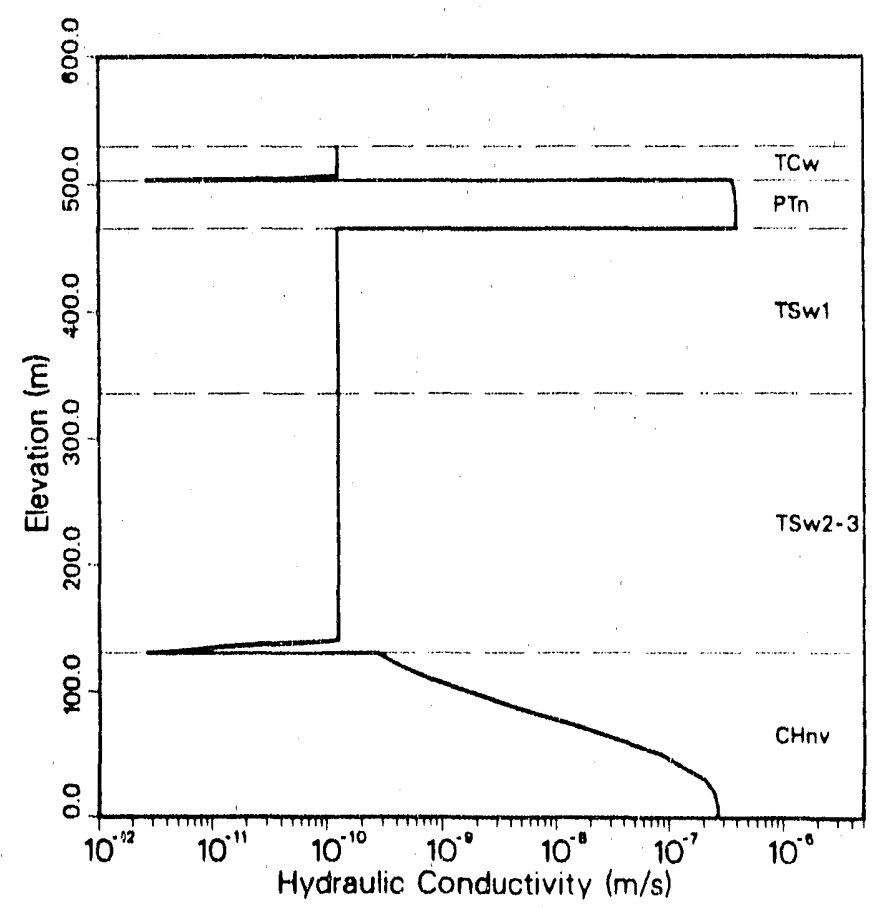

Figure 41: Hydraulic Conductivity Profile with $q_{0}=4.0 \mathrm{~mm} / \mathrm{yr}, \mathrm{CHnv}$ (Case 6) 


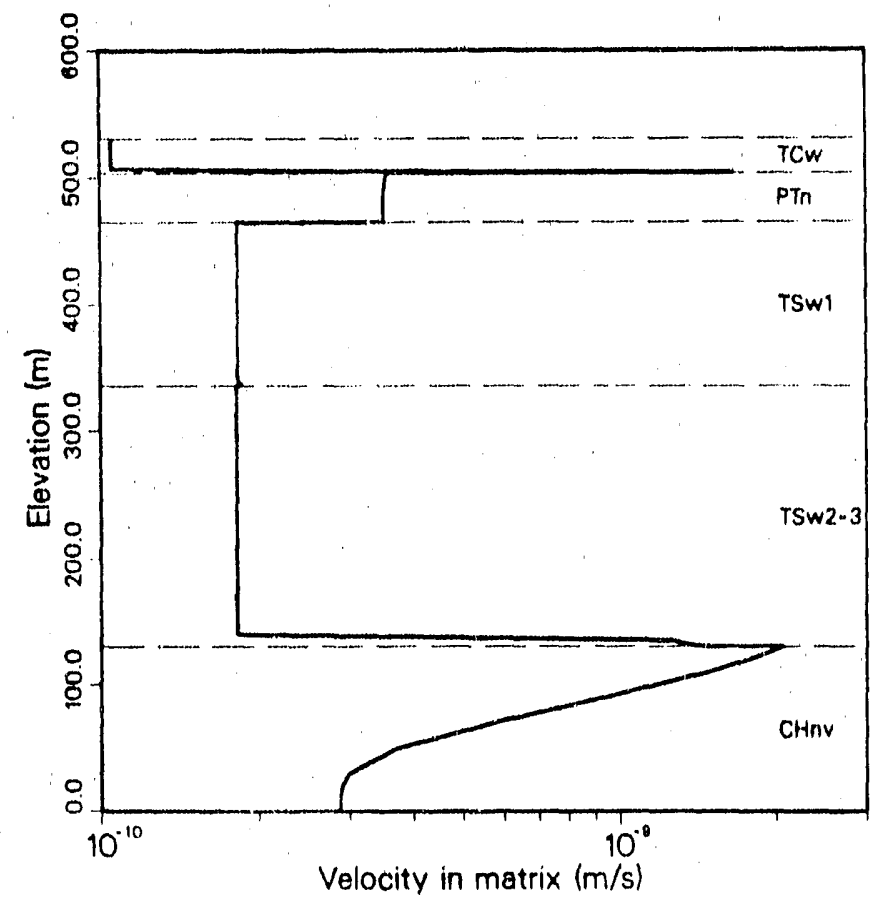

Figure 42: Matrix Water Velocity Profile with $q_{0}=4.0 \mathrm{~mm} / \mathrm{yr}$, CHnv (Case 6)

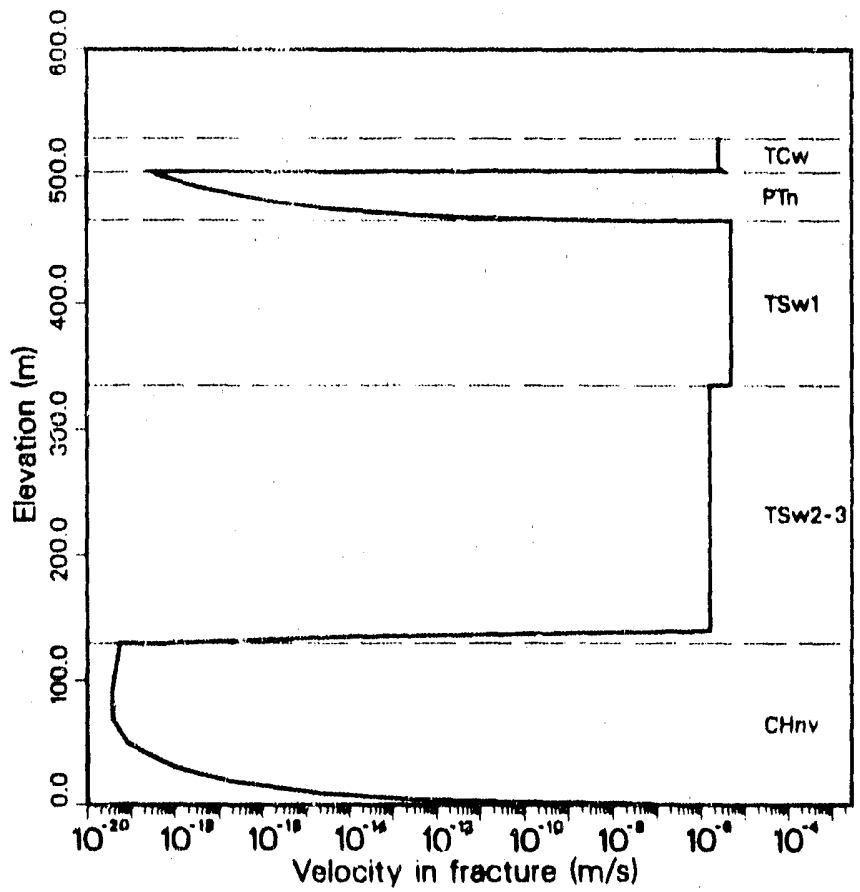

Figure 43: Fracture Water Velocity Profile with $q_{0}=4.0 \mathrm{~mm} / \mathrm{yr}, \mathrm{CHnv}$ (Case 6) 


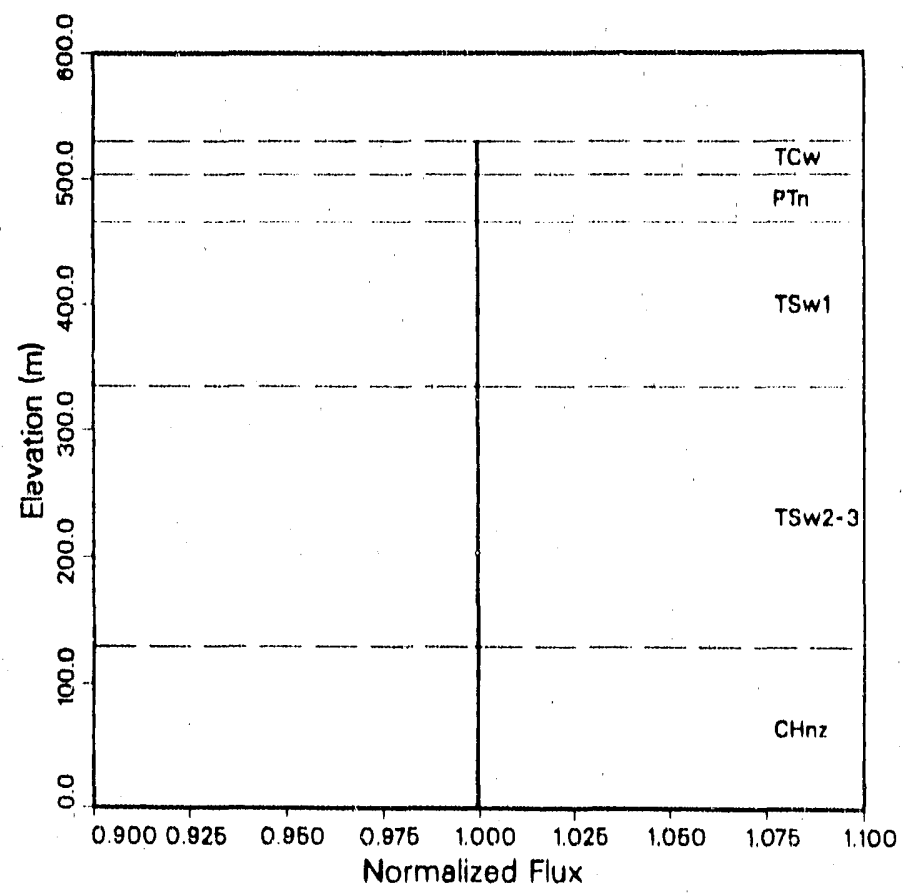

Figure 44: Normalized Flux Profile with $q_{0}=0.2 \mathrm{~mm} / \mathrm{yr}, \mathrm{CHnz}$ (Case 7)

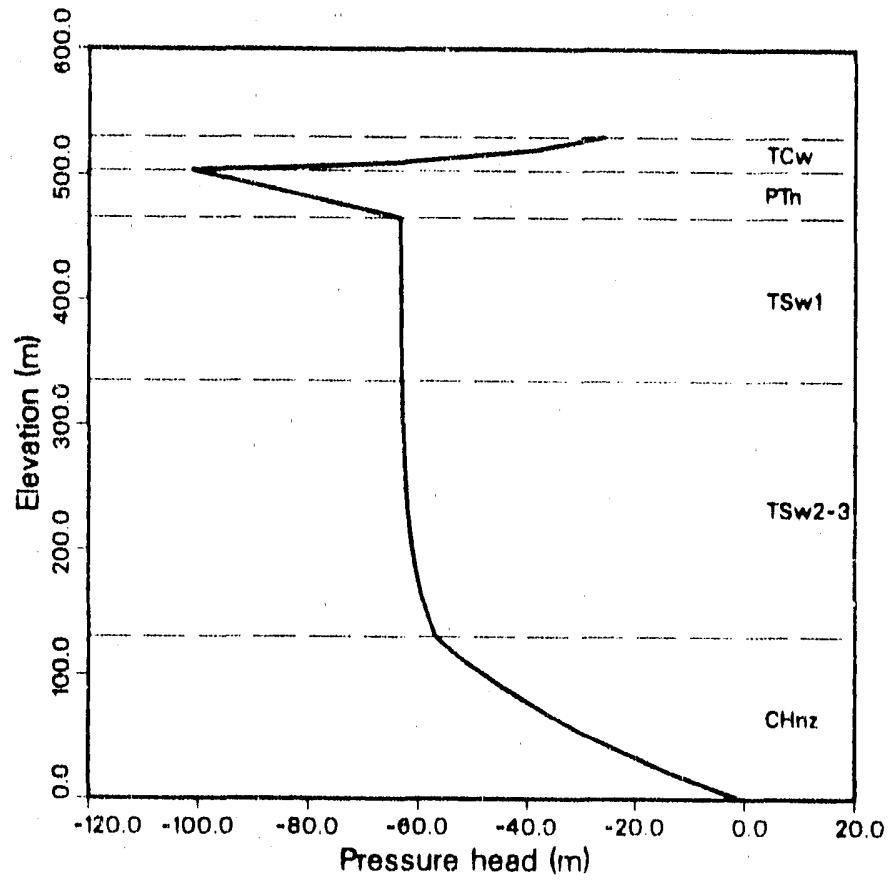

Figure 45: Pressure Head Profile with $q_{0}=0.2 \mathrm{~mm} / \mathrm{yr}, \mathrm{CHnz}$ (Case 7) 


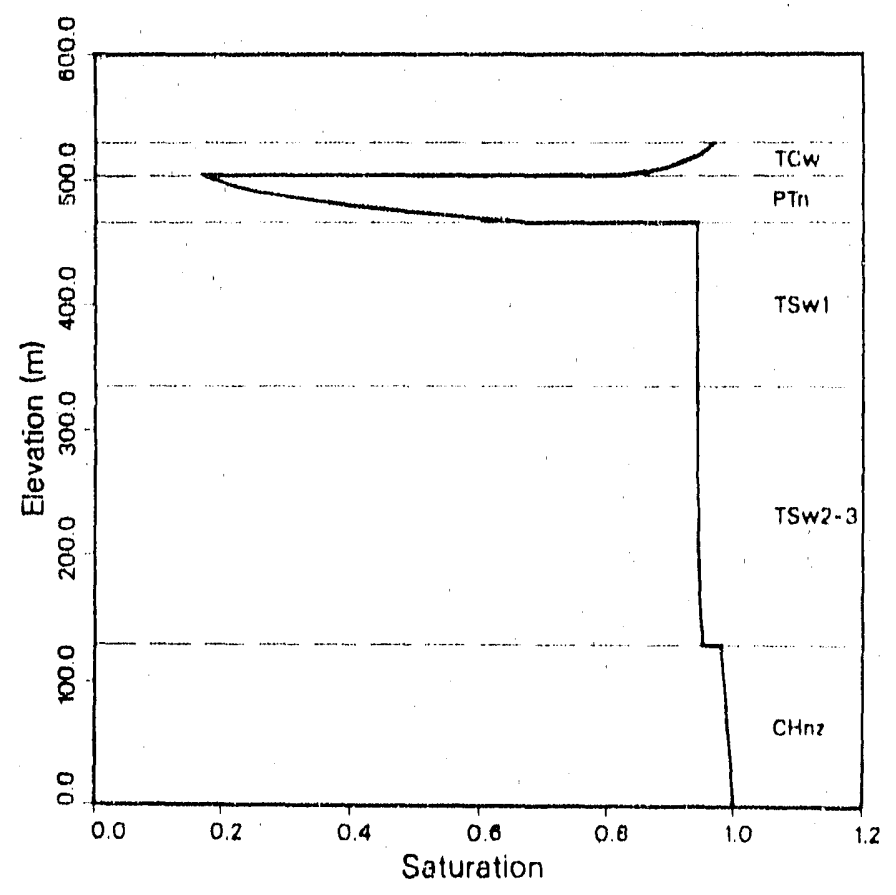

Figure 46: Matrix Saturation Profile with $q_{0}=0.2 \mathrm{~mm} / \mathrm{yr}, \mathrm{CHnz}$ (Case 7)

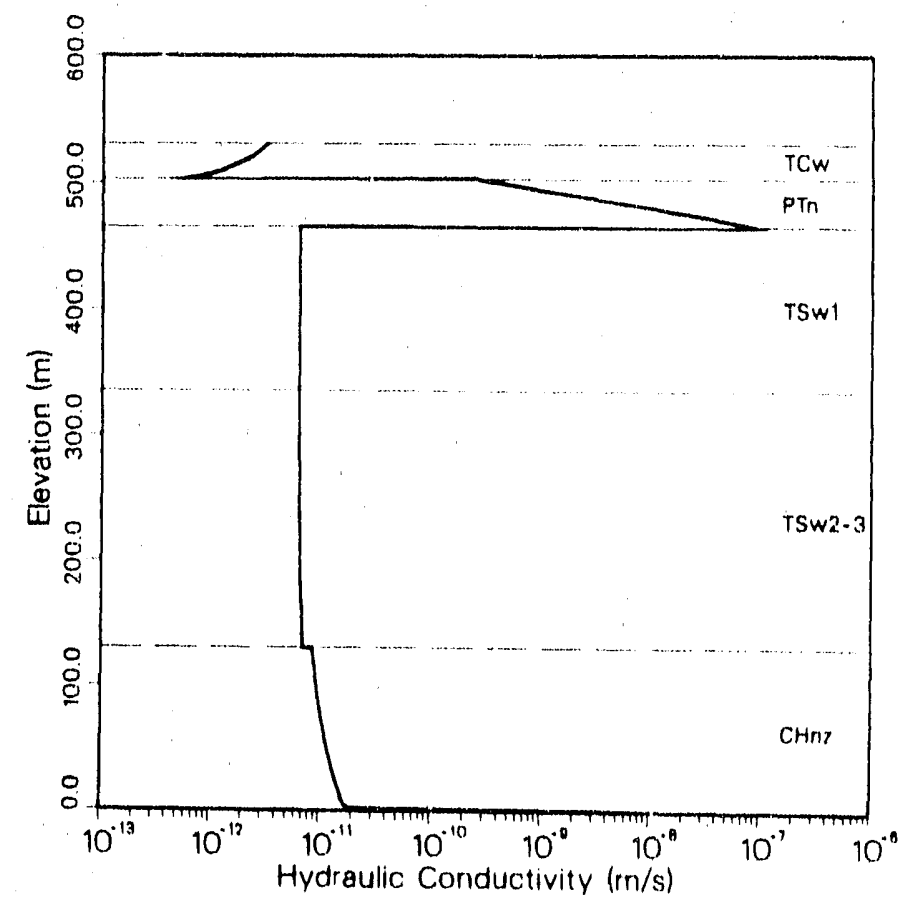

Figure 47: Hydraulic Conductivity Profile with $q_{0}=0.2 \mathrm{~mm} / \mathrm{yr}, \mathrm{CHnz}$ (Case 7) 


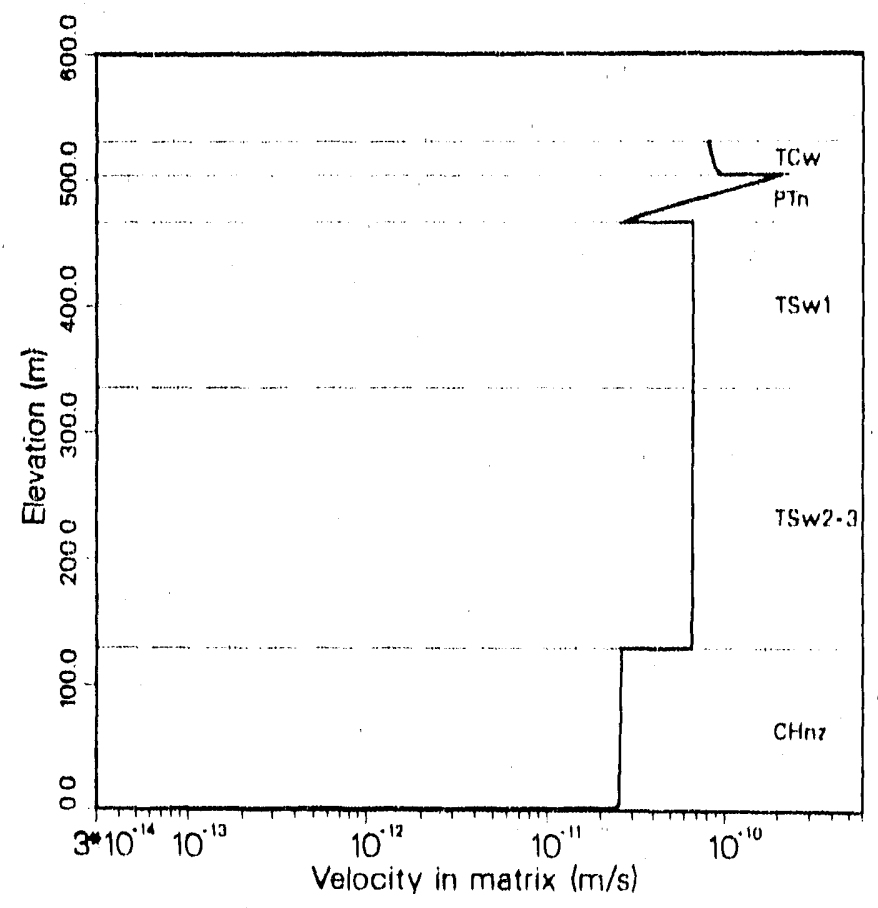

Figure 48: Matrix Water Velocity Profile with $q_{0}=0.2 \mathrm{~mm} / \mathrm{yr}, \mathrm{CHnz}$ (Case 7)

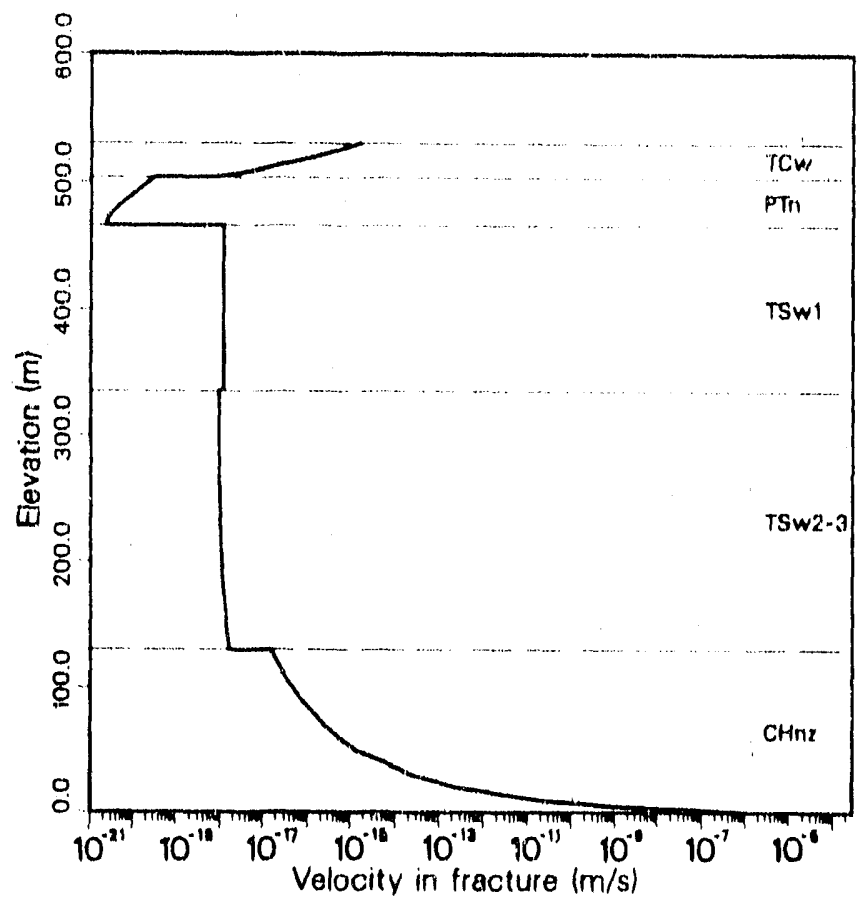

Figure 49: Fracture Water Velocity Profile with $q_{0}=0.2 \mathrm{~mm} / \mathrm{yr}, \mathrm{CHnz}$ (Case 7) 


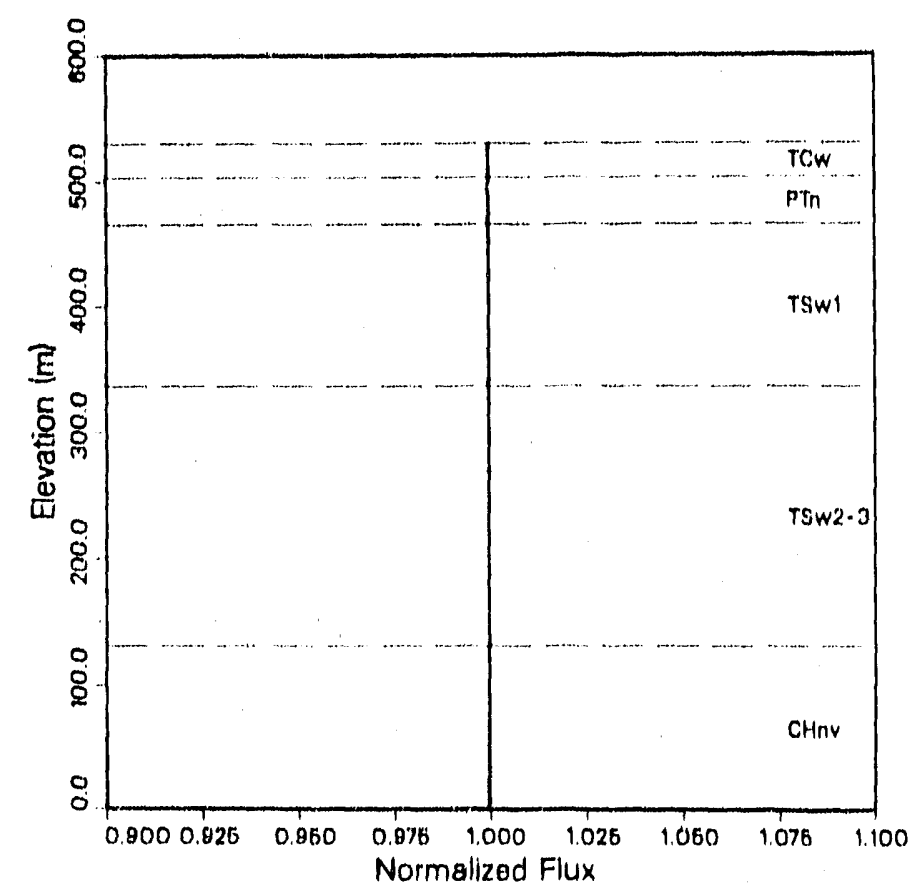

Figure 50: Normalized Flux Profile with $q_{0}=0.2 \mathrm{~mm} / \mathrm{yr}, \mathrm{CHnv}$ (Case 8)

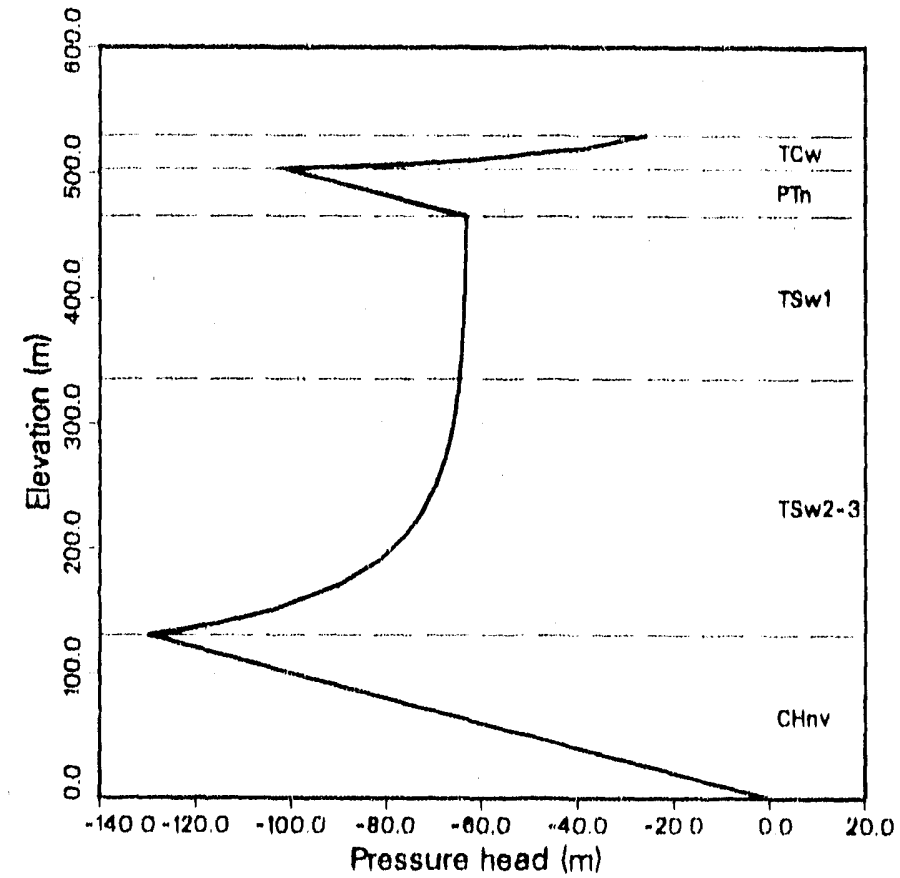

Figure 51: Pressure Head Profile with $q_{0}=0.2 \mathrm{~mm} / \mathrm{yr}, \mathrm{CHnv}$ (Case 8) 


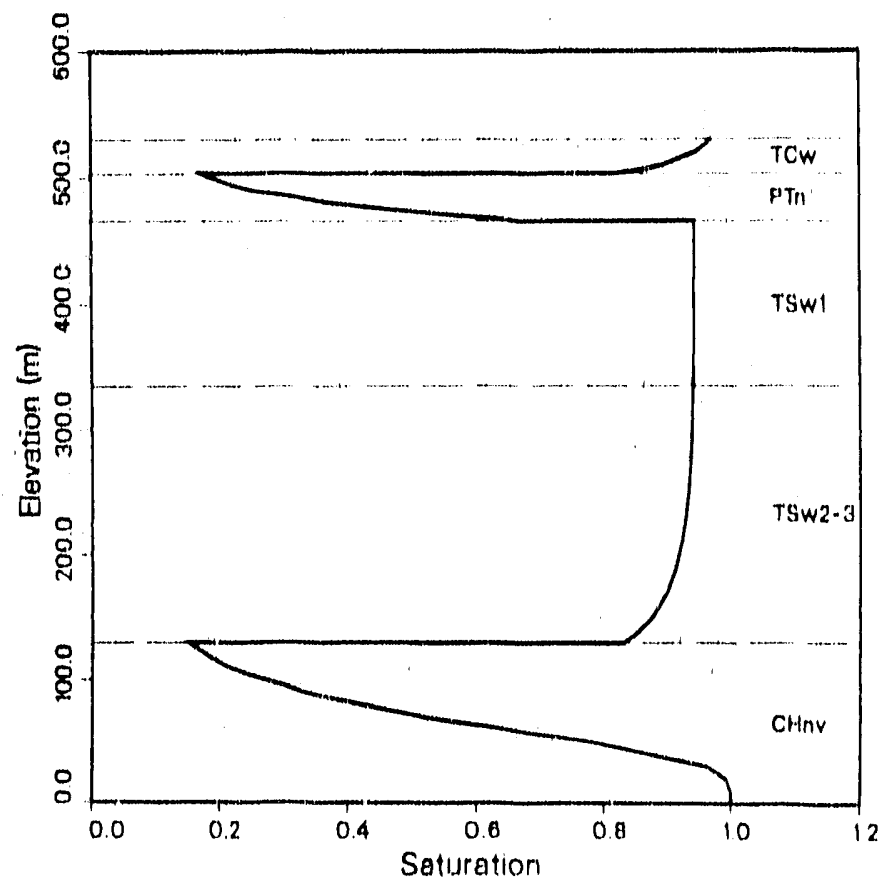

Figure 52: Matrix Saturation Profile with $q_{0}=0.2 \mathrm{~mm} / \mathrm{y} r$, CHnv (Case 8)

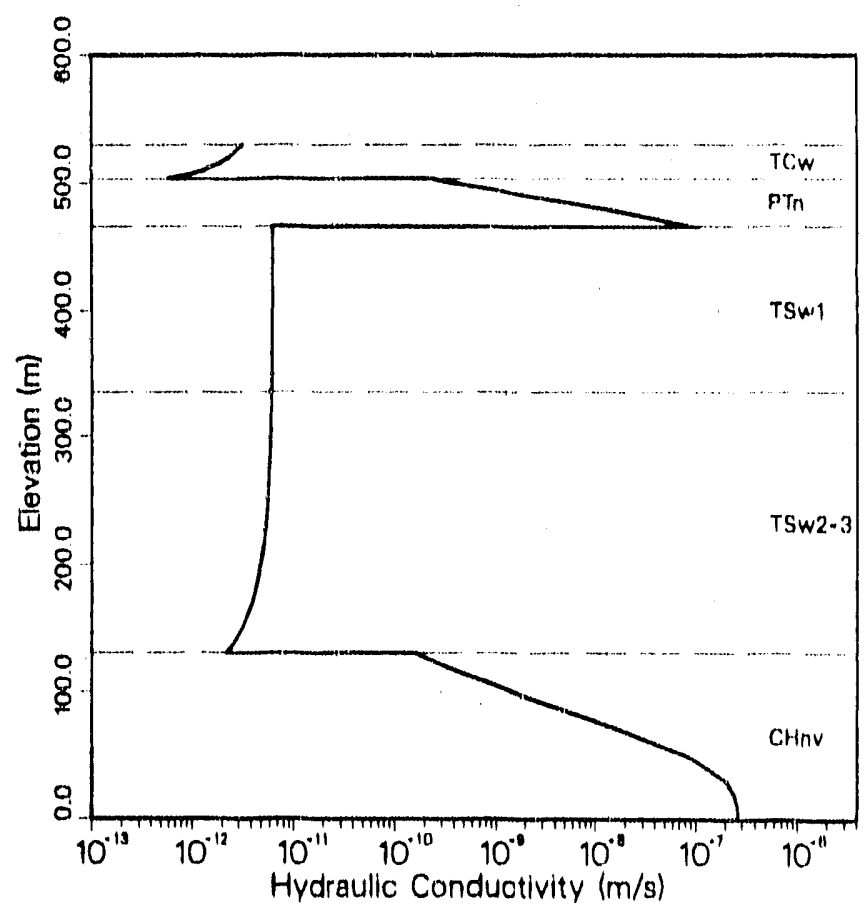

Figure 53: Hydraulic Conductivity Profile with $q_{0}=0.2 \mathrm{~mm} / \mathrm{yr}$, CHnv (Case 8) 


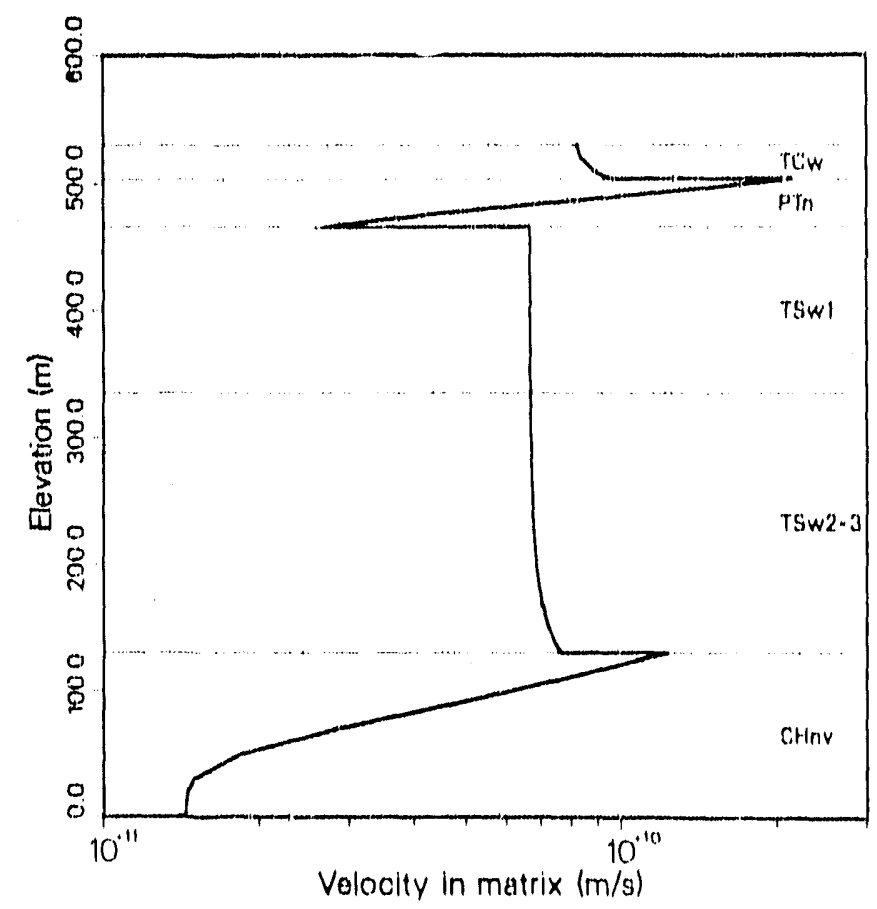

Figure 54: Matrix Water Velocity Profile with $q_{0}=0.2 \mathrm{~mm} / \mathrm{yr}$, CHnv (Case 8)

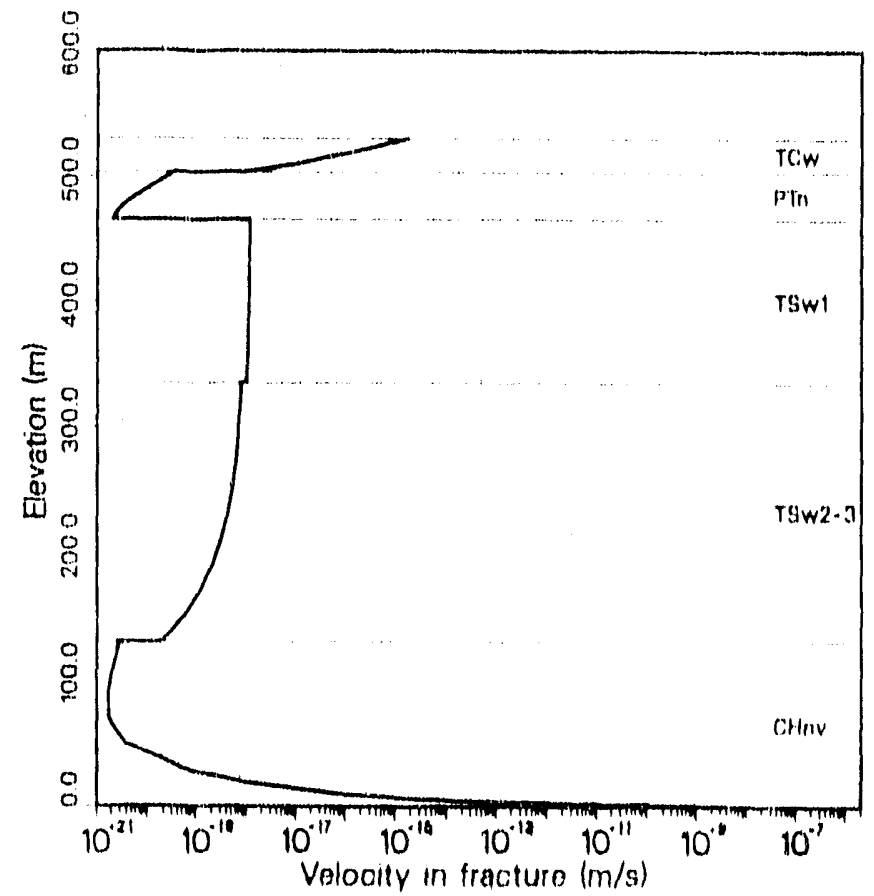

Figure 55: Fracture Water Velocity Profile with $q_{0}=0.2 \mathrm{~mm} / \mathrm{yr}, \mathrm{CH}$ ( Case 8) 


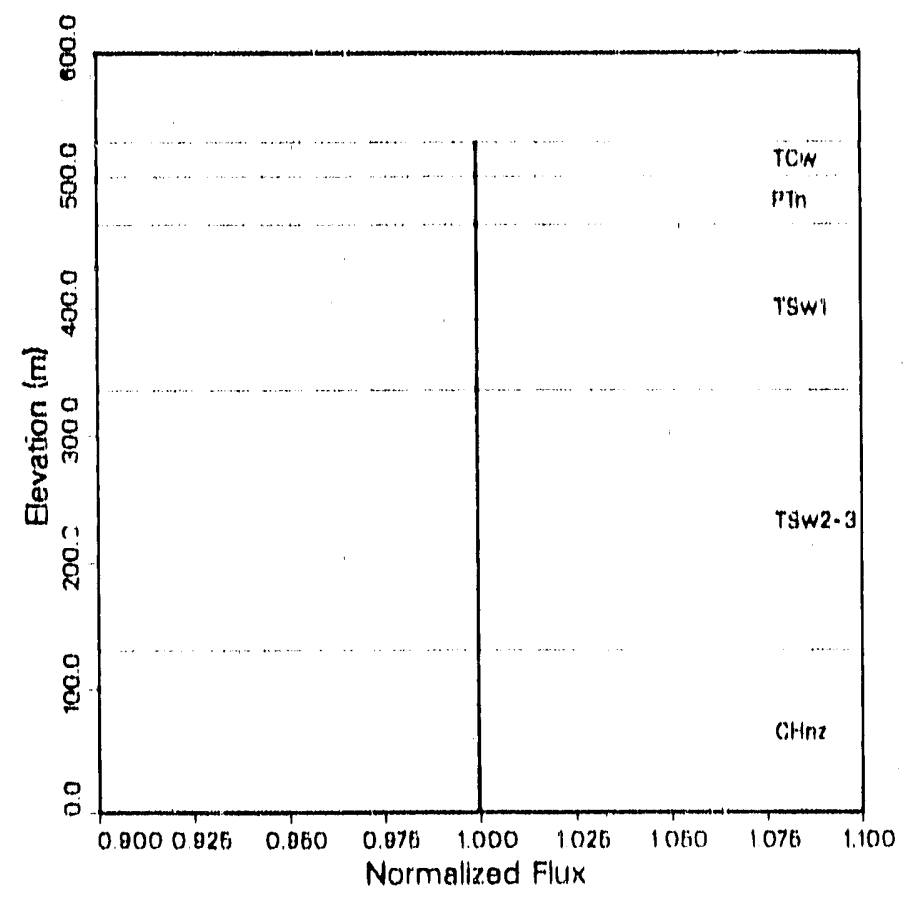

Figure 56: Normalized Flux Profile with $q_{0}=1.0 \mathrm{~mm} / \mathrm{yr}, \mathrm{CHnz}$ (Case 9)

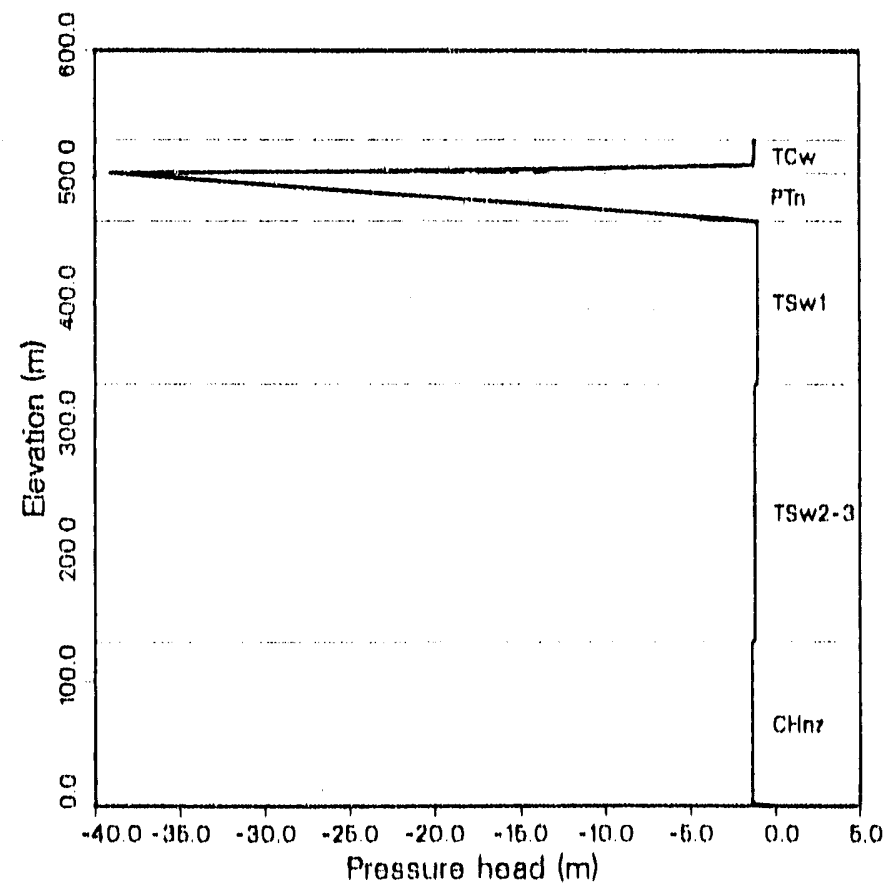

Figure 57: Pressure Head Profile with $q_{0}=1.0 \mathrm{~mm} / \mathrm{yr}, \mathrm{CHnz}$ (Case 9) 


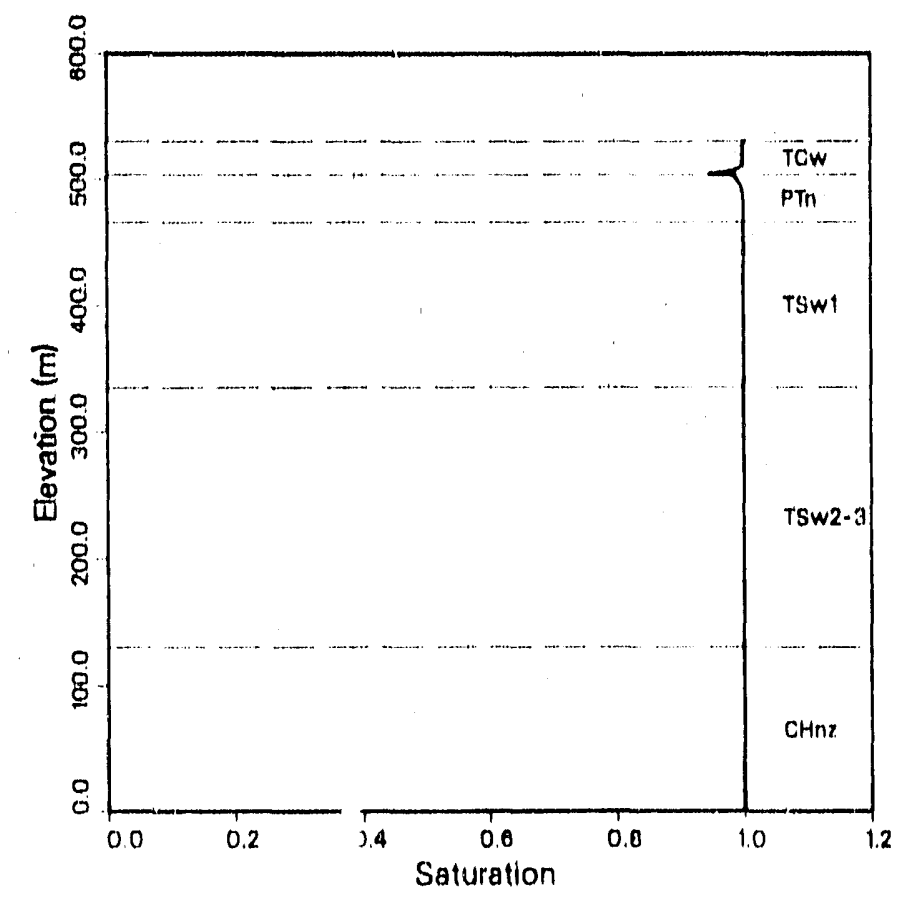

Figure 58: Matrix Saturation Profile with $q_{0}=1.0 \mathrm{~mm} / \mathrm{yr}, \mathrm{CHnz}$ (Case 9 )

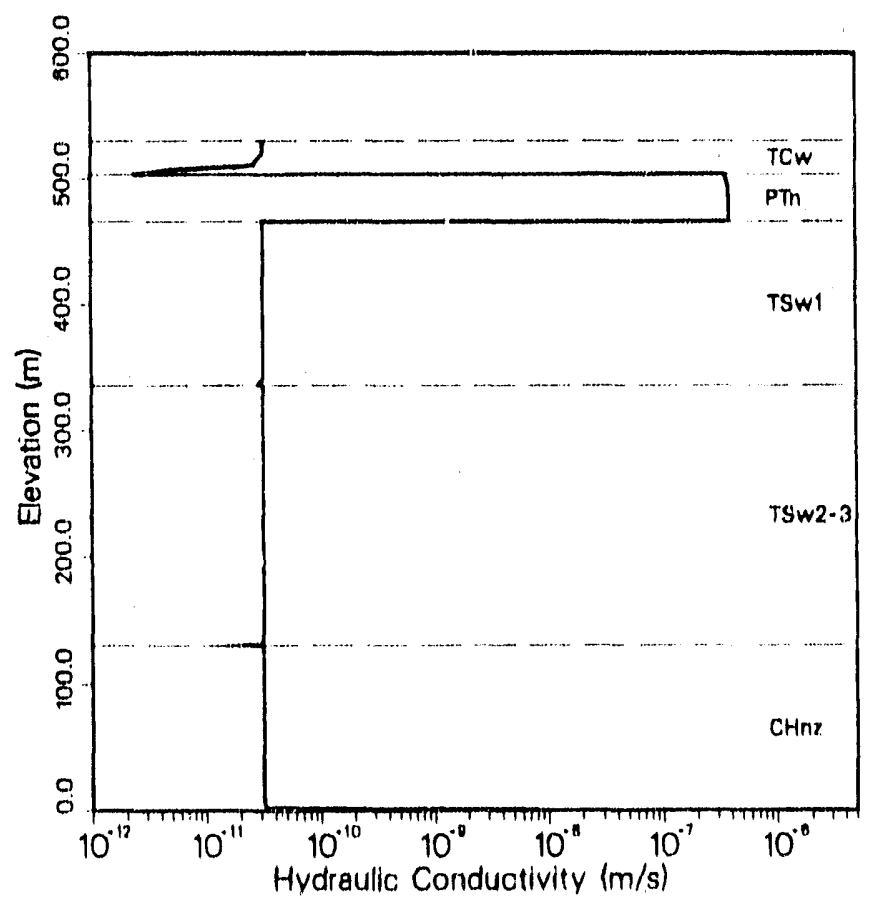

Figure 59: Hydraulic Conductivity Profile with $q_{0}=1.0 \mathrm{~mm} / \mathrm{yr}$, CHnz (Case 9) 


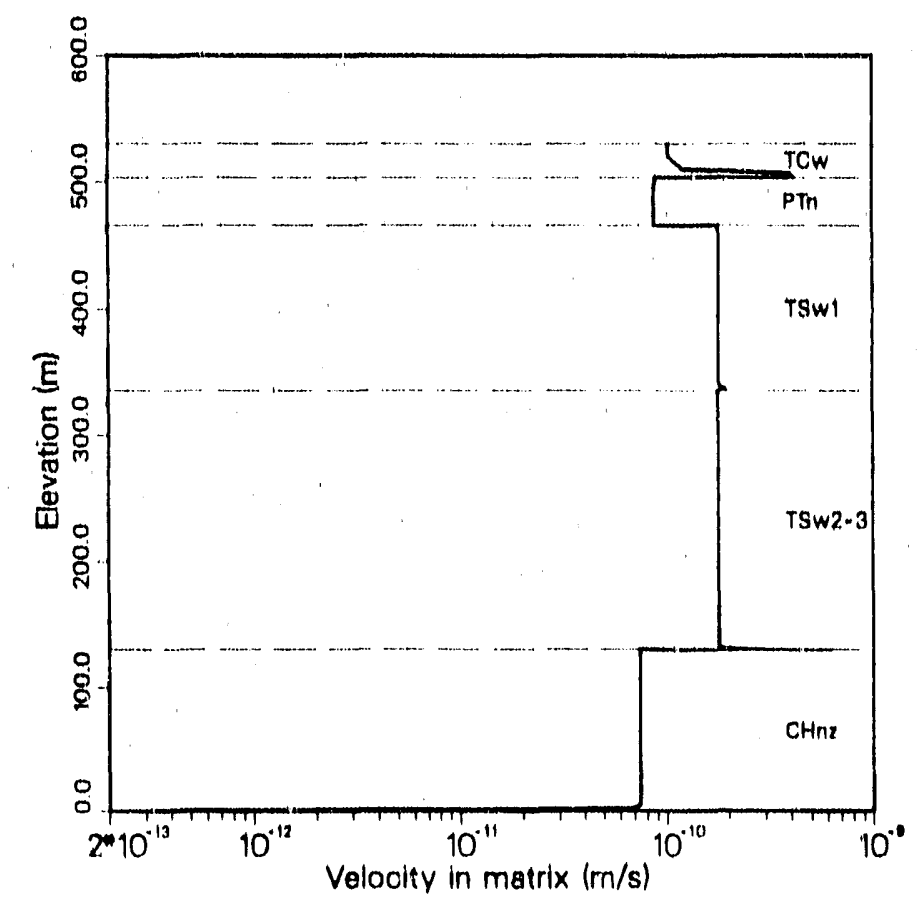

Figure 60: Matrix Water Velocity Profile with $q_{0}=1.0 \mathrm{~mm} / \mathrm{yr}, \mathrm{CHnz}$ (Case 9)

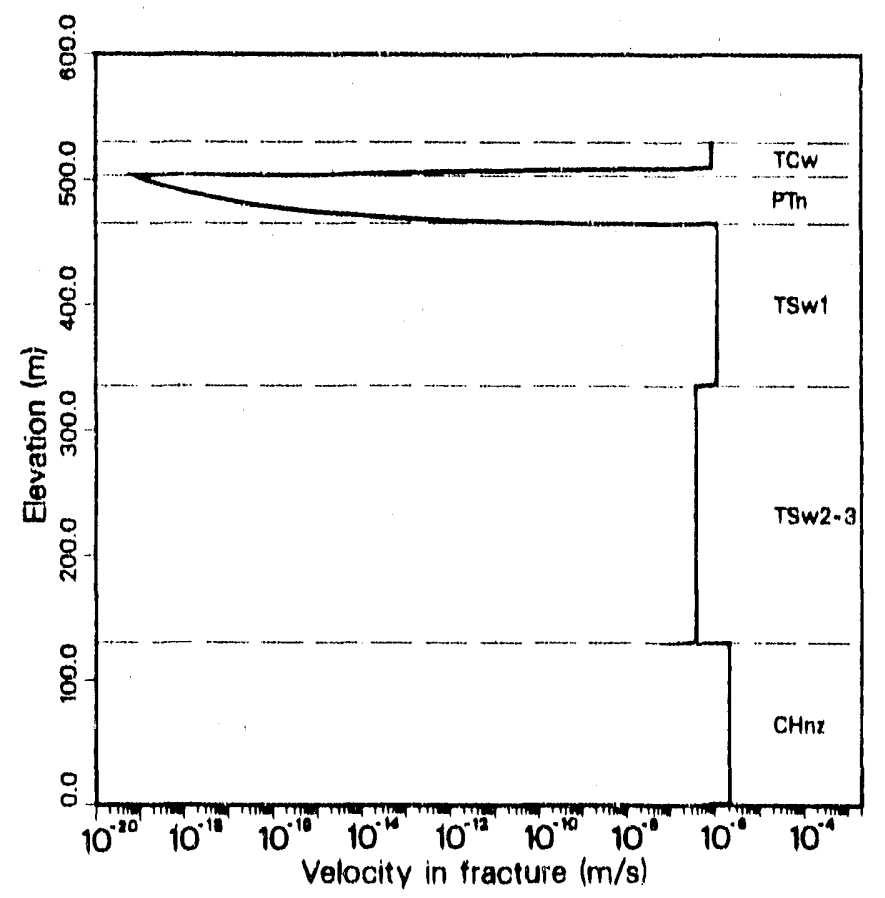

Figure 61: Fracture Water Velocity Profile with $q_{0}=1.0 \mathrm{~mm} / \mathrm{yr}, \mathrm{CHnz}$ (Case 9) 


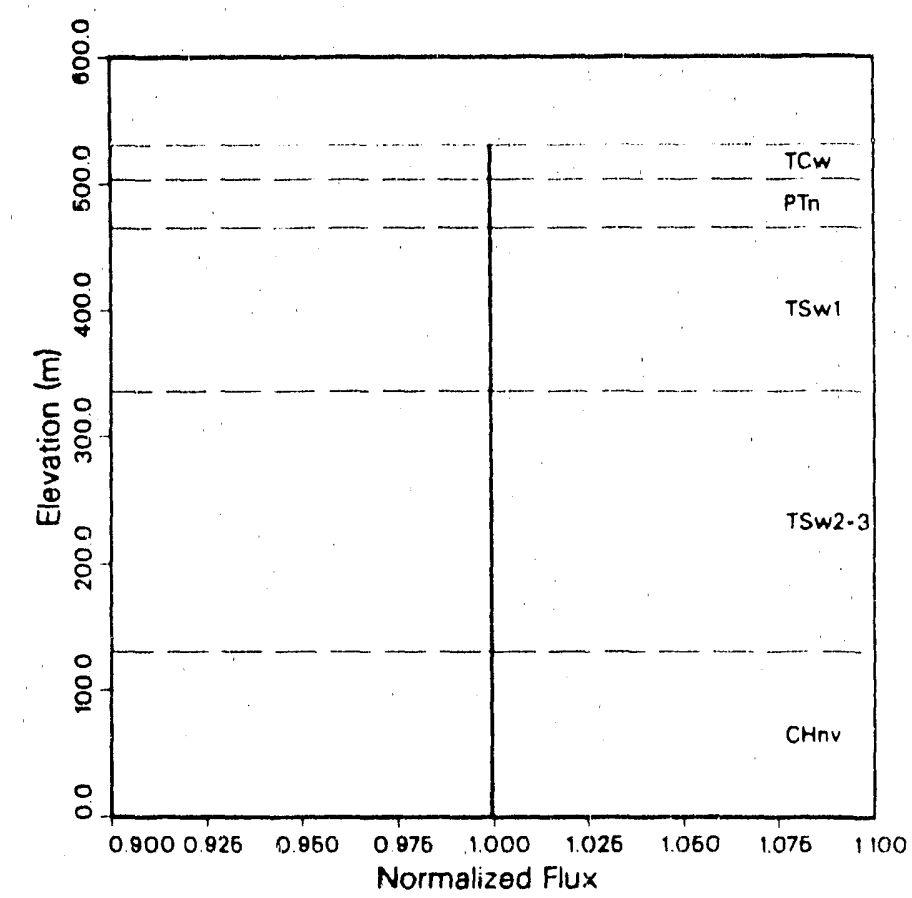

Figure 62: Normalized Flux Profile with $q_{0}=1.0 \mathrm{~mm} / \mathrm{yr}, \mathrm{CHnv}$ (Case 10)

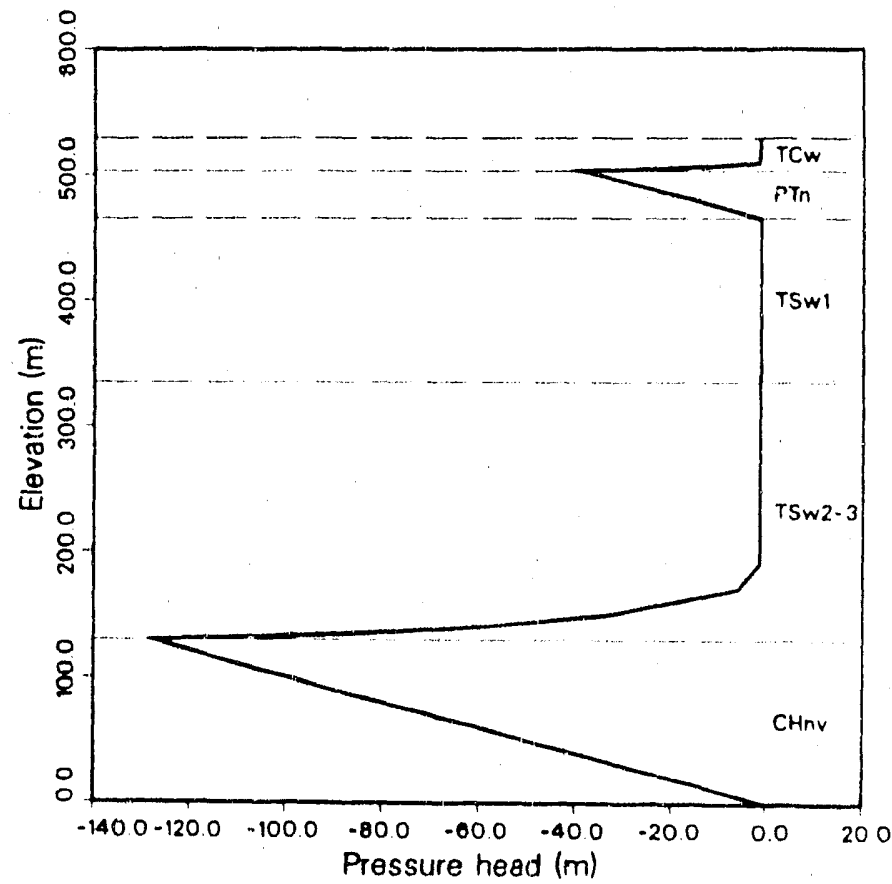

Figure 63: Pressure Head Profile with $q_{0}=1.0 \mathrm{~mm} / \mathrm{yr}, \mathrm{CHnv}$ (Case 10) 


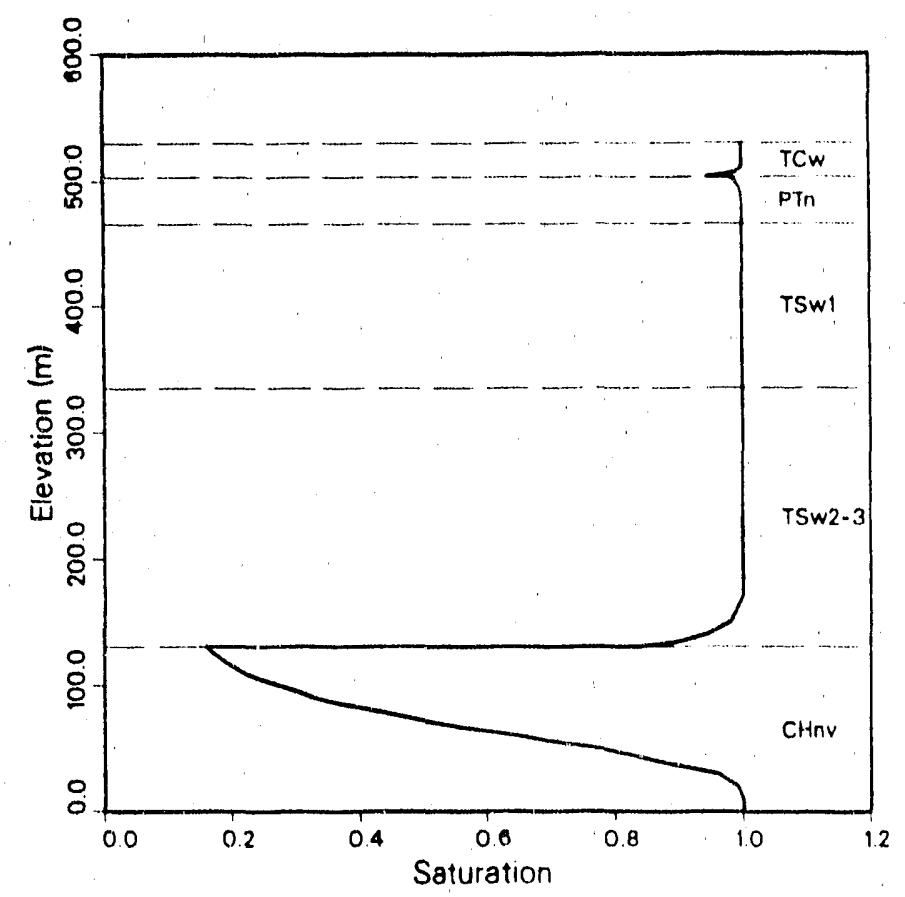

Figure 64: Matrix Saturation Profile with $q_{0}=1.0 \mathrm{~mm} / \mathrm{yr}, \mathrm{CHnv}$ (Case 10)

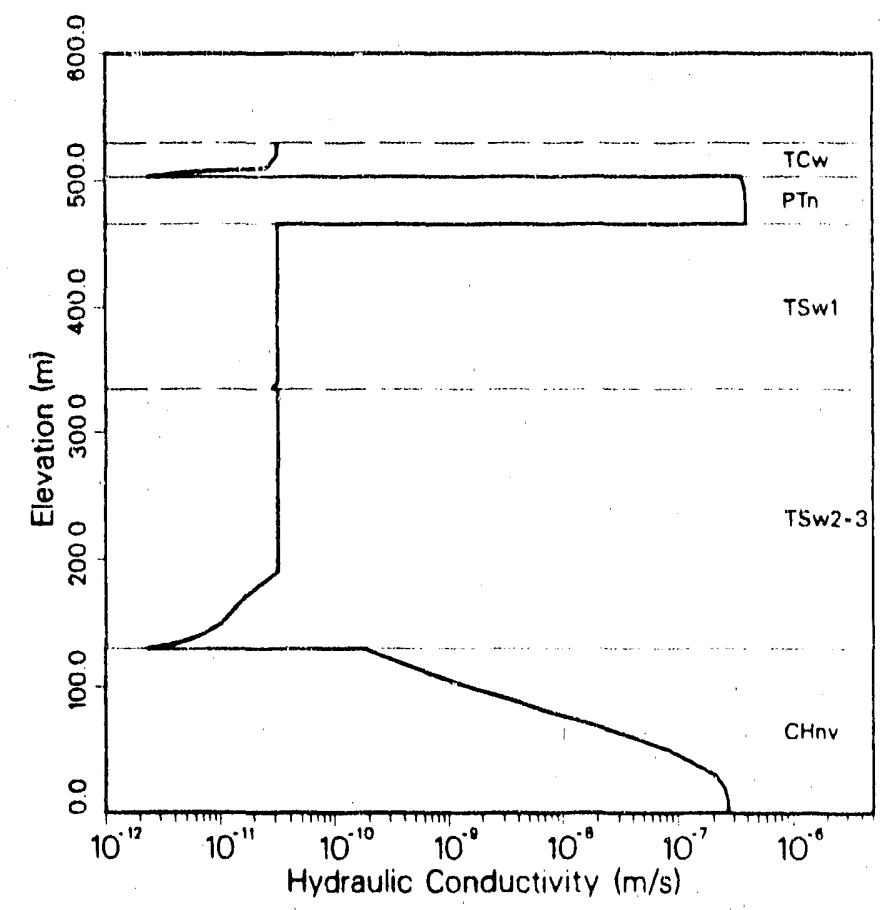

Figure 65: Hydraulic Conductivity Profile with $y_{0}=1.0 \mathrm{~mm} / \mathrm{yr}, \mathrm{CHnv}$ (Case 10) 


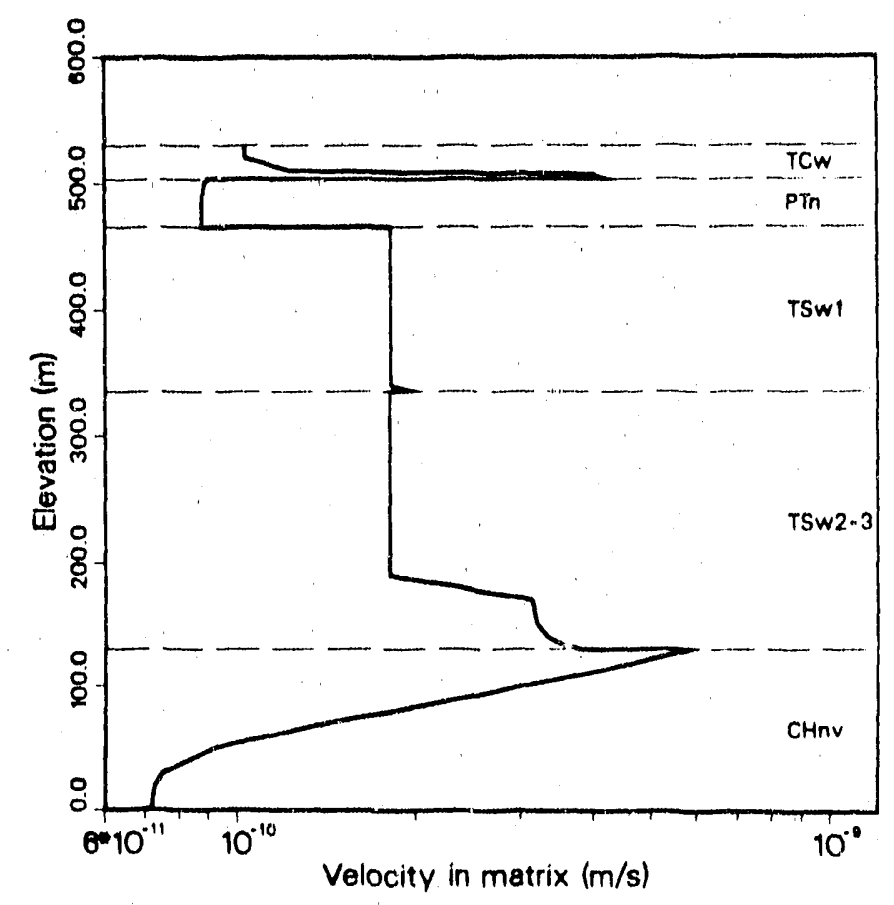

Figure 66: Matrix Water Velocity Profile with $q_{0}=1.0 \mathrm{~mm} / \mathrm{yr}$, CHnv (Case 10)

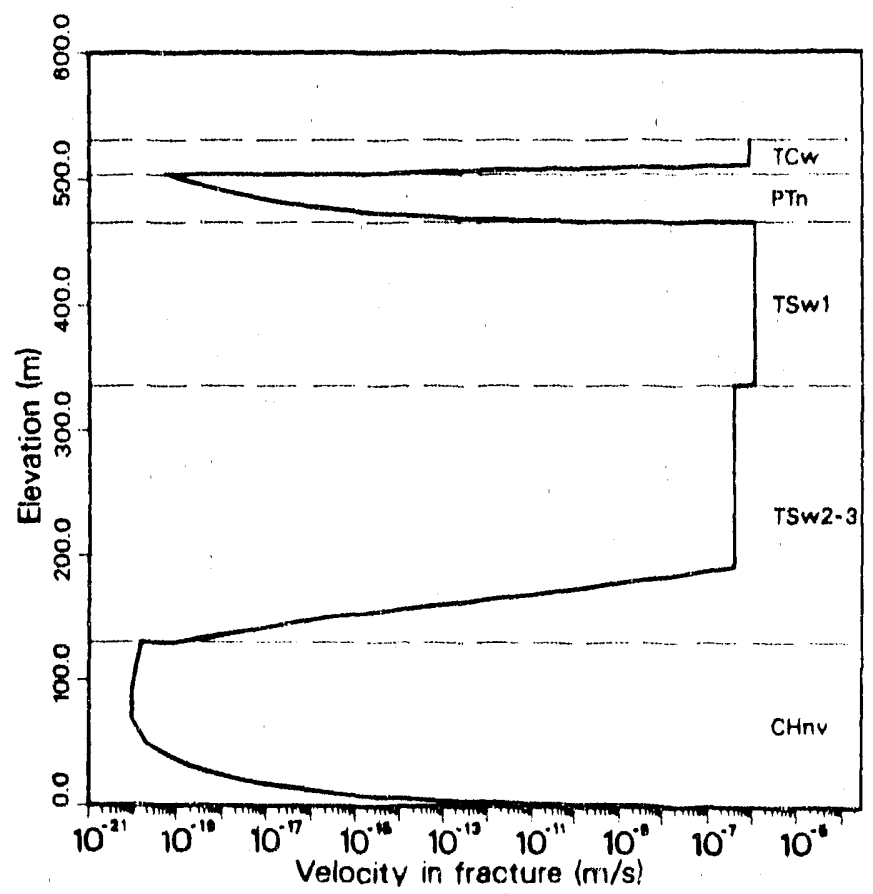

Figure 67: Fracture Water Velocity Profile with $q_{0}=1.0 \mathrm{~mm} / \mathrm{yr}, \mathrm{CHnv}$ (Case 10) 


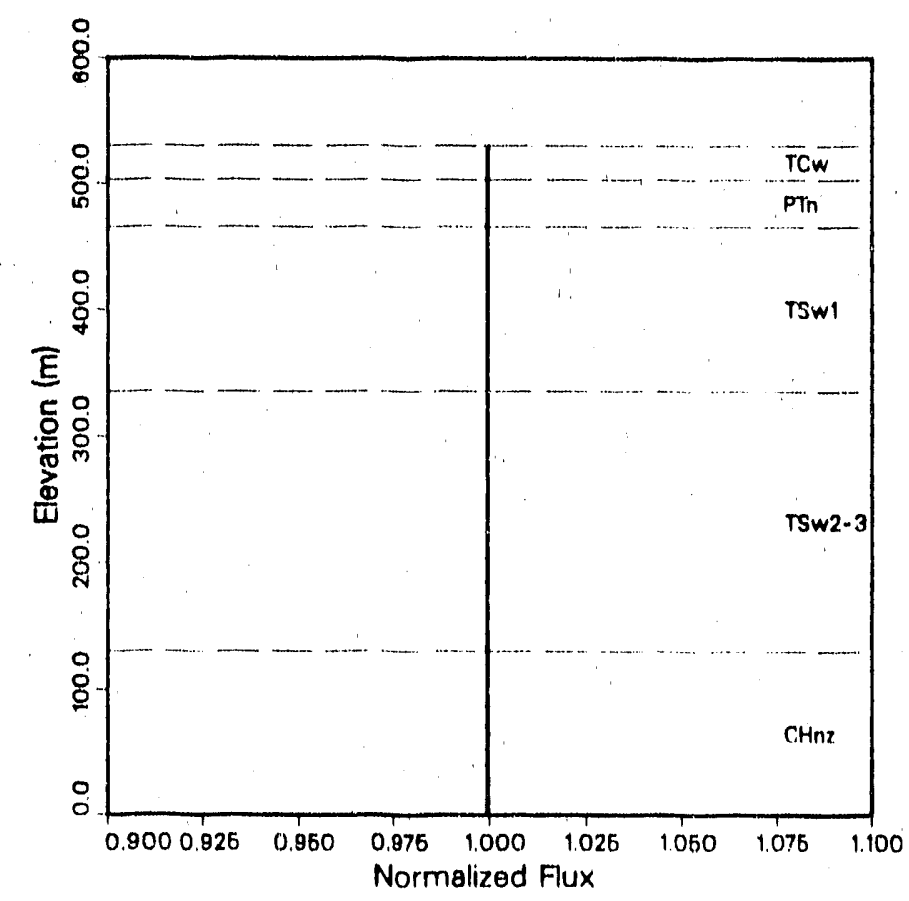

Figure 68: Normalized Flux Profile with $q_{0}=8.0 \mathrm{~mm} / \mathrm{yr}, \mathrm{CHnz}$ (Case 11)

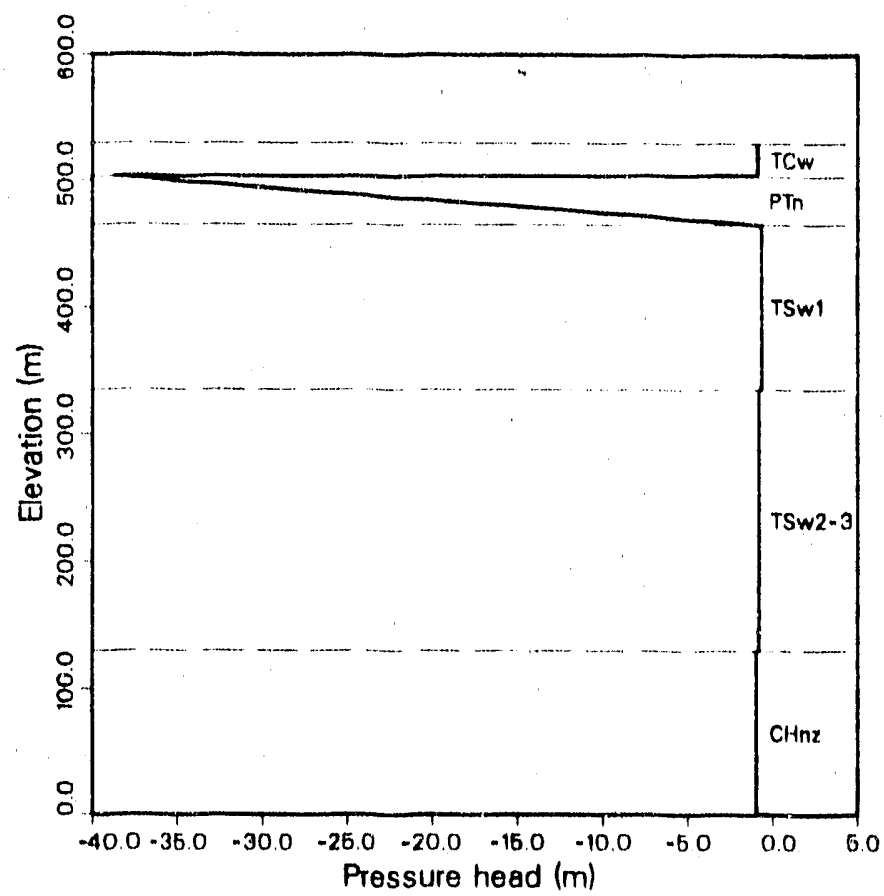

Figure 69: Pressure Head Profile with $q_{0}=8.0 \mathrm{~mm} / \mathrm{yr}, \mathrm{CHnz}$ (Case 11) 


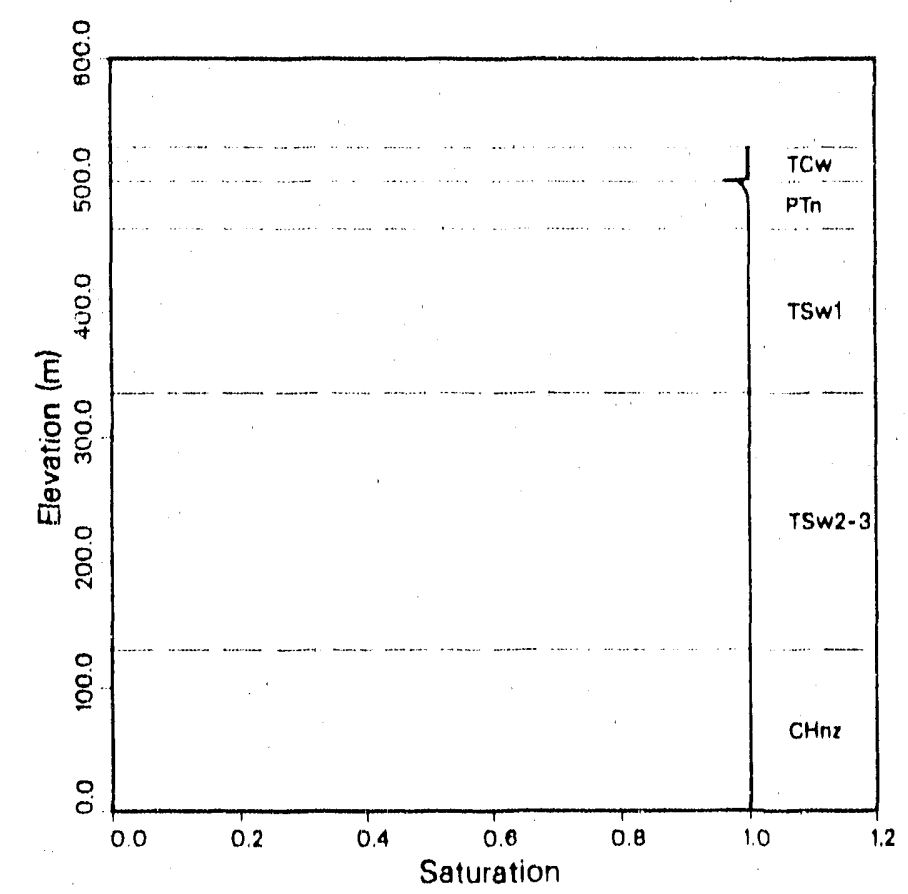

Figure 70: Matrix Saturation Profile with $q_{0}=8.0 \mathrm{~mm} / \mathrm{yr}, \mathrm{CHnz}$ (Case 11)

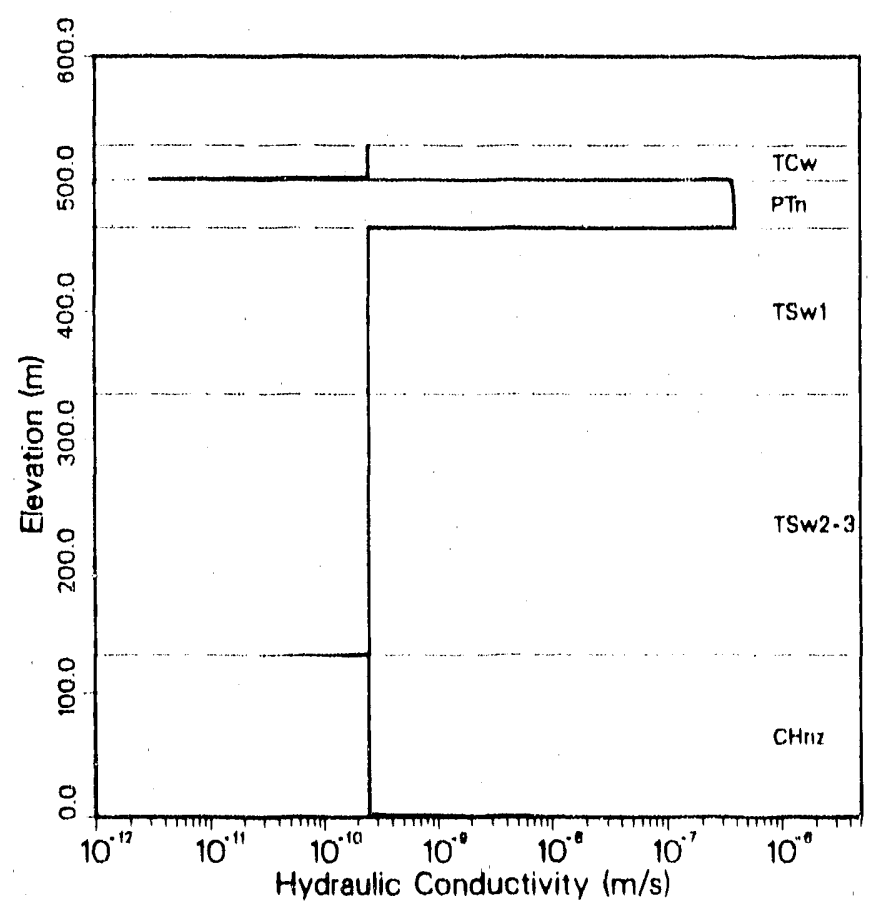

Figure 71: Hydraulic Conductivity Profile with $q_{0}=8.0 \mathrm{~mm} / \mathrm{yr}, \mathrm{CHnz}$ (Case 11) 


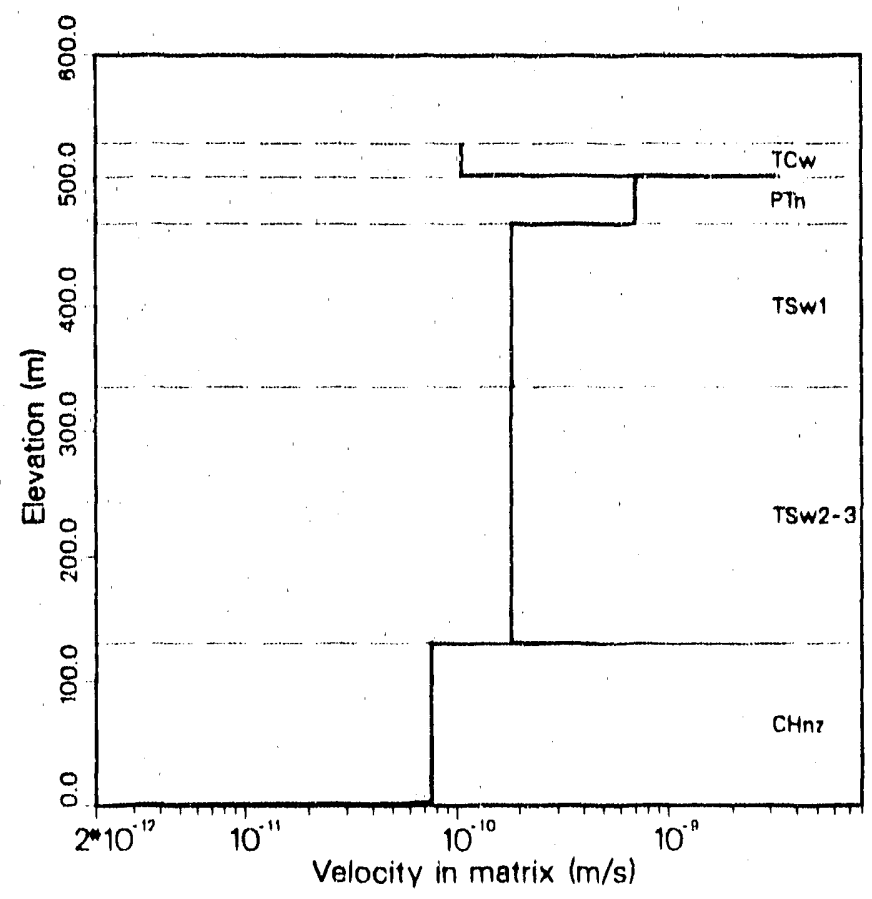

Figure 72: Matrix Water Velocity Profile with $q_{0}=8.0 \mathrm{~mm} / \mathrm{yr}, \mathrm{CHnz}$ (Case 11)

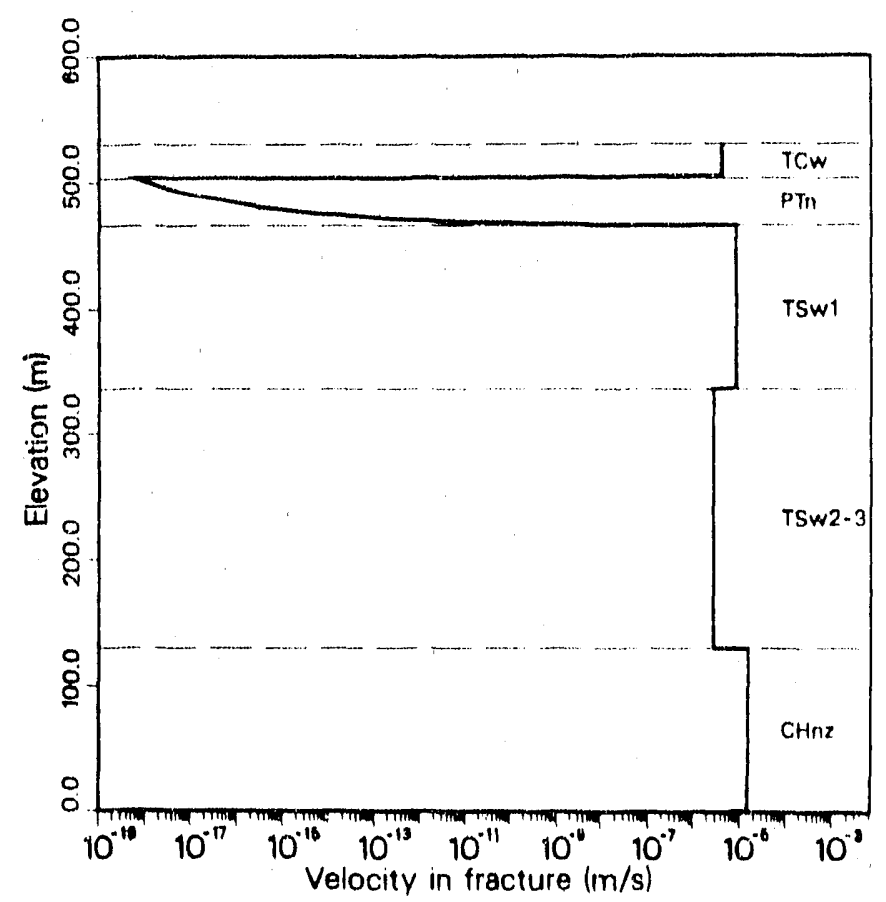

Figure 73: Fracture Water Velocity Profile with $q_{0}=8.0 \mathrm{~mm} / \mathrm{yr}$, CHnz (Case 11) 


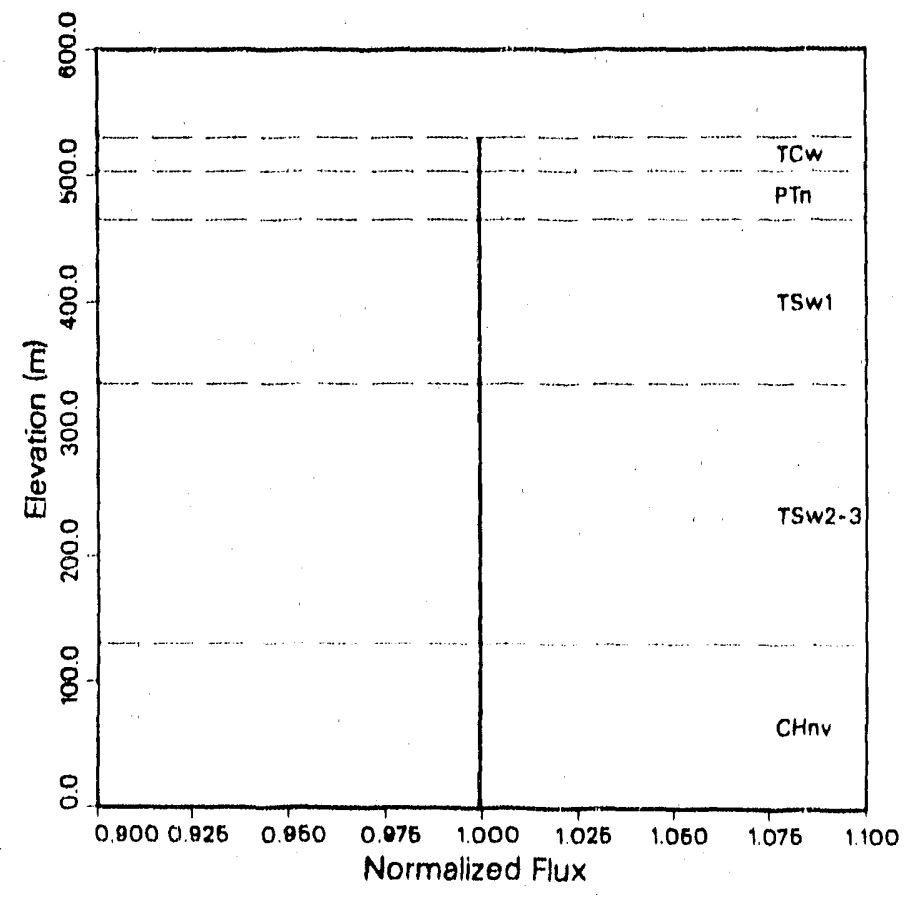

Figure 74: Normalized Flux Profile with $q_{0}=8.0 \mathrm{~mm} / \mathrm{yr}, \mathrm{CHnv}$ (Case 12)

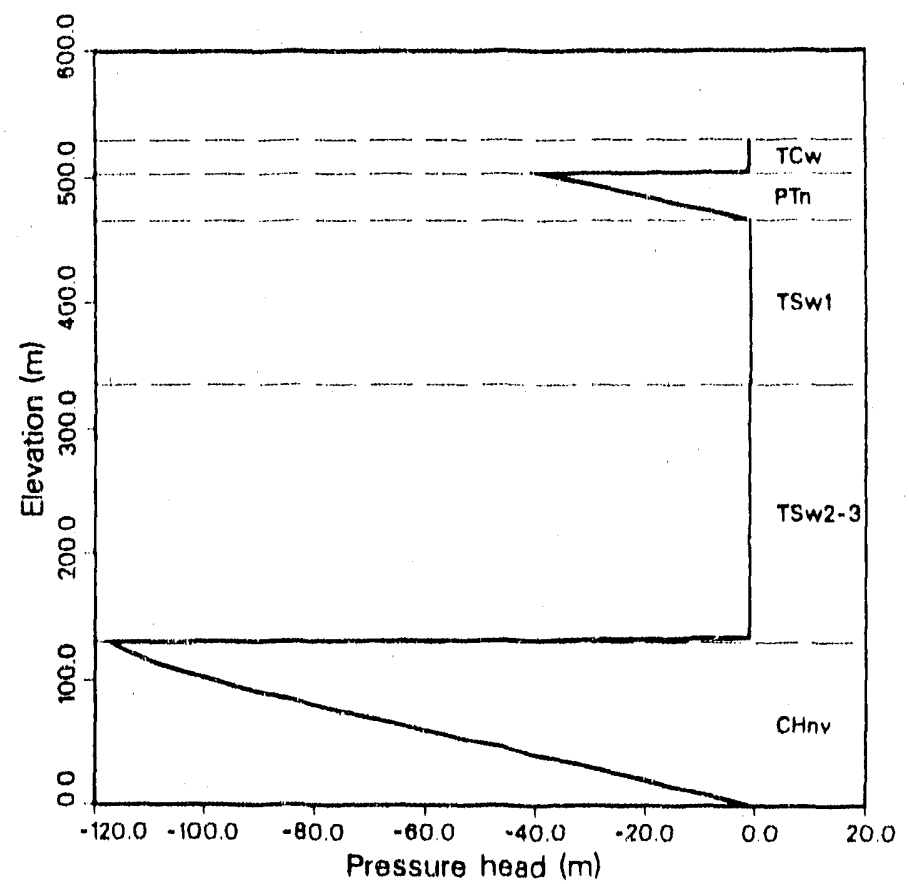

Figure 75: Pressure Head Profile with $q_{0}=8.0 \mathrm{~mm} / \mathrm{yr}, \mathrm{CHnv}$ (Case 12) 


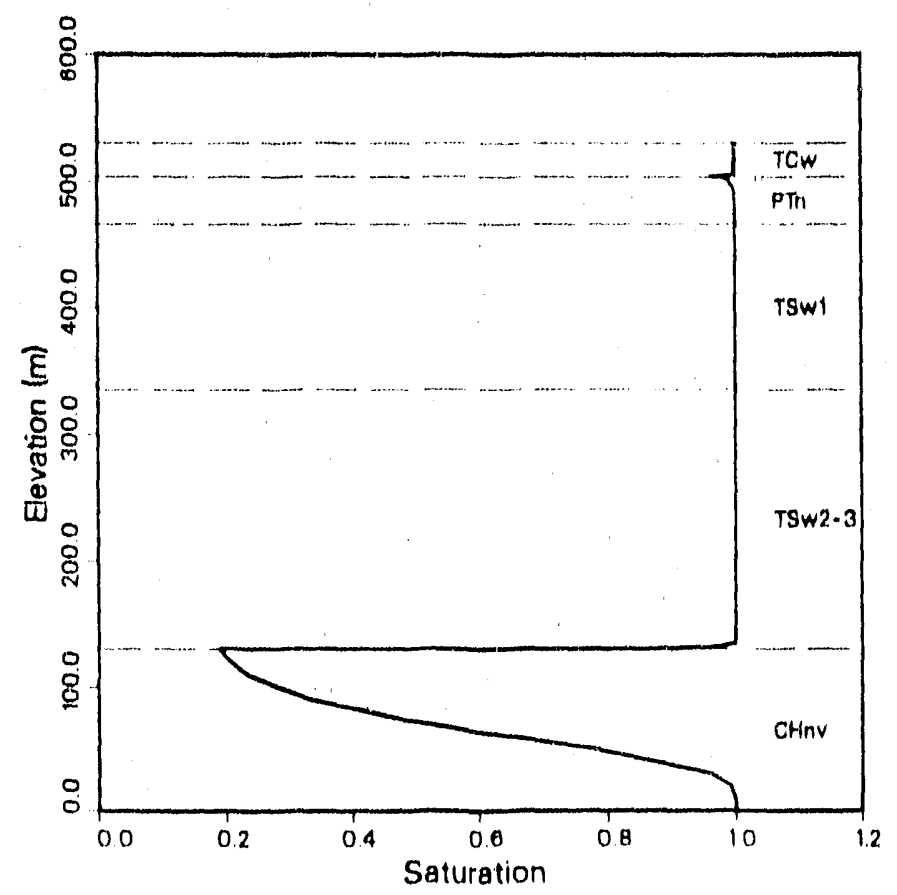

Figure 76: Matrix Saturation Profile with $q_{0}=8.0 \mathrm{~mm} / \mathrm{yr}, \mathrm{CHnv}$ (Case 12)

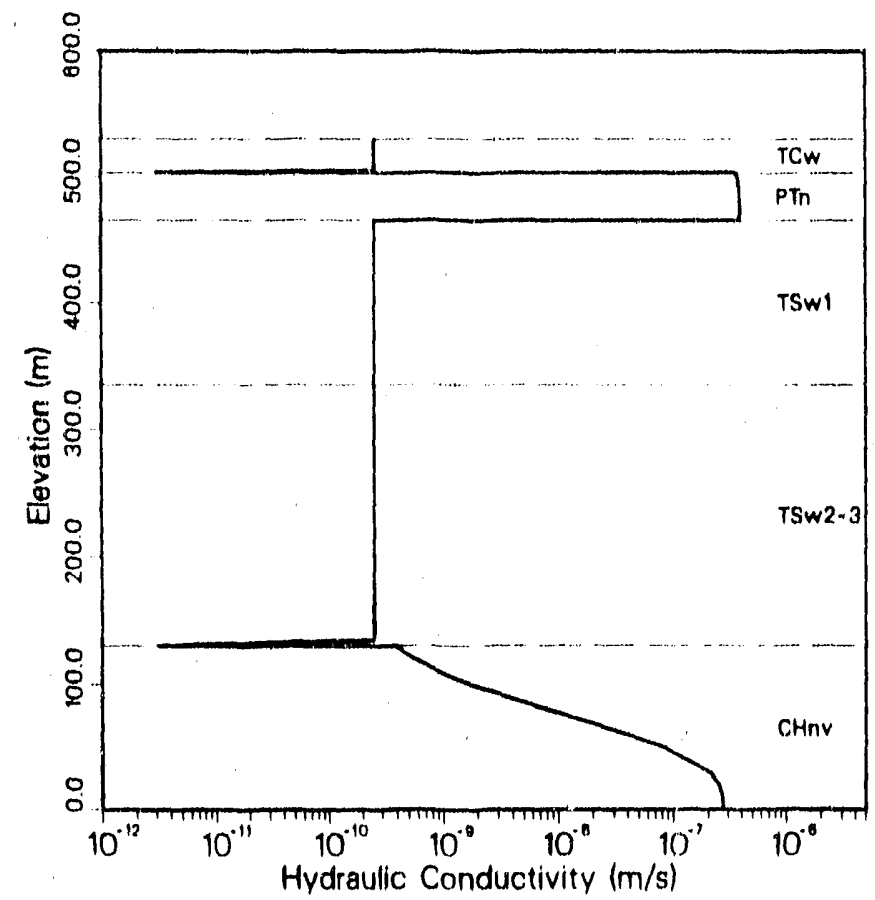

Figure 77: Hydraulic Conductivity Profile with $q_{0}=8.0 \mathrm{~mm} / \mathrm{yr}, \mathrm{CHnv}$ (Case 12) 


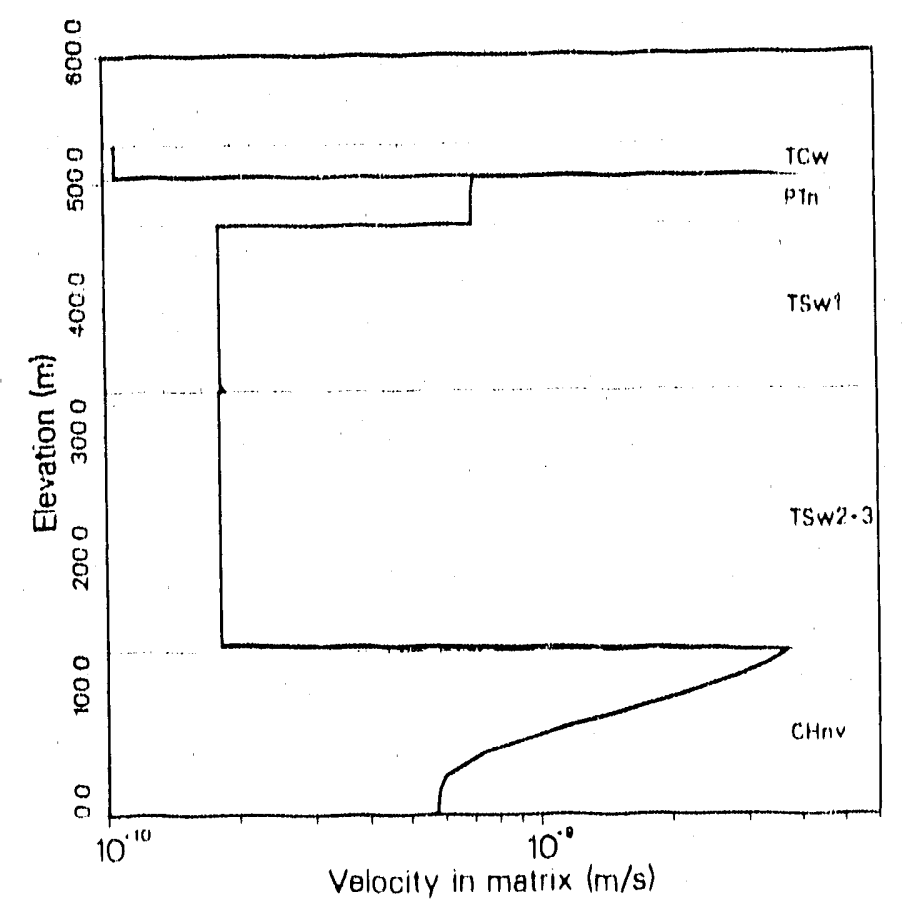

Figure 78: Matrix Water Velocity Profile with $q_{0}=8.0 \mathrm{~mm} / \mathrm{yr}$, CHnv (Case 12)

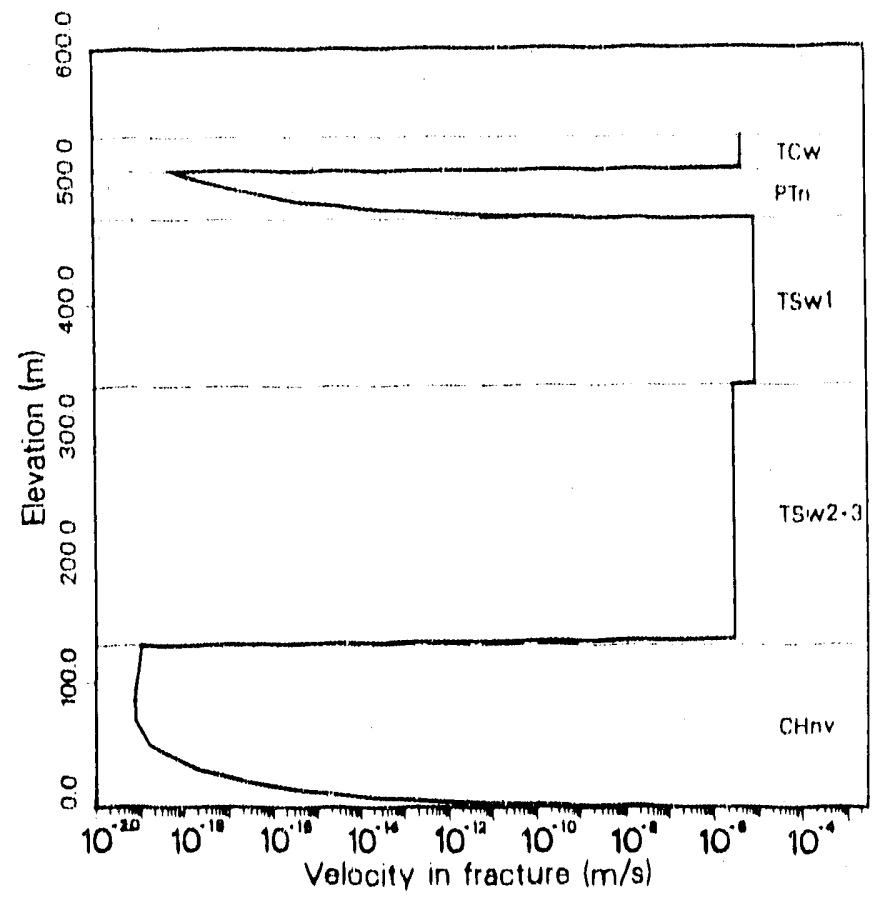

Figure 79: Fracture Water Velocity Profile with $q_{0}=8.0 \mathrm{~mm} / \mathrm{yr}$, CHnv (Case 12) 


\section{References}

1. Hopkins, P. L., and R. R. Eaton, "LLUVIA - A One-Dimensional, Steady-State Program for Flow Through Partially-Saturated Porous Media,"SAND8840558, Sandia National Laboratories, Albuquerque, NM (1990). (NN1.88110\%,0085)

2. van Genuchten, R., "Calculating the Unsuturated Hydrulic Conductivity will, a New Closed form Analytical Model," Water Resources Bulletin, Princeton University Press, Princeton University, Princeton, NJ (1978). (HQS.880517.1859)

3. Mualem, Y., "A New Model for Predicting the Hydraulic Conductivity of Insul." urated Porous Media," Water Resources Research, Vol, 1.2, No, 3, pp. 513-52.2 (1976). (HQS.880517.1803,NNA.890522.0250)

4. Peters, R. R., and R. A. Klavetter, "A Continumm Model for Waler Movement in an Unsaturated, Fractured Rock Mass," Water Besources Research, Vol. 24, No, 3, pp. 416-430 (1988). (NNA.870323.0453)

5. Peters, R. R., J. H. Gauthier, and A. L. Dudley, "The Effect of Percolation Rute: On Water-Travel T'ime ln Deep, Partially Saturated Zones," SAND85-0854, Sundiu. National Laboratories, Albuquerque, NM (1986). (NNA.870721.0066)

6. Shampine, l, F., and H. A. Watts, "DEPAC Design of n User Oriented Package: of ODE Solvers," SAND79-2374, Sandia National Laboratories, Albuquerque, NM $(1980) .($ NNA.900122,0001)

7. Hindmarsh, A. C., "ODE Solvers Cor Use With the Method of lines," UC!Rl.. 85293 (Rev. 1), Lawrence Livermore National Laboratories, Livernore, CA (1981). (NNA.890522.0213) 


\title{
6 Appendix A
}

\author{
Information from tho Roforonco Information Base \\ Uaod in this Roport
}

This report contains no information from tho Roforenco Information Base.

\author{
Cundidato Information \\ for the \\ Roforrnce Information Base
}

This roport contans no candidate information for the Roference Information Buso.

\section{Candidate Information \\ for the}

Sito \& Enginooring Proportios Data Base

This roport contains no candidate information for the Site and Enginoering Properties Data Buso. 

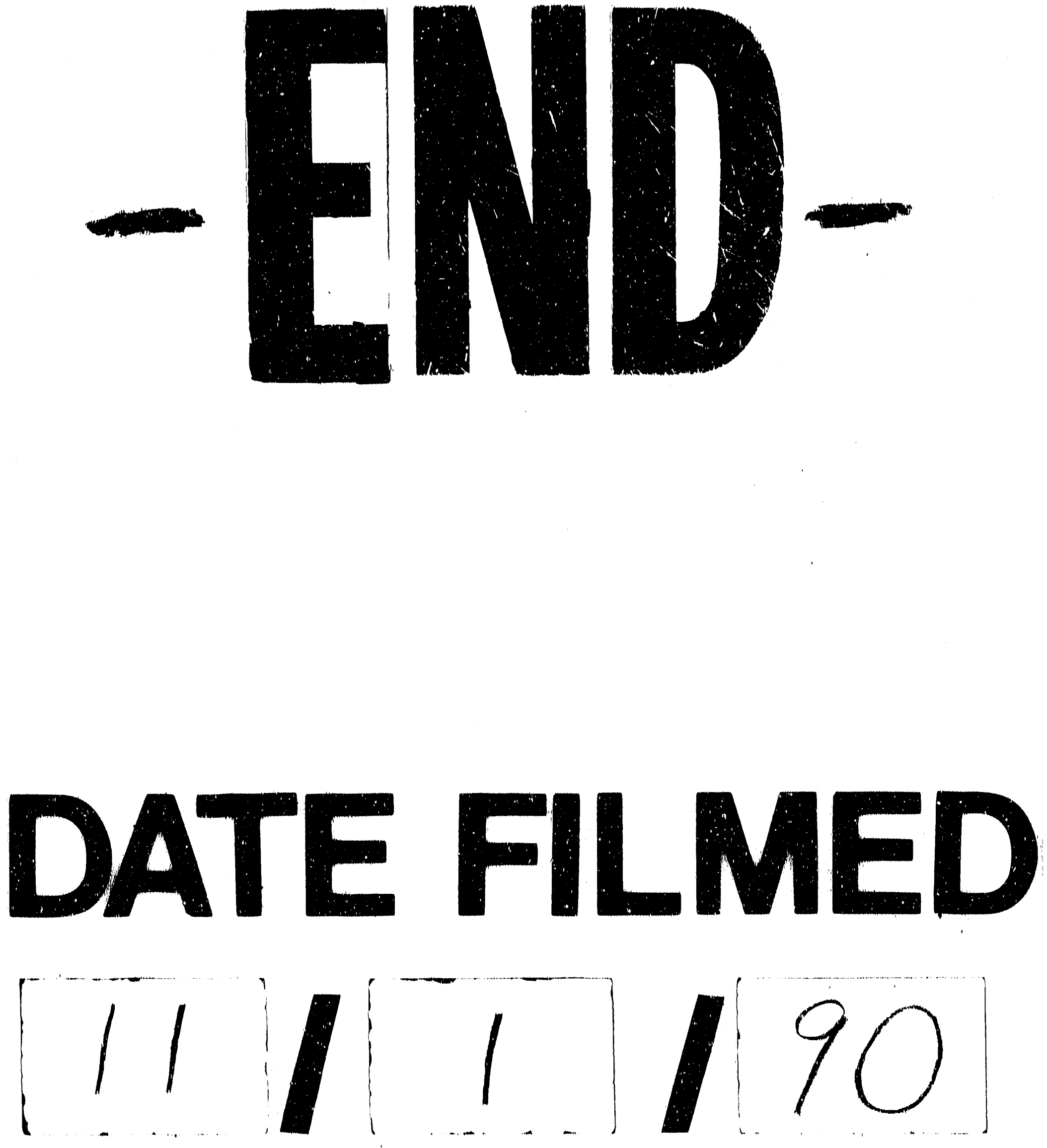
